\title{
New Forms of Collaboration in Emergency Response Systems: \\ A framework for participatory design of information systems
}

\section{Kayvan Yousefi Mojir}

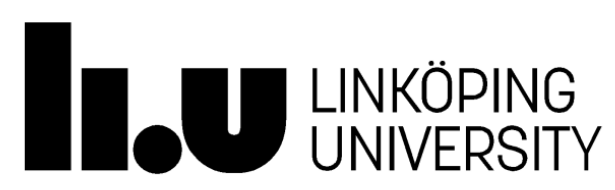

FiF-avhandling No. 119

Department of Management and Engineering, Information Systems

Linköping 2016 
@ Kayvan Yousefi Mojir, 2016

FiF-avhandnling No. 119

ISBN 978-91-7685-728-1

ISSN 1401-4637

Printed in Sweden by LiU-Tryck, Linköping, Sweden, 2016

Linköping University

Department of Management and Engineering, Information Systems

SE-581 83 Linköping, Sweden 


\section{ABSTRACT}

An emergency response systems (ERS) is usually responsible for delivering essential services to save lives and minimise environmental damage in case of small, frequent or large-scale emergencies. The ongoing global financial crisis, lack of professional resources, public sector cuts and rising public expectations are some of the challenges ERSs currently are facing. At the same time, societal trends in form of large-scale disasters such as tsunamis, storms, forest fires, terror attacks, and wars in the Middle East leading to mass migration have intensified recently and globally, increasing demand for these services in the public sector. As a result, emergency response actors are often under extreme pressure, and may need to seek assistance from and cooperate with other resources in society in order to become more effective. An emerging trend in ERSs in response to the challenges, in Sweden and internationally, is to create new forms of collaboration in emergency management (e.g., cross-sector collaboration, involving citizens in e-government, and involving volunteers). While research and practice have started to show the benefits of organising ERSs in new ways, the increasingly broad set of heterogeneous stakeholders involved in the collaborations introduce various challenges. Legal issues, unclear responsibilities of actors, difficulty in the categorisation of tasks, job insurance problems, diversity in education and background of actors, and difficulty determining actors' specific needs for IS support are some examples. Analysis of collaborations thus becomes increasingly complex, and must incorporate many aspects. Rudimentary analyses may result in failure of related projects and IS development, and ultimately in less effective collaborations. New forms of collaboration must therefore be analysed and understood rigorously, generally and in each specific context in order to develop them for ERSs and the public sector and to support actors with effective IS tools.

This thesis develops and presents a framework for analysing new forms of collaboration in ERSs. It also provides an initial suggestion on how to apply the framework with a specific focus on IS development. The study was carried out as a qualitative case study based on three kinds of collaboration in the Swedish ERS: co-operative, cross-sector use of resources, involving civil volunteers in response operations and co-location of actors. The framework has fifteen dimensions. They are: Type/Role, Attitude, Training, Background, Task and Responsibility, Availability/Accessibility, Incident Type, Communication Methods, Information Technology, Emergency Supplies, Organisational Structure, Leadership, Costs/Benefits, Environment, and Regulations and Legal Issues. Sociotechnical systems theory and participatory design principles were applied to make the framework usable in the IS field. The framework can be used generally to analyse new forms of collaboration in ERSs in order to understand its different aspects and emergent challenges, such as actors' tasks, relevant laws, leadership and organisational factors, which may otherwise be overlooked, into the analysis process. As to IS development, the framework can contribute to organisational analysis and needs analysis in the participatory design of IS for ERSs, e.g. by helping to identify key stakeholders and involve them in the development process.

The framework was initially tested at the co-location case and showed several promising benefits in terms of identifying and involving stakeholders in the development process. It was deemed helpful in determining and formulating interviews, observations, and future workshops in order to explore and study all relevant dimensions of the collaboration in the early phases of participatory design. It was also felt that the framework saved time and resources. It is argued that it may offer similar benefits in similar cases, although this will require further testing with more case studies. A standardised and developed version of the framework may also be adapted to be applicable to other public sector contexts such as e-government in which new forms of collaboration and governance are in focus. Such a framework may also help to address general challenges often associated with participatory design, add formalisation to it, and contribute to shift it from an academic to a practical approach in order to derive its benefits in complex environments. The next step will be to use the framework as a departure point for analysing the potential co-operative use of resources and cross-sector collaboration in the project 'Efficient Communal Use of Municipal Resources for Increased Safety and Security' (ESKORT) in the municipality of Norrköping. 



\section{SAMMANFATTNING}

Ett responssystem (Eng: emergency response system) är vanligtvis ansvarigt för att rädda liv och minska skador på miljö och infrastruktur i små, frekventa olyckor eller storskaliga händelser, kriser och katastrofer. Den pågående globala finanskrisen, brist på professionella resurser och nedskärningar inom den offentliga sektorn samtidigt som förväntningarna från allmänheten ökar är några av de aktuella utmaningar som responssystemet står inför. Samtidigt har globala händelser i form av storskaliga katastrofer som tsunamis, stormar och skogsbränder intensifierats och terrorattacker, och krig i Mellanöstern lett till ökade migrationsströmmar, vilket också ökat trycket inom offentlig sektor. Därför är responsaktörer ofta under extrem press och behöver söka hjälp från och samarbeta med andra resurser i samhället för att bli mer effektiva. Ett sätt att hantera utmaningarna är en framväxande trend i responssystemen i Sverige och internationellt att skapa nya samverkansformer, t.ex. tvärsektoriell samverkan, att involvera medborgare i e-förvaltning, och att involvera frivilliga. Både forskning och praktik har börjat visa på vissa fördelar med att organisera responssystemen på nya sätt. Men trots fördelarna medför också de nya samverkansformerna och de breda, heterogena aktörsgrupper som deltar i dessa olika utmaningar. Juridiska frågor, oklara ansvarsförhållanden, svårigheter att kategorisera arbetsuppgifter, oklarheter i jobbförsäkringar, variation i utbildning och bakgrund hos aktörer och svårigheter att identifiera olika aktörers specifika behov av till exempel informationssystem (IS) är några exempel. Därmed blir analysen av samverkan alltmer komplex och bör inkludera många aspekter. Alltför rudimentära analyser kan leda till otillräckliga resultat i relaterade projekt och IS-utveckling och på sikt kan detta leda till mindre effektivt samarbete mellan aktörerna. Nya former av samverkan måste därför analyseras och förstås noggrant, generellt och i varje visst sammanhang, i syfte att utveckla dem och att stödja aktörerna med effektiva IS.

I denna licentiatavhandling utvecklas och presenteras ett ramverk för att analysera nya samverkansformer i responssystemet. Den ger också ett inledande förslag på hur man kan tillämpa ramverket med särskilt fokus på ISutveckling. Avhandlingen utgörs av en kvalitativ studie baserad på tre samverkansformer i det svenska responssystemet: sambruk av resurser mellan olika samhällssektorer, att involvera civila frivilliga $i$ räddningsinsatser och samlokalisering av responsaktörer. Ramverket innefattar femton dimensioner: Typ /roll, attityd, utbildning, bakgrund, uppgift och ansvar, tillgänglighet, händelsetyp, kommunikationsmetoder, informationsteknologi, utrustning, organisationsstruktur, ledarskap, kostnad / nytta, arbetsmiljö, policy och juridik. Socio-teknisk systemteori och deltagande design principer tillämpades för att ramverket skulle bli specifikt applicerbart för IS-utveckling. Ramverket kan användas generellt för att analysera nya samverkansformer i responssystemet för att förstå dess olika aspekter och utmaningar, såsom aktörers uppgifter, relevanta lagar, ledarskap och organisatoriska faktorer, som annars riskerar att förbises i analysprocessen. När det gäller ISutveckling kan ramverket bidra till organisationsanalys och behovsanalys i deltagande design av IS för responssystem, t.ex. genom att hjälpa till att identifiera nyckelaktörer och involvera dem i utvecklingsprocesser.

Ramverket testades först vid en studie av samlokalisering vid Trygghetens Hus och visade på flera potentiella fördelar när det gäller att identifiera och involvera aktörer i utvecklingsprocessen. Ramverket fungerade som ett stöd för att identifiera respondenter och utveckla mallar för intervjuer, observationer och en Future Workshop i de tidiga faserna av deltagande design för att söka täcka alla relevanta aspekter av samverkan. Det verkade också som att ramverket sparade tid och resurser. Därför argumenteras det för att ramverket kan ge liknande fördelar $\mathrm{i}$ liknande fall men för att kunna uttala sig mer säkert om detta krävs ytterligare tester och tillämpningar med flera fallstudier. En standardiserad och utvecklad version av ramverket kan ha potential att tillämpas på andra sammanhang inom den offentliga sektorn, såsom e-förvaltning där nya samverkansformer är i fokus. Ett sådant ramverk kan också bidra till att lösa mer generella problem med deltagande design, såsom brist på formalisering, och därmed bidra till att göra ansatsen mer praktisk och tillämpbar i komplexa systemutvecklingskontexter. I nästa steg kommer ramverket användas som en utgångspunkt och ett stöd för att analysera och utveckla IS stöd för sambruk av resurser och tvärsektoriell samverkan mellan aktörer i projektet. "Effektivt gemensamt bruk av kommunala resurser för ökad säkerhet och trygghet" (ESKORT) i Norrköpings kommun. 



\title{
ACKNOWLEDGEMENTS
}

Though my name alone appears on the cover of this thesis, a great many people have contributed to it. This has been a period of intense learning for me, not only in the academic and scientific arena, but also on a personal level. I would like to reflect on the people who have offered their invaluable help and support during this period. I owe my gratitude to all of them, who have made this work possible.

First and foremost, I would like to express my sincere gratitude to my main supervisor, Associate Professor Sofie Pilemalm, for her continuous support of my licentiate study and research. Her patience, motivation, enthusiasm, and immense knowledge guided me throughout the research and writing of this thesis. Sofie taught me how to write simple, clear and fluent academic text, patiently highlighting my mistakes and providing the proper alternatives. I hope one day to become as good an author as Sofie.

My secondary advisor, Associate Professor Stefan Holgersson, has been consistently available to listen and to give advice. I am deeply grateful to him for the discussions that helped me to define the structure of my thesis. I am also thankful to him for reading and commenting on revisions of this manuscript at important stages.

I would like to thank Ida Lindgren and Johanna Sefyrin, who gave their time to review my thesis. Their precise, detailed and insightful comments and constructive criticisms allowed me to implement a higher standard in my work. Their review also revealed significant gaps, which could subsequently be filled in good time. The thesis was improved significantly by following their comments.

I would like to thank the Swedish Civil Contingencies Agency (MSB), which helped to initiate the data collection process for this research, and specifically Håkan Axelsson, Björn Sund and Jassin Nasr, who provided their valuable insights into the field of emergency management and the subject of the thesis. Their experience and knowledge enabled me to move forward. I also appreciate the financial support from the MSB that made the research at all possible.

I would like to acknowledge the entire Information Systems division at Linköping University, and especially Professor Karin Axelsson and Associate Professor Ulf Melin, whose PhD thesis seminars provided me with the opportunity to present my work and discuss it with my peers. Suggestions and comments from these seminars were extremely helpful for staying on the right track during my study.

I am also thankful to the members of the Trygghetens Hus in Östersund involved in this research, and especially the project manager, Gunilla Ågren, who assisted me in my study there by arranging interviews and a future workshop and creating the opportunity to observe the physical setting.

Last, but not least, I would like to thank my family, to whom this thesis is dedicated and who have been a constant source of love, concern, patience, support and strength all these years.

\author{
Kayvan Yousefi Mojir \\ Ljungsbro, April 2016
}




\section{LIST OF THE THESIS PUBLICATIONS}

[1] Yousefi Mojir, K. \& Pilemalm, S. (2013) A Framework for "New Actors" in Emergency Response Systems, Proceedings of the 2013 Information Systems for Crisis Response and Management (ISCRAM) conference, Baden Baden, Germany, pp. 741-745.

[2] Yousefi Mojir, K. \& Pilemalm, S. (2014) Emerging communities of collaboration: co-location in emergency response systems in Sweden, Proceedings of the 2014 Information Systems for Crisis Response and Management (ISCRAM), Pennsylvania State University, USA, pp.548-555.

[3] Yousefi Mojir, K. \& Pilemalm, S. (2016) Actor-Centered Emergency Response Systems: A framework for needs analysis and information systems development, International Journal of Emergency Management, in press. 


\section{IMPORTANT ABBREVIATIONS}

ERS Emergency Response Systems

IS Information Systems

IT Information Technology

SDLC Systems Development Life Cycle

ISDM Information Systems Development Methodology

PD Participatory Design

UCD User-Centred Design

GT Grounded Theory

MGT Multi-Grounded Theory

NPM New Public Management

ACERS Actor-Centred Emergency Response Systems

CPR Cardiopulmonary Resuscitation

MSB The Swedish Civil Contingencies Agency 


\section{CONTENTS}

\section{INTRODUCTION}

1.1 Cross-sector collaboration trends in emergency response systems and

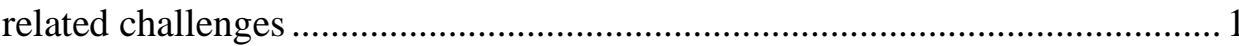

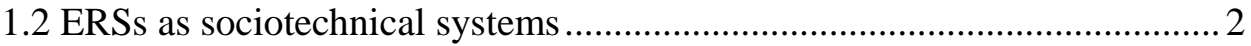

1.3 Participatory design of information systems in ERSs ............................... 3

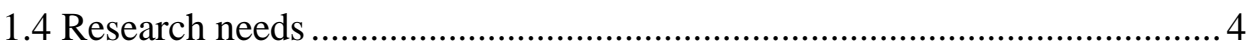

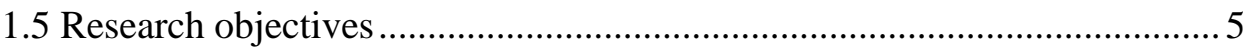

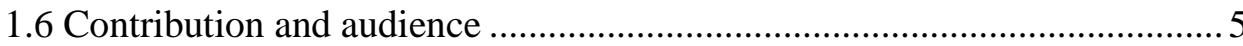

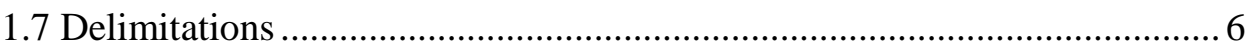

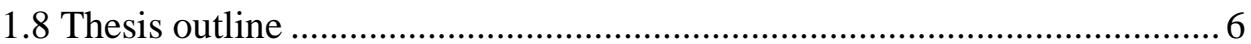

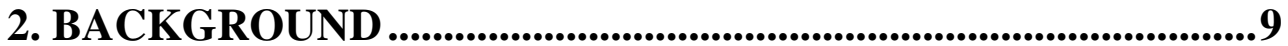

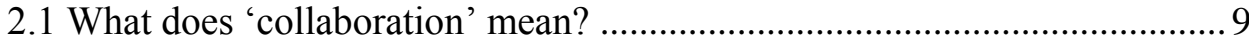

2.1.1. New forms of collaboration in the public sector................................................ 10

2.2 Emergency management and emergency response systems (ERSs) ......... 11

2.2.1 An emergency situation ............................................................................... 12

2.2.2 Emergency management and emergency response organisations in Sweden ......... 14

2.2.3 New forms of collaboration in ERSs ................................................................. 18

2.2.4 Challenges in new forms of collaboration and research needs .............................. 18

2.3 Study context: the changing Swedish ERS …......................................... 19

2.3.1 Co-operative use of resources …………………………………………….... 20

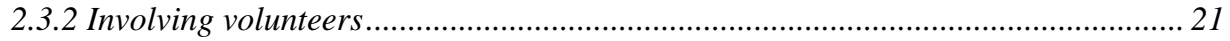

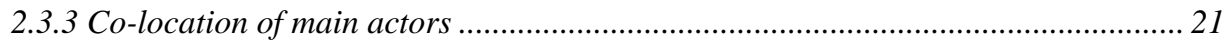

2.4 Information systems and information systems development.....................22

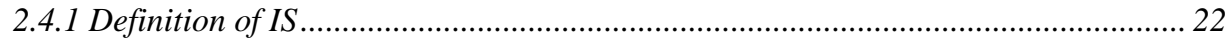

2.4.2 Information systems development- the general view............................................. 23

2.4.3 Information systems development life cycles (SDLC)........................................... 24

2.5 Customised frameworks for systems development..................................25 
2.6 IS development processes: participatory design .......................................26

2.6.1 Different PD generations and associated challenges ............................................ 27

2.6.2 Application of PD in the thesis ..................................................................... 29

\section{THEORETICAL FRAMEWORK ..............................................31}

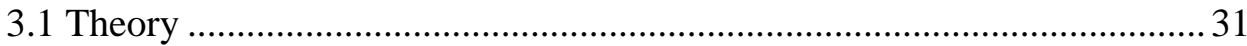

3.2 Organisational and systems theories applied in the thesis ......................... 32

3.2.1 Sociotechnical systems theory........................................................................... 32

3.2.2 Relationships between ERSs and IS as sociotechnical systems .............................. 33

3.2.3 IS development for ERSs using sociotechnical systems theory................................ 34

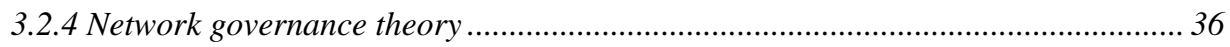

\section{RESEARCH APPROACH AND METHODS..............................37}

4.1 Research process and research design ...................................................... 37

4.2 Theoretical and philosophical assumptions ............................................. 40

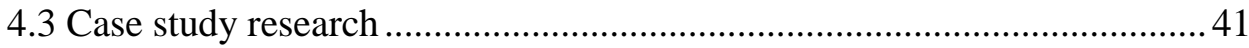

4.3.1 Influences from action research and participatory action research........................ 42

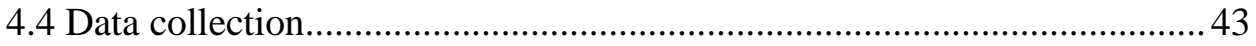

4.4.1 Literature and documents reviews ...................................................................... 43

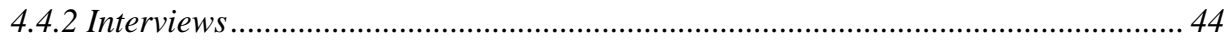

4.4.3 Participant observation …………………………………………………. 46

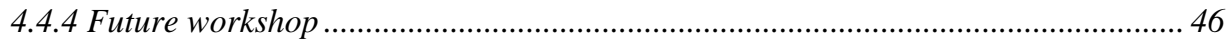

4.5 Data analysis: multi-grounded theory ..................................................... 47

4.6 Summary of research methods ................................................................5

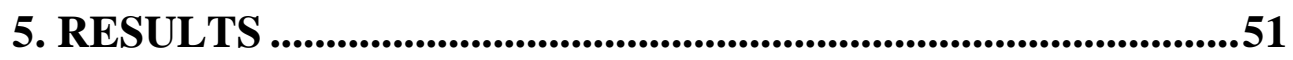

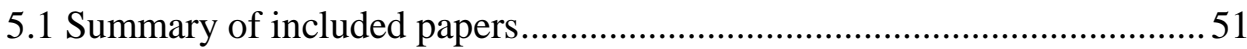

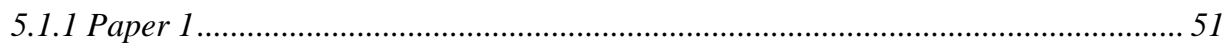

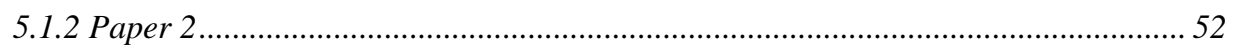

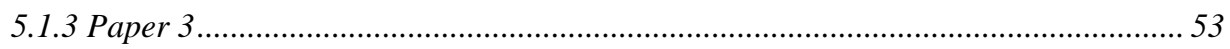

5.2 Results in relation to thesis objectives ...................................................55 
5.2.1 To identify, categorise and highlight key aspects in new forms of collaboration in ERSs

5.3 Initial suggestion for using the framework in IS development for ERSs .. 60

5.3.1 General principles for using the ACERS framework ................................................ 61

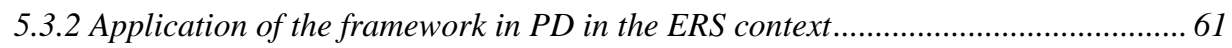

\section{DISCUSSION ...................................................................67}

6.1 ERSs as increasingly complex systems and the ACERS framework ........67

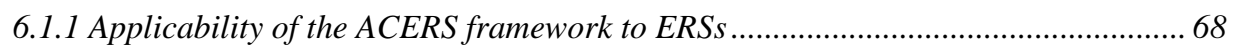

6.1.2 Everyday emergencies versus large-scale disasters ................................................ 69

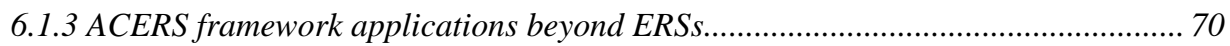

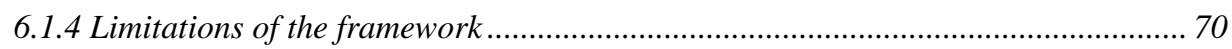

6.2 Using frameworks in line with emerging generations of PD.................... 71

6.2.1 Potential of the ACERS framework for adding formalisation to PD sub-processes 72

6.2.2 Potential and challenges of using the framework in PD ...................................... 74

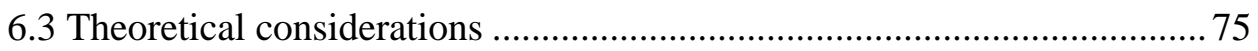

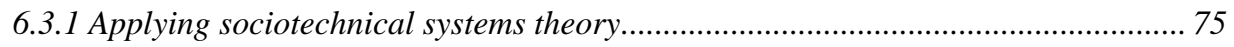

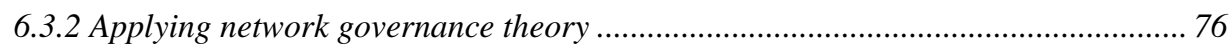

6.3 .3 E-government as an enabler of cross-sector collaboration .................................... 77

6.3.4 New public management as a potential future perspective ...................................... 77

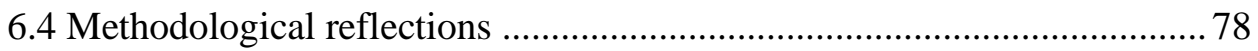

\section{CONCLUSION AND FUTURE WORKS .....................................81}

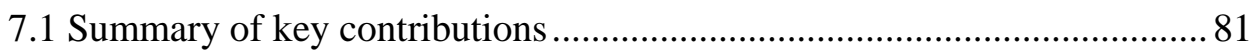

7.2 A changing world: the increasing need for analysis of new forms of

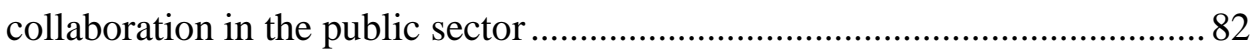

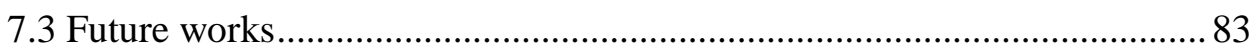




\section{INTRODUCTION}

In recent times, the public sector in general and emergency management organisations in particular have moved toward new forms of collaboration with other resources in society in order to overcome challenges such as resource shortages and budget cuts. However, equal consideration has not yet been given to developing formal ways of analysing such collaborations and developing new related technologies. This chapter provides an overview of the problem domain, related research gaps, thesis objectives and expected contributions.

\subsection{Cross-sector collaboration trends in emergency response systems and related challenges}

In the public sector, resource shortages and budget cuts due to the worldwide financial crisis have moved organisations to seek help from other organisations and sectors (Goldsmith \& Eggers, 2004; O'Leary \& Bingham, 2009). Cross-sector collaborations, involving different societal sectors, private organisations, non-governmental organisations and civil citizens in the delivery of services have been on the increase in recent decades. The approach has been cited as one of the key solutions to many of the challenges societies now face, including climate change, environmental protection, and emergency management (Agranoff, 2007; Waugh \& Streib, 2006).

The collaborations, hereafter referred to as new forms of collaboration, exist today in different forms. However, it is a relatively new phenomenon for organisations when such collaborations need to be established systematically in order to effectively overcome existing challenges. The thesis will focus on new forms of collaboration in emergency management. As the core of emergency management, an emergency response system (ERS) can be defined as:

a system, including organisations, technologies, procedures and rules, which aims at saving lives and minimising human suffering and material damage in emergencies such as traffic accidents, fires and health crises, as well as in large-scale incidents such as floods, storms and earthquakes (Haddow et al., 2013).

A major challenge in the emergency management field is to continue to improve ERSs by reducing response time and increasing the quality of response and to maintain public services in a time of scarce resources and rising public expectations (Wankhade \& Murphy, 2012). Moreover, societal challenges such as climate change, migration, urbanisation, an ageing population, and increasing socioeconomic differences and segregation leading to social unrest have put enormous strain on ERSs and emergency management-related organisations. ERSs worldwide may need to reorganise themselves and involve resources from other areas of society (Quarantelli, 1994; Venema et al., 2010; Waugh \& Streib, 2006) to cope with the emergent challenges and compensate for the shortage of professional resources. 
Both research and practice have begun to highlight the potential benefits of organising ERSs in new ways by creating new collaborations between the existing main professional resources (hereafter referred to as actors) and other resources in society (hereafter referred to as new actors) (e.g. Gunnarsson \& Svavarsdóttir, 2007; Sund, 2006; Venema et al., 2010). However, the new collaborations are not without difficulties. Insufficient categorisation of tasks, responsibilities, structures, competences and legal issues all present challenges (e.g. Pilemalm et al., 2013). Factors such as trust, legitimacy, uniform understanding of the situation, actors' level of experience, training, incident type, commitment and competence have all been claimed to have a decisive role in response operations (Fischer et al., 2011; Palm \& Törnqvist, 2008; Pelinka et al., 2004). The identified challenges are spread through the literature and have not yet been aggregated to produce frameworks, models and methods. Hence, it can be difficult for researchers and emergency management organisations to gain a profound understanding of the collaborations, their nature and the related challenges and opportunities. This, in turn, may negatively affect the development of such collaborations and the related equipment and technology support, thereby impeding achievement of the envisioned goals. In short, there is a perceived gap in developing structured ways of facilitating understanding of new ERS settings/collaborations and the actors involved.

\subsection{ERSs as sociotechnical systems}

ERSs may be viewed as sociotechnical systems, i.e. complex interactions between technology, people and environment in which it is impossible to separate technical issues from social and organisational issues (Ropohl, 1999; Strauss et al., 1985). It is generally claimed that to develop socio-technical systems and related subsystems, it is important to understand the setting and the actors involved (Mumford, 2006). One of the important types of subsystem in ERSs is Information Systems (IS). IS are ubiquitous in modern societies and are used extensively in emergency management (Walle \& Turoff, 2008) to support decision-making, facilitate communication, enable information sharing, provide geographical information and situational awareness, train actors, and so on (Chen et al., 2007; Walle \& Turoff, 2006). In the thesis, IS are seen in line with the ensemble view of technology, i.e. technology as a package of people, tasks, devices, artefacts, and policies (Orlikowski \& Iacono, 2001) and thus as a sociotechnical system. IS may be seen as systems that include information technology (IT), humans, and their interaction with each other in order to support the achievement of organisational goals. IS in new forms of collaboration may, for example, facilitate communication between new actors and professional actors, or be used to position new actors. IS are therefore central when developing, studying and researching new forms of collaboration in ERSs.

Information systems development approaches have successively acknowledged that proper understanding of users, their tasks and the context in which they work is essential before developing a system or product (Avison \& Fitzgerald, 2006a; Christel \& Kang, 1992). From a sociotechnical systems perspective, various non-technical factors (e.g. human, organisational and juridical) must be taken into account in order to develop successful IS. The necessity of 
incorporating non-technical factors into the development process by using a sociotechnical perspective has been acknowledged in the ERS context. For example, a set of design principles for ERS-related IS are presented by Turoff et al. (2004), in which factors such as the scale of incidents, information needs and geographical position of users are presented as important to the proper functionality of IS. Schraagen and Ven (2011) have highlighted the importance of considering human factors such as skills in communication and sense-making.

It is generally accepted that using different frameworks for performing analysis and IS development in new domains helps to structure the domain. Examples include Thomson and Perry's (2006) framework for understanding the mechanism of collaboration, Bryson et al.'s (2006) framework for analysing cross-sector collaboration, frameworks related to stakeholder analysis (Freeman et al., 2010) and the framework for applying sociotechnical systems design in practice presented by Baxter and Sommerville (2011). Such frameworks aim to facilitate understanding of the context and the related actors and stakeholders. Efforts have been made to apply different frameworks in order to analyse the specific domain of ERS. For example, Ki Kim and Sharman (2006) suggest a framework for analysing IS in ERSs in which technical and non-technical risk factors are considered. However, these frameworks usually apply at a general level, i.e. are not specific to new forms of collaboration, or focus only on particular functions involved in emergency response (e.g. information filtering, user interfaces, decision-making or communication). Furthermore, they give a limited view by involving only one set of factors (e.g. human) while ignoring other crucial factors (e.g. organisational). If key aspects and requirements are overlooked by systems developers in the development of IS related to new forms of collaboration, this may result in rudimentary systems analysis, failure of IS projects and ineffective IS for emergency organisations. To conclude, there is a perceived lack of ERS frameworks developed specifically for new forms of collaboration that can be used by researchers and organisations in emergency management to successfully develop appropriate $I S$.

\subsection{Participatory design of information systems in ERSs}

Many design professionals have claimed that applying sociotechnical perspectives to the design and implementation of IS can facilitate a more profound understanding of actors' tasks and the context in which they work, and thus more accurate identification of their needs, for example, in clinical systems and command control systems (e.g. Reddy et al., 2003; Walker et al., 2008). Research has also shown that approaches which actively involve the end users of a system, e.g. participatory design (PD), will ensure a better fit between the technology and the way people perform their work (Kensing \& Blomberg, 1998). However, while the focus of PD in the beginning was exclusively on end users, researchers have since pointed out that there are other stakeholders who must also contribute to the understanding of a new context (e.g. Pilemalm \& Timpka, 2008). There have also been discussions about the challenges of applying PD in complex contexts in which several heterogeneous user groups from different organisations or societal sectors are working together (Pilemalm et al., 2015; Pilemalm \& Timpka, 2008). 
Difficulties in identifying and involving relevant user groups (Gulliksen \& Eriksson, 2006; Karlsson et al., 2012), and PD being time-consuming and lacking in formalisation (Gallivan \& Keil, 2003; Wilson et al., 1997), are commonly reported. In IS development, frameworks and theories exist for identifying stakeholders and users, for example, stakeholder theory and the related developed frameworks (e.g. Freeman et al., 2010; Lindgren et al., 2013). However, these are at a general level and not specific to ERSs. As to PD, it has been applied in the ERS context (Kristensen et al., 2006; Kyng et al., 2006), but existing studies do not focus specifically on emerging forms of cross-sector collaboration and new actors - contexts in which user groups are not well-known, tasks are not clearly defined and users come from different sectors with different organisational rules. Furthermore, PD focuses primarily on involving end users in development processes; however, when applying it to new forms of collaboration, there are other heterogeneous stakeholders from different organisations that need to be involved. In summary, there is a perceived lack of frameworks and PD methods specifically applicable to new forms of collaboration in ERSs for identifying end users and other important stakeholders and involving them in the IS development process.

\subsection{Research needs}

Based on the outlined challenges and gaps, the related research needs can be summarised as follows:

1) There is a need for formalised and systematic ways of analysing new forms of collaboration in ERSs, i.e. for frameworks constructed for this specific context. Formalisation may help to:

- Understand the nature of new forms of collaboration and the challenges involved

- Identify a set of factors which will likely influence new forms of collaboration to be considered in the analysis process

- Categorise these factors, e.g. in terms of tasks, responsibilities, roles and types of actors

2) There is a corresponding need to adapt IS development methods and frameworks for designing IS for new forms of collaboration in ERSs. More specifically, this includes:

- Developing practical ways for identifying and analysing users' and other stakeholders' IS needs in this context

- Investigating how such methods and frameworks could contribute to and formalise PD processes in this context

- At a more general level, investigating how such methods and frameworks could contribute to and formalise PD in complex contexts involving heterogeneous stakeholders/groups

The first point (1) will be covered extensively in the thesis and will be formulated as the primary objective. The second point (2) is considered as a secondary objective and will be satisfied only preliminarily by presenting an initial suggestion on how it might be possible to meet this need. 


\subsection{Research objectives}

According to the research gaps outlined above, the primary and secondary research objectives are thus formulated as follows:

\section{Primary Objective:}

To identify, categorise and highlight the key factors that may influence new forms of collaboration between different actors in ERSs; to present them in a framework; and to describe and exemplify them. The method for developing the framework will also be described.

\section{Secondary Objective:}

To provide an initial suggestion for how the framework may be used to perform organisational analysis and needs analysis in the early phases of PD for new forms of collaborations in ERSs.

The main result or output of the thesis is thus a conceptualised framework for analysing new forms of collaboration in ERSs. The second result is an initial proposal for how the framework can support PD for new forms of collaboration in ERSs. The second result will be elaborated upon in future work, and the thesis does not include evaluation of the framework or the proposal in general. In addition, the ways in which the thesis framework and similar frameworks can be used to enhance PD in general is not an explicit part of the thesis; however, it is discussed briefly as a basis for future work.

The framework presented is based on new forms of collaboration in the Swedish ERS and is thus specific to Swedish circumstances and experiences. However, as previous research has shown, ERSs worldwide as well as other parts of the public sector in different countries experience many of the same difficulties, such as lack of resources and budget cuts. New forms of collaboration, such as cross-sector collaborations and involving volunteers, are emerging public sector global trends, and organisations will need to find ways of managing the challenges that arise in collaboration between different heterogeneous organisations and actors with different rules and policies. ERSs worldwide and other parts of the public sector engaging in these kinds of collaborations can likely benefit from the framework presented, or adapted versions of it.

\subsection{Contribution and audience}

The overall contribution of the thesis is to the ERS field, by providing a conceptual framework for the analysis of new forms of collaboration in ERSs in order to better understand collaborations, actors' tasks within them, and the emergent related challenges. In a more general sense, the framework might potentially contribute to the analysis of new forms of collaboration in the public sector. Further, the thesis contributes specifically to the IS field by presenting a framework for developing IS for actors involved in new forms of collaboration in ERSs. In this sense, the framework aims to support researchers in the ERS field or specifically in ERS/IS to 
incorporate various related factors into the analysis processes. The results of the thesis may also influence IS development research in the ERS context by showing the importance of involving non-technical factors in IS development processes. The framework itself is constructed for both researchers and practitioners in emergency management. Project managers and systems developers are some examples of practitioners who may benefit from the framework, since it is intended to be used specifically to enhance IS development and to facilitate the development of broad and organisationally feasible IS for new forms of collaboration.

\subsection{Delimitations}

The delimitations of the thesis relate to the exclusion of certain perspectives, theories and data. They are listed as follows:

- Large-scale emergencies (such as earthquakes, storms, etc.) do not figure explicitly in the empirical data and are not discussed as a main theme in the thesis. However, the possibility of applying the results of the research on everyday emergencies to largescale emergencies, and vice versa, is discussed.

- The thesis focuses on the response phase of emergencies. Other phases and processes in emergency management, such as preparedness, recovery and mitigation, are excluded. However, the results may be relevant to other phases if these become subject to new forms of collaboration. Also, the phases are most often related (e.g. you cannot respond without some preparations).

- New forms of collaboration are also being discussed in several other areas of research, e.g. in new public management (NPM) and in e-government. These areas are not explicitly included in the thesis but are touched upon briefly in the background, the discussion and the future works sections.

- The focus of the thesis is on the early phases of IS development processes, such as organisational analysis, needs analysis, and requirement elicitation. Other phases, such as design, implementation and evaluation, are discussed only briefly.

- PD approaches in particular are applied in the thesis. Other user involvement approaches, such as user innovation and user-centred design, are not discussed in detail despite their close similarities to PD approaches.

- The thesis does not include an evaluation of the effectivity and efficiency of using the framework in PD.

\subsection{Thesis outline}

Chapter 2 presents the study context and concepts and provides the background to new forms of collaboration, ERSs, and IS development. Chapter $\mathbf{3}$ describes the theoretical framework applied in the thesis, including sociotechnical systems theory and network governance theory. 
Chapter 4 explains the research approach, including case study research, philosophical assumption, and influences from grounded theory and from action research. It also describes the practical research design, the overall research process, and the empirical data collection and methods. Chapter 5 presents the results of the thesis in relation to the thesis objectives. Chapter 6 presents a discussion of the results in relation to the current societal problems and trends affecting ERSs, outlining the potential contribution of the thesis to ERSs globally, to the public sector, and to the IS field. Chapter 7 summarises the results and contributions of the thesis and the implications of the work for future research. 
New Forms of Collaboration in Emergency Response Systems:

A framework for participatory design of information systems 


\section{BACKGROUND}

This chapter defines and explains the concepts and background that play an important role in the thesis. Firstly, the general concept of collaboration and, specifically, new forms of collaboration in the public sector are explained. Secondly, emergency response systems (ERSs) generally and the Swedish ERS in particular are described. Subsequently, definitions of emergency response systems, emergency situations, rescue operations and descriptions of the relevant actors are provided. The study context, including recent trends towards new forms of collaboration in the Swedish ERS, is also explained. The remainder of the chapter provides definitions and background knowledge relevant to information systems (IS), the systems development life cycle (SDLC), participatory design (PD) and how they are used in the thesis.

\subsection{What does 'collaboration' mean?}

'Collaboration' as a word and as a concept is elusive, theoretical and difficult to put into practice (Gajda, 2004). Different terms may be used to refer to collaboration, such as "working in partnership," "working jointly with others", "joining forces", "pooling resources", "acting as a team" and "co-operating with one another" (Gajda, 2004). In the context of the thesis, and specifically relating to new forms of collaboration, the collaboration between autonomous actors and/or organisations (generally from different sectors) is of interest and referred to as cross-sector collaboration or simply collaboration. The definitions in Table 2.1 below are close and deemed relevant to the definition of collaboration in the context of the thesis:

Table 2.1: Different definitions of collaboration relevant to the thesis.

\section{Definition}

Source

Collaboration is a process in which autonomous actors interact through formal and informal negotiation, jointly creating rules and structures governing their relationships and ways to act or decide on the issues that brought them together; it is a process involving shared norms and mutually (Thomson \& Perry, 2006) beneficial interactions.

[Cross-sector] collaboration is the linking or sharing of information, resources, activities, and capabilities by organisations in two or more sectors to achieve jointly an outcome that could not be achieved by organisations in one sector separately.

[Cross-sector] collaboration is a process of assisting and managing multiorganisational arrangements to solve problems which are not easily solved by an organisation alone.

(Agranoff

McGuire, 2003)

Despite the differences between the definitions shown above, they also share many similarities. Actors collaborate to achieve a shared goal and to solve a problem that is not easily solved by one or a few actors alone. At the same time, actors are autonomous and have their own 
identities. Their collaboration usually includes sharing of information and resources. The collaboration is seen as a process, rather than as a status or destination. 'Collaboration' and 'cooperation' are sometimes used interchangeably in the literature; however, in the thesis, 'collaboration' is used to mean a mode of co-operation involving joint activities, shared commitment and trust among actors (Alford \& O'Flynn, 2012)

\subsubsection{New forms of collaboration in the public sector}

In the thesis, recent emerging forms of collaboration in the public sector, aimed at coping with societal current challenges in an era of scarce resources are called new forms of collaboration. This includes cross-sector collaboration, involving e.g. the private sector, non-governmental organisations, volunteers and citizens in the delivery of services (Agranoff, 2007; Agranoff \& McGuire, 2003; Goldsmith \& Eggers, 2004; Kettl, 2005). New forms of collaboration have been in focus and studied continuously. (e.g. Alter \& Hage, 1993; Fleishman, 2009; Gazley, 2008; Levine \& White, 1961; Thomson \& Perry, 2006). Contemporary public challenges, such as climate change, environmental protection, poverty, natural resource management, natural disasters, the educational achievement gap, emergency management, and others are difficult to address without cross-sector understanding, agreement and collaboration (Agranoff \& McGuire, 2003; Bryson et al., 2006; O’Leary \& Bingham, 2009; Vigoda, 2003). Greater efficiency, reduced biases, higher quality of services, and improved organisational accountability are some examples of the perceived benefits of new forms of collaboration (Alford \& O'Flynn, 2012; Brinkerhoff, 2002; Salamon, 1995). Despite many similarities between new and traditional forms of collaboration, an increasing number of studies argue that to achieve the new forms is not an easy task (Greve \& Hodge, 2005; Huxham \& Vangen, 2000; Wondolleck \& Yaffee, 2000). Several researchers have alluded to challenges such as distrust, managerial complexity, cultural conflict, power imbalance, risk of dependence, and lack of incentive for collaboration (Babiak \& Thibault, 2009; Gazley \& Brudney, 2007; Wondolleck \& Yaffee, 2000; Young, 2000).

In the thesis, the phrase 'new forms of collaboration' refers mainly to cross-sector collaborations and/or those collaborations involving volunteers, non-governmental organisations and private persons in the public sector. Such collaborations already exist in some form; for example, in Sweden, fire and rescue services collaborate with security guards in some municipalities, and volunteers participate in emergency response operations in sparsely populated areas. However, these activities are not yet an integrated part of organisations and society, and are new for the actors involved. In the past, these collaborations were not seen as important and therefore were not planned from the top down by politicians and policymakers (e.g. the Swedish Civil Contingencies Agency), and have yet to be established systematically in order to effectively overcome contemporary challenges (Agranoff \& McGuire, 2003). Therefore, this trend is also partly new from a research perspective and in the thesis. New forms of collaboration share certain characteristics, e.g. involvement of a variety of autonomous actors from different domains with different rules; as a result, they also share potential challenges in their establishment (Thomson \& Perry, 2006). A 'new form of collaboration' is thus defined within the thesis as: 
A process in which different autonomous actors attempt to create a new setting by establishing new ways of sharing information, resources and capabilities and by performing joint activities in order to solve a problem that is difficult to solve within the old setting.

\subsection{Emergency management and emergency response systems (ERSs)}

Haddow (2013) describes emergency management as "A discipline that deals with risk and risk avoidance”. Emergency management generally consists of four different phases (Figure 2.1).

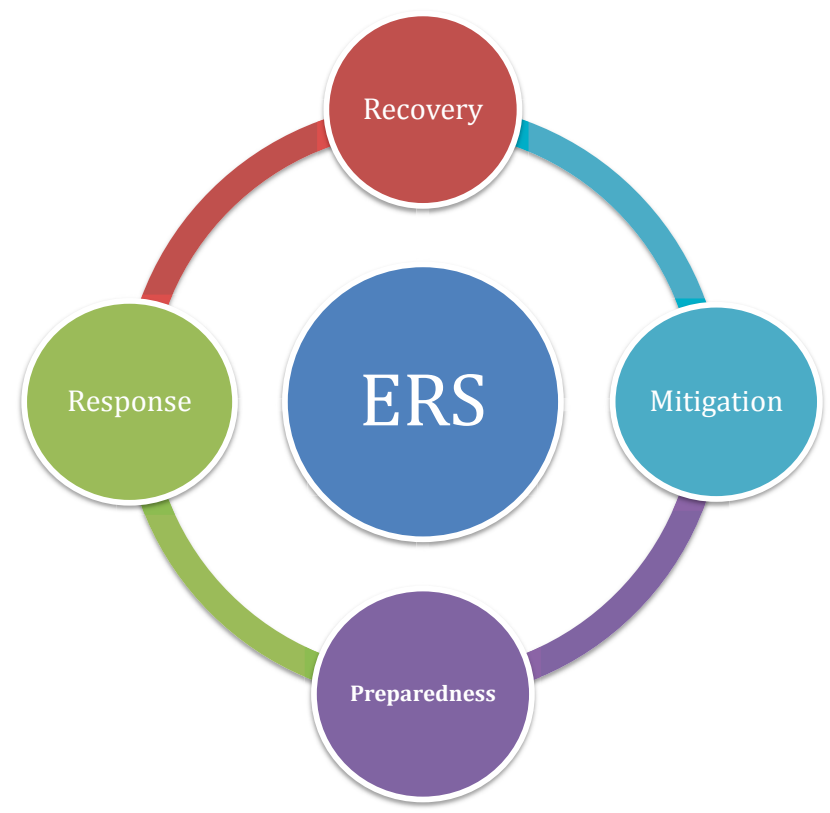

Figure 2.1: Emergency management generally has four different phases. The focus of the thesis is on the 'response' phase and "emergency response systems".

The preparedness phase includes those actions, procedures and equipment that make response organisations and society as a whole ready to tackle emergency situations. The recovery phase (sometimes referred to as restoration) intends to restore the situation to its normal state, e.g. reconstruction of property and damaged infrastructure. The mitigation phase (sometimes referred to as prevention) comprises actions carried out with the intention of reducing the frequency of future emergency situations and/or their impact on society. The response phase commences immediately after the emergency has occurred, e.g. the operative phase. Actors may be injured and equipment and machinery may be damaged in this phase. A response/rescue operation is an action taken immediately following the incident, the priorities of which are preserving human lives, assisting injured people, and mitigating the consequences of the current 
emergency on people, infrastructure, property and the environment (Bergmark \& Tollander, 2008; Civil Protection Act, 2003:778). Since the time delay between the occurrence of an emergency and the taking of response action is required to be as short as possible, there is seldom sufficient information about the situation initially available. Rescue operations are complex processes, resources must be used optimally, and the different actors involved should be well-coordinated (Fredholm, 2006).

'Emergency management' and 'emergency response' are sometimes used interchangeably in the literature. However, 'emergency management' has a broader scope (Waugh \& Streib, 2006). In this thesis, the focus is on response operations, and the systems that deal with the response phase are referred to as emergency response systems (ERSs). An ERS is defined within the thesis as:

A system, including organisations, technologies, procedures and rules, which aims at saving lives and minimising human suffering and material damage in emergencies such as traffic accidents, fires and health crises, as well as in large-scale incidents such as floods, storms and earthquakes

ERSs as systems operate differently in various countries; however, they also share many similarities, including roles, resources, training, technology and equipment needs. The Swedish response system is in focus in the thesis, but is considered as a model for the study of ERSs worldwide. Therefore, the results of the thesis may be relevant and of interest to all ERSs which share similarities with the Swedish ERS.

\subsubsection{An emergency situation}

Emergencies, ordinary or large-scale, have immediate impacts on people, property, and the environment, in terms of e.g. casualties and damages. They may occur without the influence of human factors, for example, natural disasters such as floods and storms, or as a result of human or machine errors (Räddningsverket, 2008), such as nuclear power plant failures and chemical spills.

There are qualitative and quantitative differences between everyday or frequent emergencies and large-scale emergencies. Everyday emergencies tend to occur frequently and therefore are generally not complex to manage for the rescue services and other professional actors in ERSs. Their societal impacts are usually seen within a short time frame. However, the number of victims claimed and damage caused to the environment by frequent emergencies over time may be comparable to the impact of a larger-scale disaster. For instance, Bull-Kamanga et al. (2003) discuss that in large cities, traffic accidents occur frequently and the number of people killed in these accidents each year is not seen as disastrous, even if it may exceed the number of mortal victims in many larger incidents. Everyday emergencies are thus seen as 'normal' emergencies and are usually handled locally. Building fires, drownings, and traffic accidents are examples of frequent emergencies (Danielsson et al., 2010). However, even a 'normal' emergency situation may evolve unpredictably over time and lead to a large and disastrous situation. Taber 
(2008) acknowledges that a seemingly small incident may quickly develop into a large-scale emergency if the variables interact in unfortunate ways, for example, direction of the wind in the case of a forest fire.

A large-scale emergency, on the other hand, usually interrupts societal functions and demands a large amount of resources and the co-operation of heterogeneous recourses locally, nationally and even internationally. Severe weather, storms, flooding and manmade incidents such as chemical spills are some examples. Large-scale emergencies may lead to a disaster or crisis if they cannot be handled in time or if they cause tremendous devastation to infrastructure and/or loss of human life. Catastrophes are situations in which large proportions of infrastructure, societal services and resources are not available for a significant period. The triggers of catastrophes can be similar to those of disasters and crises (Trnka \& Woltjer, 2014).

Other parameters such as the culture of a society, geographical position, and quality of infrastructure vary and alter the definitions of 'everyday' and 'large-scale' emergencies. What is seen as a disaster in a given society may be dealt with as a minor accident in another, and vice versa (Bull-Kamanga et al., 2003).

Table 2.2 shows examples of frequent emergencies and large-scale emergencies in Sweden (https://www.krisinformation.se/, 2015).

Table 2.2: A classification of emergencies in Sweden.

\section{Frequent emergencies Large-scale emergencies}

- Building fire

- Traffic accident

- Non-building fire

- Emission of dangerous substances

- Fall

- Drowning

- Building collapse

- Animal in danger

- Person in danger

- Water damage
- Communicable/infectious disease outbreak

- Server weather and natural hazards

- Avalanche and/or landslide

- Severe winter weather

- Thunderstorm

○ Flood

- Electrical failure (disruptions)

- Transportation failure

- Internet security and privacy issues

- Nuclear power plant technical failure

- Terrorism

- Economic crisis

The thesis will focus on everyday or frequent emergencies and new forms of collaboration in this specific context. However, response operations in both everyday emergencies and largescale emergencies often employ the same resources, personnel and systems. As such, some of 
the results may be applicable to and subsequently be discussed also in the context of large-scale emergencies.

\subsubsection{Emergency management and emergency response organisations in Sweden}

In Sweden, the emergency management approach is bottom-up. The emergency is first to be managed locally, inside the municipality. In case of lack of resources and/or knowledge, and when facing difficulties, the situation is managed at a higher level, moving first to regional, then to national level. The hierarchy of the Swedish ERS is shown in Figure 2.2.

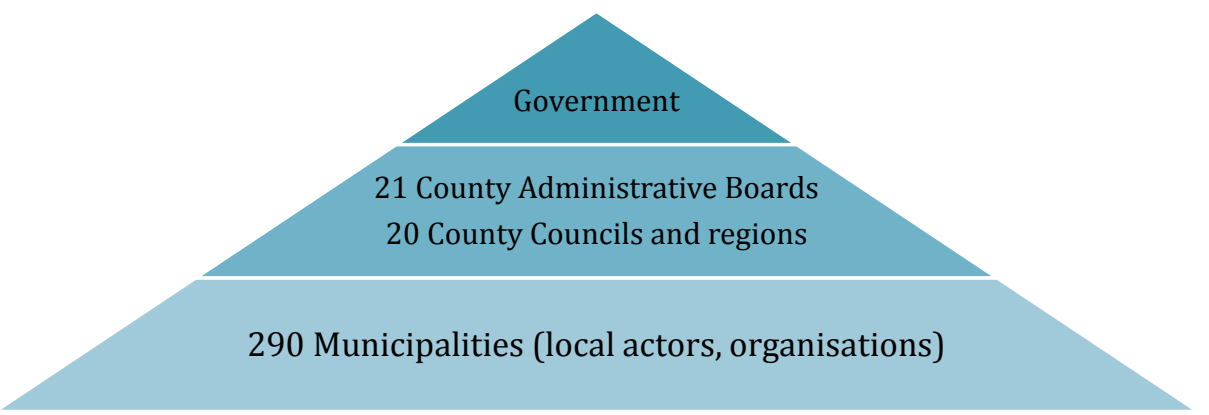

Figure 2.2: The Swedish ERS hierarchy in which the municipalities are primarily responsible for managing emergency situations. Higher levels may intervene in some emergency situations, such as large-scale emergencies.

There are several different actors in the Swedish ERS. In the context of the thesis, 'actors' are those either connected to ERSs or having the potential to be involved in ERSs. The level of assistance required determines the actors' roles in ERSs (Fredholm, 2006). They range from e.g. first responders, who take action immediately after the emergency occurs, to those who receive alarms in alarm management centres and actors at higher organisational levels and municipal authorities, such as management and decision-makers. Since first responders are involved directly in response operations, they are considered central actors who need to be studied in order to determine what they require to be more effective and efficient. In the thesis, first responders are defined as:

Those who usually take the first actions at the emergency site in order to save lives and prevent damage to the environment.

In the thesis, actors may be direct or indirect users of IS in ERSs. The former are also called end users. Actor is a term also used as a micro perspective to organisations and generally refers to persons who work in emergency management-related organisations. The term 'stakeholder' may refer to either a representative from an organisation or the whole organisation. In this thesis and particularly in relation to $\mathrm{PD}$, the term 'stakeholder' has a broader definition than 'end user' in that a stakeholder can affect or be affected by the achievement of an ERS's objectives. 
The different actors in the Swedish ERS that are relevant to the thesis are categorised and presented in Figure 2.3.

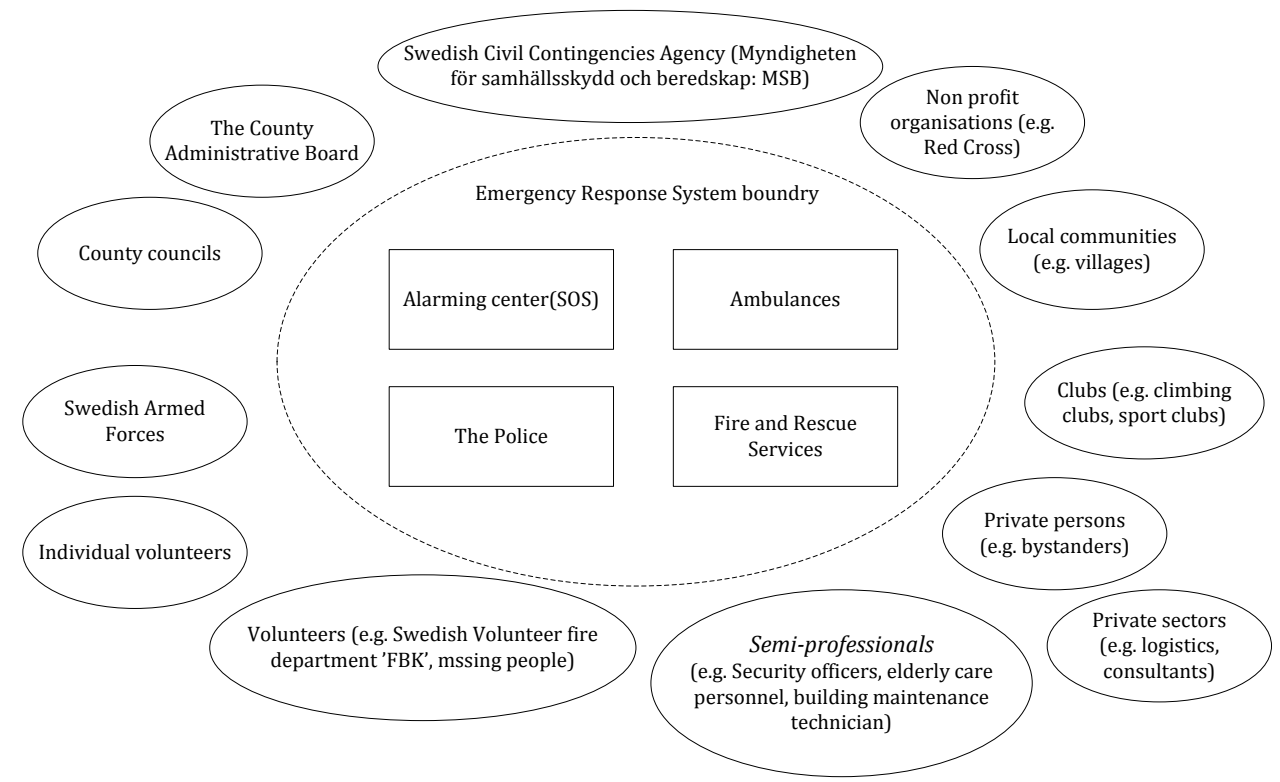

Figure 2.3: Existing and potential actors in the Swedish ERS that are relevant to the thesis ${ }^{1}$.

The municipal fire and rescue services, the police, ambulance services, and the alarm centres are usually referred to as main professional actors in the Swedish ERS and are shown in the centre of Figure 2.3. The Swedish Civil Contingencies Agency (hereafter referred to as MSB), the municipal fire and rescue services, the police, the Swedish Armed Forces, SOS Alarm and security guards (semi-professionals) have been directly involved in the data collection process for the thesis. Other actors such as the county administrative boards (Länsstyrelsen) and county councils (Landsting), while not directly part of the empirical data, nevertheless have a role in the Swedish ERS deemed relevant to the thesis. Actors such as local communities, private persons and volunteers also figure in the discussions and in the framework.

The government of Sweden is responsible for emergency management at the national level, including strategic questions and demands. The MSB is the central actor in the Swedish ERS at the government level. The MSB does not manage, lead or take responsibility for other organisations in the ERS. This means that those who are responsible for a given activity under normal circumstances are also responsible for this activity in emergency situations. Knowledge enhancement, supervision, and strategic questions are examples of the MSB's field of activity (the MSB Official Website, www.msb.se, 2015).

\footnotetext{
${ }^{1}$ Other actors are also connected to the Swedish ERS but not part of the thesis. Some examples include the Swedish Coast Guard (Kustbevakningen), the Swedish Maritime Administration (Sjöfartsverket), Media, Digital Volunteers (in social media), the Swedish Sea Rescue Society (Sjöräddningssällskapet), and the Swedish Meteorological and Hydrological Institute (SMHI).
} 
The county administrative board (Länsstyrelsen) is a state authority, which creates a link between people and municipalities on one side and the government, Parliament and other state authorities on the other. Sweden has twenty-one county administrative boards and these are mainly active on strategic areas such as energy, water, and environmental issues (http://www.lansstyrelsen.se, 2015). In the Swedish ERS, the county administrative boards are responsible for the coordination of municipalities, county councils, authorities, companies and the relevant organisations in emergencies where the municipality cannot handle a situation itself and resources are not sufficient (www.krisinformation.se, 2015). Within the ERS, each county council has a programme outlining how they can use local resources (focusing mainly on healthcare and public transport) to minimise the negative effects on the region and society in case of an emergency (SKL official website, 2015; Kris Information official website, 2015).

In Sweden, there are 290 municipalities (Kommuner) which are responsible for a large part of the services provided to society, such as pre-schools, care of the elderly, and social services. The municipalities are the building blocks of the Swedish ERS which enable society to face and to control emergency situations. According to the Civil Protection Act (2003:778), the municipalities are responsible for responding to emergency situations in their geographical areas which are not the responsibility of the state, for example, building fires, traffic accidents, drownings, and forest fires. Each municipality has its own organisations (such as the municipal fire and rescue services) which co-operate under the authority of the municipality to provide rescue services in the relevant areas.

\section{Municipal fire and rescue services}

All municipalities in Sweden should have at least one fire rescue service that is organised by that municipality alone or in co-operation with other municipalities. For all the rescue services not under the responsibility of the state, the municipality should answer in its geographical area. Fire, traffic accidents, drowning, and accidents involving dangerous chemicals are examples of emergencies in which the municipal fire and rescue services are responsible for controlling the situation.

\section{The police}

According to the Police Act (1984:387), the mission of the police is to increase public safety by taking actions such as preventing crime, monitoring public order and safety, carrying out criminal investigation and providing related information and assistance where required. The police force is a national organisation controlled by the state and organised differently from region to region. In the Swedish ERS, in certain types of emergencies, the police may co-operate with other actors that have primary responsibility for the response operation. The main duties of the police in such situations include blocking off and monitoring the emergency site, regulating traffic, and carrying out searches and interrogation. 


\section{Ambulance services}

According to the Health and Medical Services Act (1982:763), county councils and municipalities are responsible for the emergency medical services and transport (ambulance services). The appropriate organisations within the county councils and municipalities should provide this service. In case of an emergency, county councils and municipalities in different regions may use their resources to help each other as required.

\section{SOS Alarm}

SOS Alarm AB was established in 1973 with the aim of creating a central organisation to handle incoming alarm calls from across society. Fifty per cent of it is owned by the state, twenty-five per cent by the county councils and twenty-five per cent by the municipalities (SOS Alarm Official Website, www.sosalarm.se, 2015). The role of SOS Alarm is to handle incoming 112 (emergency line) calls and to coordinate and mobilise different units (e.g. fire and rescue services, ambulance services) during response operations, calling on the available resources based on the requirements of the emergency.

\section{The Swedish Armed Forces}

The Swedish Armed Forces, though not counted officially among main response organisations, has a role in the Swedish ERS during peacetime aside from its main mission of defending the country in case of armed attack. Transportation is the main form of assistance it can provide in case of an emergency. Vehicles such as cars and air force helicopters and planes can be deployed as part of response operations (www.krisinformation.se, 2015).

\section{New actors in the Swedish ERS}

In addition to those mentioned above, there are other actors that sometimes intervene and assist in ongoing response operations, as shown in ovals in Figure 2.3. These are called new actors in the thesis and are defined as:

Existent or new actors who are not an officially integrated part of an ERS, but who may help in an emergency situation to shorten response time or to compensate for a limited number of professional actors. Their designation as 'new' refers not to their identity or function but to their current lack of integration/convergence to ERSs, and the fact that investigating their needs and characteristics is a relatively new research area. For example, a great many volunteers already partake in response operations in sparsely populated areas of Sweden, but have not been counted as an official part of any response system and are not given the same attention as main actors in order to develop their collaboration and support them with IS. These actors are therefore considered as 'new' actors in the thesis, both from a research perspective and for emergency response organisations.

There are several different types of new actors. Semi-professionals (e.g. eldercare nurses, taxi drivers, building technicians and security guards) usually belong to a particular occupational field, but may take action outside their usual area of responsibility in case of an emergency if given basic training. Non-profit organisations such as the Red Cross assist the ERS mainly in large-scale disasters where professional resources are not sufficient. Different clubs (e.g. sports clubs, climbing clubs) have the potential to assist professional response actors in situations 
where professional resources are not sufficient or are far from the emergency site, for example, by providing transport or helping victims in mountainous places. Social and local communities have important roles in rural areas to act as first responders in cases where the main response organisations are located far from the emergency site. Volunteer groups and individuals are other important groups that can be very helpful in larger-scale emergency situations.

\subsubsection{New forms of collaboration in ERSs}

To address the current challenges in ERSs, new forms of collaboration in emergency management have been established and discussed both for large-scale crises and for smallerscale or frequent emergencies. The establishment of 'mega communities' (Kleiner \& Delurey, 2007) has been described as essential to complex crisis management, with actors from different sectors collaborating in response operations, for example, by performing first aid, providing transportation, or collecting food supplies. Equipping non-professional or semi-professional first responders (e.g. bystanders, volunteer groups) who may be the first to arrive at an emergency site has been suggested as a way to empower emergency management (Jack, 2005). In Katrina, a lack of good collaboration with voluntary organisations such as the Red Cross has resulted in inadequate treatment of injured people (Tierney et al., 2006). The role of bystanders in helping injured people in emergencies such as traffic accidents and drownings has been shown as important (Brodsky, 1984; Venema et al., 2010). Firefighters as medical first responders have been tested in both Australia and Sweden (Smith et al., 2001; Sund et al., 2012), and the role of security officers as key first responders in emergencies such as cardiac arrests and fire incidents has been described as positive (Weinholt \& Andersson Granberg, 2015; Valenzuela et al., 2000). A community-based Emergency First Aid Responder (EFAR) system was implemented in Cape Town in order to involve local communities for a more effective response to emergencies (Sun \& Wallis, 2012). The emerging role of nongovernmental actors, private parties and volunteers has been mentioned many times in the research literature (e.g., Ali et al., 2006; Gunnarsson \& Svavarsdóttir, 2007; Larson et al., 2006; Pilemalm et al., 2013; Waugh \& Streib, 2006).

\subsubsection{Challenges in new forms of collaboration and research needs}

An emergency situation may evolve unpredictably over time, and a short response time is one of the key factors for minimising casualties and damage, e.g. in cardiac arrests or fire incidents (Hollenberg et al., 2009; Mattsson \& Juås, 1997). ERSs are often dealing with limited, delayed and sensitive information, time pressure, exceptions to routines and a highly collaborative working environment with flexible teams of first responders. Collaboration with organisations from outside the immediate boundaries of ERSs, which have various functions, structures and cultures, makes an ERS an open system requiring ad-hoc coordination of different responders (Turoff, 2002). The importance of the time factor in the early phases of the response operation demands rapid decision-making and responsive IS to avoid risking human lives. There are many benefits to be gained if new forms of collaboration can be successfully established; however; according to the specific characteristics of ERSs mentioned above, there is also a risk of failure involved, with potentially high costs to society. 
Despite their potential to improve ERSs, new forms of collaboration involve certain challenges, ambiguities and difficulties. It has been claimed that different types of new actors, their role in emergencies, their responsibilities, tasks, and required competences have not been sufficiently identified, discussed and categorised (Pilemalm et al., 2013). Little consideration has been given to having a uniform understanding of an emergency situation, actors' experiences, and trust between actors, despite the importance of these to the effectiveness and efficiency of response operations (Palm \& Törnqvist, 2008). Different studies have also shown that research on new forms of collaboration and the involvement of new actors is often carried out from a limited perspective, such as medical or technical, and does not sufficiently consider organisational and social aspects (Hallstrom, et al., 2004; Stenberg et al., 2010; Weisfeldt et al., 2010). The type of emergency and the training of actors are also key factors that need to be taken into account in new forms of collaboration (Fischer et al., 2011; Jungert et al., 2006; Pelinka et al., 2004). Conflicting rules and policies may cause problems in cross-sector collaborations when actors come from different organisations (Christensen et al., 2013).

All the relevant studies illustrate a perceived lack of comprehensive understanding of new forms of collaboration in ERSs. There have been some studies, for example, on general crosssector collaboration, that give a broad view of its different dimensions (e.g., Bryson et al., 2006). However, it has not been discussed how such understanding can be gained in ERSs, specifically with the help of methods and frameworks. This lack of understanding may lead to inadequate development of new forms of collaboration, failure of collaborations or failure to fulfil their full potential. It also limits analysis and exploration, and as a result, impedes theorising about new forms of collaboration from a broader perspective. The thesis represents an effort to make a comprehensive understanding more achievable by providing a framework which clearly shows the important dimensions of new forms of collaboration in ERSs, and how the development of IS solutions for related actors can be performed with help of the framework.

\subsection{Study context: the changing Swedish ERS}

The thesis is based on emergency management in Sweden. In addition to the general challenges faced by ERSs globally, Sweden faces specific challenges related to its geographical demography. Sweden is the third-largest country by area in the European Union, with a population of around ten million, and thus a low population density. The majority of the population live in the southern half of Sweden, while the northern part is relatively sparsely populated (Statistics Sweden, http://www.scb.se, 2016). The physical distance between response organisations and populations is great, especially in northern areas, making new forms of collaboration all the more important. At the same time, the Swedish rescue services are localised to increasingly fewer places in society, e.g. by shutting down fire stations in favour of creating larger, centralised Federations of fire services. This trend of centralisation extends to other response organisations, such as the police (Holgersson, 2005). As a result, many response organisations diminish or become responsible for a larger geographical area than before, and the distance between rural populations and response organisations increases further. At the 
same time, in many types of emergencies, e.g. traffic accidents, the first actor to arrive at the emergency site is often a civil citizen rather than a professional first responder and may be able to carry out e.g. first aid if he or she has the appropriate training and/or equipment.

The challenges mentioned above have resulted in substantial ongoing efforts in Sweden to find new ways of responding to emergencies. In 2009, the Swedish government presented the Swedish Civil Contingencies Agency (MSB) with a mission called the "strategy for strengthening societal resources for coping with emergency situations". This simply means to involve actors from outside of professional response organisations in certain phases of emergencies, allowing them to combine and collaborate with professional resources. The aim of these efforts is to reduce response times and/or to compensate for depleted levels of professional resources. It is assumed that, by involving complementary societal resources, response operations can be made faster and more effective, thereby saving lives, reducing the number of casualties, mitigating damage to infrastructure and, ultimately, saving money. Crosssector collaborations, social networks, volunteer assistance and non-profit groups, and even engaging bystanders in order to improve the overall quality of response operations, especially in cases where short response time is crucial, has also been a focus of several Swedish studies (e.g. Pilemalm et al., 2013; Stenberg et al., 2010; Sund, 2006).

Current efforts in Sweden (notable from project reports, the MSB policies and news) can be divided into three different forms: (1) co-operative use of equipment including on-call societal resources, (2) involving volunteers in response operations and (3) permanent co-location of actors (Figure 2.4).

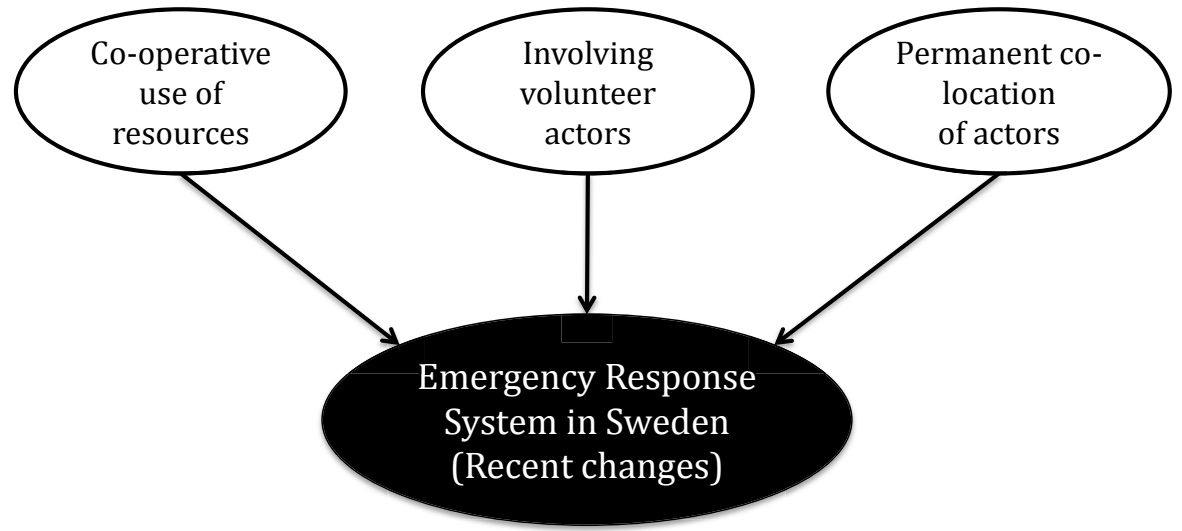

Figure 2.4: Recent new forms of collaboration in the Swedish ERS.

\subsubsection{Co-operative use of resources}

There are different semi-professional actors (see 2.2.2) who may intervene in an emergency situation, either to assist professional first responders or to act as first responders themselves. These actors are frequently on duty in society, may be in different physical locations, and may 
have equipment such as vehicles and communication devices that can be used in response operations. They may have or receive basic emergency management training such as cardiopulmonary resuscitation (CPR) or fire suppression that may be of use in rescue operations. One example is that of security guards, who are usually employed by companies providing guard and security services and patrol inside municipalities to monitor assigned objects or properties and report related crimes and offences. Öckerö, Nyköping, Falkenberg and Varberg are examples of municipalities that have already begun using semi-professionals in response operations. In IVPA (while waiting for ambulances), the fire rescue services are despatched together with eldercare nurses in serious medical emergencies where ambulances are not immediately available or are far from the emergency site. In Nyköping, the fire and rescue services and social care services share vehicles, equipment and techniques in order to reduce costs. Alarms are also centralised in these municipalities in order to shorten response time. In the SALSA ${ }^{2}$ project, certain resources (e.g. taxis) were equipped with defibrillators to give aid to people suffering cardiac arrests (Hollenberg et al., 2009).

\subsubsection{Involving volunteers}

Another example of recent collaboration in the Swedish ERS is involving volunteers in emergency response operations. For instance, volunteers can act as first responders in rural areas where the main professional actors are not located nearby to reduce response times in critical situations. In a project in Medelpad, volunteers are trained in CPR, basic firefighting, first aid and basic life support in case of cardiac arrests, traffic accidents, fires and drownings. In the event of such an emergency, the volunteers are alarmed at the same time as the municipal fire and rescue services. Another project called SMS Life Saving uses SOS Alarm to send an SMS to registered volunteers who are or live nearby in the event of a person suffering a cardiac arrest. Available volunteers can then travel to the site and start performing CPR.

\subsubsection{Co-location of main actors}

A third example of recent collaboration in the Swedish ERS is the co-location of existing response resources, where professional response organisations share a building with other actors supporting or having some responsibility in response operations. Examples include the municipality of Nyköping, where the fire and rescue services and the social care services share a building in addition to co-operative use of vehicles and equipment. Another example is the Safety House in the city of Östersund, where the main response actors are located together. This arrangement aims to improve alarm management in order to shorten the despatch time of professional response, shorten response time by improving collaboration between actors, allow actors to quickly gain a common understanding of the emergency situation, and create a platform and citizen-centred service for shared information management and disseminating information to media and the public.

\footnotetext{
${ }^{2}$ Saving Lives in the Stockholm Area. SALSA was conceived to equip vehicles other than ambulances with defibrillators and ensure that these extra resources are alarmed when cardiac arrests occur. Police cars, taxis and buses are examples of alternative resources.
} 


\subsection{Information systems and information systems development}

The systems view applied in the thesis is broad and includes actors, systems, technology, procedures, rules and policies. According to this definition, information systems (IS) are systems that can be seen as part of the overall facilitating of an ERS, for example, used for communication, decision-making and dissemination of information and for achieving organisational related objectives. However, an ERS can be analysed without focus on IS because an ERS has specific objectives and can exist without any IS, for example, fighting a fire with an extinguisher without use of any information technology. Where it is necessary to focus specifically on the IS aspect of an ERS in the thesis, the specific term 'IS' is used accordingly.

This thesis is in the information systems field. Therefore, it is assumed that readers are familiar with basic concepts in the field of IS. However, it is important to clarify certain concepts that may be subject to interpretation. Therefore, a definition of IS relevant to the thesis, and descriptions of relevant systems development approaches, and related challenges will be provided. More specifically, user involvement approaches and the participatory design approaches are described.

\subsubsection{Definition of IS}

In the early 1960s, Emery and Trist began to question the traditional hard systems thinking approach that was the dominant school of thought before 1960 (Emery \& Trist, 1960). They argued that in order to understand and gain a clear picture of a system, its social dimensions should be taken into account. They used the term 'sociotechnical systems' to present the need to analyse jointly the social and technical issues in systems when developing such systems. Enid Mumford took this idea further and later applied it to IS development processes to emphasise the necessity of considering both social and technical issues when designing new systems (Mumford, 2000). In a separate endeavour at Lancaster University during the 1970s, Peter Checkland developed 'soft systems methodology' in opposition to hard systems (Checkland \& Holwell, 1997). He shifted the IS field from a positivist approach to an interpretive approach based on qualitative understanding of the world. More recently, the ensemble view developed by Orlikowski and Ianoco (2001) looks at technology (i.e. IT) as a package of people, tasks, devices, artefacts and policies. Unlike previous views, the ensemble view focuses on the interaction between people and technology, whether during construction, implementation, or use in social contexts.

In the thesis, IS are seen conceptually similar to soft systems and sociotechnical systems in that they are comprised of technical (e.g. IT artefacts) and non-technical elements (e.g. users, routines, policies, information). Similar to the ensemble view of technology, the thesis focuses on the interaction between technological and non-technological elements and their effect on each other in order to analyse, design, and implement IS. This is also in line with soft systems thinking, according to which factors other than technical factors are involved in analysing systems. This becomes even more important in complex settings such as new forms of 
collaboration in ERSs where there are many non-technical factors influencing IS development, such as ERS-specific characteristics, the nature of the collaboration and the identity of new actors.

The identity, scope and unified definition of IS have been debated extensively by IS scholars, and a degree of controversy surrounds the border of IS as a field or discipline (e.g. Agarwal \& Lucas, 2005; Benbasat \& Zmud, 2003; El Sawy, 2003; Orlikowski \& Iacono, 2001). Some believe in expanding the IS field in order to benefit from theories from other fields, while others insist on narrowing it in order to distinguish IS theories from others. It is therefore important to define IS before using it in a context. In the thesis, the terms 'IS field' and 'IS discipline' are used interchangeably, since the scope of the thesis is not to establish the boundaries of IS and define its identity. The definition of IS in the thesis is influenced by those schools of thought described above which seek to broaden the scope of IS and include both technical and nontechnical factors in IS research (e.g. soft systems thinking, the sociotechnical approaches, and the ensemble view). A clear and rigid identity of IS is not deemed important in the thesis, since it does not bring any substantial benefit to the subject. However, the view on IS should be made clear in order to facilitate the contribution of the thesis to the field. The definition of IS given by Lee (2001) is close to the sociotechnical systems approaches and appropriate to the purpose of the thesis. According to Lee, IS research is a field that

"examines more than just the technological system, or just the social system, or even the two side by side; in addition, it investigates the phenomena that emerge when the two interact" ( $\mathrm{p}$. iii).

By this definition, IS research is concerned with the use of information technology (IT) in a social context. Accordingly, IS as a field or discipline in the context of the thesis and related to ERSs is defined as:

A field or a discipline that generally deals with the use of IT in a social context (here ERSs), and looks at the interaction between actors in an ERS and the IT they use as part of their activities, including response operations. An IS as a system within an ERS is a package of IT artefacts, people, tasks and policies by which a goal, such as e.g. communication, decisionmaking, information dissemination, or geographical positioning, is intended to be achieved.

\subsubsection{Information systems development- the general view}

Information systems development methodology (ISDM) is the process by which IS are conceived, analysed, designed, and implemented (Avison \& Fitzgerald, 2006a). Early computer applications or computerised information systems, mostly before 1960, were designed and implemented with little or no attention to the construction of methodologies for rigorously identifying user needs (Avison \& Fitzgerald, 2006b; Walters et al., 1994). The dominant methodology was rule-of-thumb and based on experience, tradition and common sense, which often resulted in inappropriate IT systems that were not responsive to user needs (Avison \& Fitzgerald, 2006b). As a reaction to this, in the late 1950s and early 1960s, when the use of computerised systems in organisations was becoming widespread, the Systems Development 
Life Cycle (SDLC) emerged as an approach to IS development, and consequently the waterfall model methodology was introduced as the first IS development methodology (Lee, 1987). The SDLC consists of a general set of development phases, with the purpose of guiding the design and implementation of systems that will be suited to user needs and helping to deliver systems on time and to budget. Although the initial SDLC and waterfall model methodology were useful for documenting activities and thus improved communication within development teams, a number of disadvantages were identified when applying it to IS development projects (Avison \& Fitzgerald, 2006b; Lee, 1987; Walters et al., 1994). For example, 'system delays' occurred due to changes in user needs during development; 'user dissatisfaction' was common where users were involved only after the system was finished. The associated costs of revising and maintaining systems in order to meet user needs were high.

In response to these issues, a number of alternative approaches to IS development emerged in the 1970s and onwards. Soft systems methodology (SSM), strategic approach, structured approach, incremental or evolutionary development (e.g. prototyping) and participative approaches (e.g. ETHICS) are some examples (Checkland \& Scholes, 1990; Martin, 1991; Mumford, 1995). The promise that methodologies would solve most of the problems of IS development has not entirely been met, since methodologies from different approaches were variously considered difficult to use, complex, instable, not contingent, or built on invalid assumptions (such as assuming the environment is stable) (Avison \& Fitzgerald, 2006b). During a process of adaptation and refinement over recent decades, emphasis has shifted to involving users, having iterative development processes in order to answer emerging changes in user needs, and having contingent IS development methods. Different approaches based on user involvement such as PD, user-centred design (UCD) and user innovation (UI) have emerged, which are explained in further detail in 2.6. Recently, Agile development approaches have also emerged as more concrete methods for IS development, with emphasis on iteration in the development process, collaboration with stakeholders, response to changes, and regular delivery of products. Examples of agile approaches are extreme programming (XP) and SCRUM methodologies (Lindstrom \& Jeffries, 2004).

\subsubsection{Information systems development life cycles (SDLC)}

In the thesis, the SDLC, regardless of the type of methodology, is defined as a set of general activities or phases carried out in order to create or alter a system (Avison \& Fitzgerald, 2006a; Sommerville, 2004). These activities are usually iterative and include the phases:

- Investigation, needs and requirements analysis: This phase consists of a series of activities, including context analysis and analysis of user needs, which result in the system requirements specification.

- Design: In this phase, the different components of the system, their relations to one another, the architecture, and the way in which the system will be implemented are designed and finalised.

- Implementation: This phase involves the realisation and execution of the design specifications. The tasks in this phase may range from programming, graphical user 
interface, database coding, and data conversion to training users, system deployment, changing work routines and preparing organisations to use the system.

- Testing and validation: In this phase, IS are checked for errors. It is also verified that the system fulfils the requirement specification.

- Review and maintenance: This phase consists mainly of reviewing the system to ensure that it meets user needs and the estimated costs. Maintenance work (e.g. correcting errors) and response to new needs due to changes in organisations are also parts of this phase.

\subsection{Customised frameworks for systems development}

The use of IS has accelerated the emergence of different forms of collaboration in the public sector. In ERSs, new actors and new forms of collaboration are supported by certain IS and technology, e.g. dynamic resource handling systems, optimisation systems, graphical positioning systems, and mobile applications (Andersson Granberg \& Värbrand, 2007). New techniques are developed in parallel with the establishment of new forms of collaboration, for example, optimising the location of ambulances and fire services (Andersson Granberg \& Värbrand, 2007) or introducing new communication platforms (e.g. RAKEL). Nevertheless, new techniques must meet user needs, including new actors. Therefore, the ERS context and domain should be thoroughly understood and analysed before any new technology is designed.

Different theories and frameworks have been constructed with the aim of facilitating IS development by identifying and characterising the relevant stakeholders and understanding the context. In the context of collaboration, frameworks already exist for facilitating understanding of the concept of collaboration by showing the interconnection between its different elements. According to Ring and Van de Ven (1994), collaboration has four interconnected elements, namely negotiation, commitment, assessment and implementation, and these should be studied and understood as parts of a cyclic and iterative process. Thomson and Perry (2006) suggest five key dimensions for understanding the process of collaboration: governance, administration, organisational autonomy, mutuality, and norms of trust. In another effort, specifically targeted to cross-sector collaboration, Bryson et al. (2006) present a framework centred on the type of collaboration, structure, governance, and public value. While each of these frameworks aims at focusing on significant aspects of collaboration and/or cross-sector collaboration in order to understand it, they may be considered too general and/or highly abstract (e.g. Gajda, 2004). It therefore seems difficult to use them in a specific context and for the particular purpose of IS design.

An important part of the early phases of IS development is stakeholder identification. Stakeholder theory and the associated theories and frameworks aim at identifying and characterising stakeholders (Freeman et al., 2010). Mitchell et al.(1997) have generated a typology of stakeholders to identify and characterise salient stakeholders. In another example, Lindgren (2013) constructed a framework for identifying stakeholders in public e-service 
design in the context of e-government. Bryson (2004) also reviews a range of stakeholder identification and analysis techniques and argues that proper use of stakeholder analyses can help to frame issues and solve them technically and politically. Baxter and Sommerville (2011) also provide a framework for IS development to apply sociotechnical systems theory in practice in order to involve contextual factors and stakeholders in development processes. However, these theories and frameworks are not bound to ERSs, and it is not clear how systems developers should think and act in order to involve a range of heterogeneous stakeholders from different sectors when there is no concrete and practical context-related way to do so. It may be challenging to use these frameworks directly in IS design for ERSs, since they do not incorporate ERS-specific aspects such as incident characteristics and the roles of specific actors such as first responders.

ERS-specific frameworks have also been constructed. For example, Turoff et al. (2004) present a set of general design principles for a "Dynamic Emergency Response Management Information System" drawn from a literature review of ERSs. In Ki Kim and Sharman's (2006) framework for analysing IS user needs in ERSs, factors such as information sharing, resource allocation, privacy, and coordination with national resources were cited as important considerations. Rasmussen \& Svedung (2000) have designed a framework for risk management based on sociotechnical systems analysis, in which sociotechnical systems are presented and analysed by their different layers such as technique, human factors, management. However, these frameworks do not incorporate recent changes in ERSs regarding new forms of collaboration. For example, new actors such as volunteers and communities are not taken into account. Therefore, direct application of these frameworks may result in overlooking important context-related aspects. In conclusion, there is a perceived need to develop a new framework which is constructed specifically for new forms of collaboration in ERSs and which can be used practically in analysis of collaborations and the development of related IS.

\subsection{IS development processes: participatory design}

One of the major challenges in IS development is inadequate requirements and system functions which fail to meet user needs due to an incomplete understanding of users by systems developers, incorrect assumptions and inconsistent requirements (Boehm \& Papaccio, 1988; Young, 2002). In order to mitigate this problem, proper understanding of users, their tasks and the context in which they work has been continuously and increasingly emphasised as a crucial early stage in IS development (Checkland \& Scholes, 1990; Christel \& Kang, 1992; Mumford, 1995, 2000). Checkland and Scholes (1990) argue that understanding of an organisation depends strongly on including its people in the analysis.

As mentioned in 2.4, different schools of thought for the involvement of users in technology design began to emerge in the 1970s and 80s. The early sociotechnical approach has been further developed in the Scandinavian countries to empower employees to design and organise their own work environment. This tendency led to the development of the principle of co- 
operative design (Bjorn-Andersen \& Eason, 1980; Kuutti, 1996). The term 'co-operation' was subsequently replaced by 'participation' in the international community, and is now commonly called 'participatory design' (PD). PD broadens the focus of sociotechnical systems in that it explicitly relies on the direct involvement of users throughout the technology development process to ensure that the final product meets their needs (Ehn, 1993; Ehn \& Kyng, 1987). The original basis of PD was to offer a more democratic approach to the design process by empowering workers to participate directly in the design of their technology and IS (Kensing \& Munk-Madsen, 1995; Schuler \& Namioka, 1993). It has been claimed that eventually, PD results in more effective systems based on user needs (Ehn, 1993).

Various benefits of using PD in IS development have been claimed (e.g. Kensing \& Blomberg, 1998; Maiden \& Rugg, 1996; Markus, 1983), for example:

- It results in a more accurate formulation of requirements and user commitment to the implemented system.

- It ensures a better fit between the technology and the way its users perform their work.

- It increases acceptance of a system among users.

- It leads to innovative solutions and systems.

A similar approach to PD is user-centred design (UCD), which emerged in the early 1980s in the domain of human-computer interaction (HCI) (Norman \& Draper, 1986). In UCD, users are seen not as active agents in the design process but rather as a source of information, and systems developers should have sufficient business knowledge to understand who the users are and what they require (Gould \& Lewis, 1985). Moreover, UCD often relies heavily on user-interface design to satisfy users. Another school of thought is user innovation (UI), which also focuses on innovative system functionalities suggested by users (von Hippel, 1986) in product development. However, UI requires a distinct organisational context and a pre-defined set of user groups for the development process, which is difficult to establish from the beginning in new forms of collaboration.

\subsubsection{Different PD generations and associated challenges}

PD is conceived not as a particular method, but rather as a philosophy characterised by a commitment to social concerns and the relationship between systems developers and participating users (Schuler \& Namioka, 1993). PD has evolved over the decades to improve technology design for end users in line with social trends and technological development. The early generation of PD had a clear ideology of active involvement of end users, usually homogenous primary end users (e.g. civil citizens, shop-floor actors) in urban planning and technology design (Ehn, 1993). Managerial personnel and other stakeholders were initially not in focus. In the second generations, PD was extended from ideological focus to practical application in order to derive its benefits in collaborative working environments, usually inside organisations, with the focus remaining on end users (e.g. Tollmar, 2001). The later generations of PD also sought to enhance the approaches by defining and categorising users to include larger groups (Damodaran, 1996; Iivari et al., 2010; Lundman, 2006). The third generation of PD may be defined by the successive involvement of heterogeneous end users in increasingly complex 
work environments and large-scale systems, in which other stakeholders who can help to establish a better understanding of contextual factors gained attention in design groups (Pilemalm \& Timpka, 2008). For example, Action Design (AD) expands the concept of design groups and insists on involving stakeholders who are affected by system design, such as toplevel management and system owners (Pilemalm, 2002). In a recent categorisation by Pilemalm et al. (2015), it was suggested that the fourth generation of PD must adapt to contemporary trends towards cross-sector collaboration and e-government, involving heterogeneous stakeholders and users such as volunteers, non-profit organisations and citizens, and that this has several implications as to how the approach should be applied..

Each generation of PD and their associated challenges has in certain respects reflected societal trends and technological development. However, there are also general challenges involved with the applicability of PD in practice. It has been claimed that implementation of PD can be complex and time-consuming, given the fact that systems developers are required to contact and motivate users, facilitate meetings and offer a point of focus for user contributions (Wilson et al., 1997). Users at the shop-floor level in particular do not always have enough time or the required attitude to invest in systems development work (Gulliksen \& Eriksson, 2006; Wilson et al., 1997). More recent challenges include difficulties in identifying and involving large heterogeneous stakeholder groups, an unclear picture of end user groups and their associated organisational tasks, lack of organisational belonging for participation in design groups (e.g. civil citizens) and lack of concrete methods for achieving the original fundaments of PD (Jansen, 2006; Oostveen \& van den Besselaar, 2004; Pilemalm et al., 2015). Some of these challenges are specifically relevant to the thesis and are expanded upon below.

\section{Difficulties in identifying user groups and stakeholders and involving them in the IS development process}

Despite a strong emphasis on user involvement, PD does not provide clear methodologies for achieving such involvement in complex contexts such as collaborations involving different organisations, citizens, volunteer groups and external experts (Oostveen \& van den Besselaar, 2004). Heterogeneous stakeholders with different backgrounds and needs and at different organisational levels should be identified, motivated, informed and involved in development projects. One challenge is thus to identify a broad set of users and stakeholders and to involve them using proper methods (Jansen, 2006). The importance of including not only end users but other types of stakeholders in PD projects has gained increased attention from scholars in recent decades (e.g. Følstad et al., 2004; Pilemalm, 2002). For example, Lindgren (2013) argues that the use of a framework for stakeholder identification and analyses in the early phases of user involvement (PD) processes is often overlooked, but necessary for designing public e-services. Similarly, Pilemalm el al. (2015) discuss that the growing complexity of cross-collaborative work processes and the need for sophisticated IS and e-services for a broad range of user groups demand a strong emphasis on stakeholder identification in the early phases of systems development processes in new applications of PD. Recent changes in ERSs are clearly in line with the above discussions, and even increase these challenges as participant selection takes place among an ever-broader set of stakeholders. 


\section{Lack of formalisation in user involvement and relevant processes}

It has been argued that a lack of formalisation, methodologies and clear working methods in PD processes has restricted PD to an academic approach, used infrequently in practice/industry or in a much weaker sense than it promises. As a result, the products delivered have mainly been small, stand-alone IS (Besselaar, 1998; Tollmar, 2001). The democratic principles of PD to respect workers and achieve their consensus is usually time- and resource-intensive, and time pressures also constrain workers' abilities to engage in design groups (Pilemalm, 2002; Trigg, 2000). For these reasons, PD has repeatedly been criticised as an ineffective approach. PD generally focuses on the early phases of development processes to identify user needs and gain knowledge from users, and little attention has been given to the possible application of PD in later phases of the SLDC. It has been argued that without a clear development process, there may not be a final product (Gallivan \& Keil, 2003; Wilson et al., 1997). The challenge is even greater when IS are required to function in line with new societal trends (e.g. cross-sector collaboration and involving citizens) and recent organisational forms (e.g., network organisations) (Pilemalm et al., 2015). In summary, there is a perceived lack of formalisation in PD and a need for frameworks and similar tools, methods and processes in order to make it effective and applicable as an approach to contemporary IS development.

\subsubsection{Application of PD in the thesis}

In the thesis, 'participatory design' refers to the extensive use of PD approaches by the active involvement of end users in the development of IS. The term as applied in the thesis has the meaning that IS users (also called 'actors in the ERS context') are central to the entire analysis process. The thesis view of PD is in line with recent approaches in the field, and thus insists on involving not only primary end users but also other stakeholders who can provide insights into the context of new forms of collaboration from different viewpoints. Consequently, the term 'stakeholders' is used in a more general sense and refers to those groups who affect or are affected by organisational objectives, ranging from top-level management to end users. Where it is necessary to refer to a certain group of users, the term 'user' is employed. The term 'participant' in PD may also be used to refer to stakeholders (including users) and systems developers.

An initial suggestion is made for how the framework presented in the thesis can be used in the early phases of PD in ERSs to address the above challenges. It is then discussed how the framework may be used in other contexts, in the early phases of PD and even in the later phases. The discussion will be a point of departure for future research to evaluate the framework and to demonstrate its benefits and potential contribution to the field of PD. 
New Forms of Collaboration in Emergency Response Systems:

A framework for participatory design of information systems 


\section{THEORETICAL FRAMEWORK}

This chapter presents the theoretical framework applied in the thesis. Firstly, 'theory' as a concept is defined. Following this, sociotechnical systems theory is described and a sociotechnical view of ERSs is presented. The selection of sociotechnical systems theory as the main theory applied in the thesis is justified. The relation between the IS and ERS context is explained and the adapted sociotechnical systems model is presented. Network governance theory, which is touched upon in the thesis, is also briefly explained.

\subsection{Theory}

In the research literature, there are different definitions of what constitutes a theory (DiMaggio, 1995; Sutton \& Staw, 1995; Weick, 1995). Sutton and Staw (1995) argue that it is easier to define what a theory is not than to define the concept of a theory. They clearly state that data, diagrams, models, references, list of variables, definitions, and pure hypotheses and predictions are not counted as theories. Rather, they see a theory as the "answer to queries of why" and define it as follows:

"Theory is about the connections among phenomena, a story about why acts, events, structure, and thoughts occur. Theory emphasises the nature of causal relationships, identifying what comes first as well as the timing of such events. Strong theory, in our view, delves into underlying processes so as to understand the systematic reasons for a particular occurrence or non-occurrence. [...] It usually is laced with a set of convincing and logically interconnected arguments." (Sutton \& Staw, 1995, p. 378)

On the other hand, Wieck (1995) views theory as a process that includes abstracting, generalising, relating, selecting, explaining, synthesising and idealising as attempts to build theories. Weick does not explicitly exclude products such as data, diagrams and variables from being 'theory', but rather argues that any theory building should include these components. To reject a study in its early stages of theory development is problematic, since theory and theory development are based on a process and cannot be seen exclusively in terms of a complete product. Theories do not need to be strong in their first stages and may start, for example, with the creation of models and diagrams as part of a process that may lead to progressively stronger theories (Wieck 1995).

Sutton and Staw's view of theory, which clearly excludes certain components from being counted as theory when presented alone, has been applied in the thesis. This helped to structure the thesis components. Based on their view, concepts (e.g. collaboration), definitions (e.g. emergency situations), fields (e.g. ERS and IS), approaches (e.g. PD) and methods (e.g. systems development methods) are not included in Chapter 3, since they are not counted as theory but rather as useful background or as examples of the application of existing theories which 
empower the reader to understand the content of the thesis. Accordingly, these elements are presented in Chapter 2. The present chapter focuses instead on sociotechnical systems and network governance theories, which are in line with the above definition of theory. For example, sociotechnical systems theory states why technological design fails for actors when both technical and non-technical aspects of systems are not studied in parallel.

Using Sutton and Staw's view of theory does not have any effect on methodology or theory selection, but only on structure and the way in which the components of the thesis are presented. Moreover, the framework presented in the thesis is not considered as a theory in itself, but as an initial step towards formulating theories for new forms of collaboration in ERSs in the future.

The main output of the thesis is a conceptual framework. A framework can be defined as follows:

"A framework explains, either graphically or in a narrative form, the main things to be studied - the key factors, concepts or variables and the presumed relationship among them" (Miles \& Huberman, 1994, p. 18).

The framework presented in the thesis conforms to this definition and will thus include the key factors to be considered in the analysis of new forms of collaboration in ERSs, and to some extent the relationships between such factors. The framework may have the potential to be used in the development of future theories on new forms of collaboration. The results of the thesis may be seen as an initial step in the process of theory generation, in line with Wieck's definition, by which a framework is created and developed in several steps.

\subsection{Organisational and systems theories applied in the thesis}

In the thesis, an ERS is defined as a system that comprises different organisations (actors) and sub-systems; it is considered a complex interactive system in which diverse heterogeneous actors with different characteristics, tasks and needs collaborate in response operations. It is also a tightly coupled system because problem in any part of the system (e.g. in collaboration between actors) usually worsen the quality of response operations. Moreover, an ERS is viewed as a sociotechnical system as it is defined in the following.

\subsubsection{Sociotechnical systems theory}

Sociotechnical systems theory sees a system as a package of technology and its social context. The term 'sociotechnical system' comes from the work of Emery and Trist at the Tavistock Institute in the 1960s, which illustrated the need for a fit between technical and social subsystems within organisations (Emery \& Trist, 1960; Mumford, 2000). The term 'sociotechnical' describes a system involving complex interactions between technology, humans and the environment. Sociotechnical systems theory stresses the reciprocal interrelationship between technology and humans (Ropohl, 1999). The outcome of applying 
this theory is a better understanding of how social, organisational and technical factors affect work processes and the use of technical systems, with the potential for improvements to organisational structures, work processes and technical systems design (Baxter \& Sommerville, 2011). The success of a system depends on the types of interaction between its social and technical factors, and it is impossible to separate these two factors (Strauss et al., 1985). However, it may not be possible to develop a technical system without considering organisational- and social-related systems and factors. Relationships between culture, technology and structure are also important in analysing High-Risk Organisations from a sociotechnical point of view (Nævestad, 2009). In the sociotechnical systems view, humans and technology are two separate, self-contained entities that interact with each other, affect each other and create the social context (substantialist ontology) (Kaghan \& Bowker, 2001).

Researchers from various fields have conducted sociotechnical analysis of systems, for example, in clinical systems (Reddy et al., 2003) and air-traffic control systems (Bentley et al., 1992). Sociotechnical systems theory has also been used to investigate the organisational and social complexities that may lead to failure in IS (Bostrom \& Heinen, 1977), the results of which indicate that success of IS projects depends on how well social and technical aspects are jointly optimised. This approach has been echoed by several other scholars (e.g. Laudon \& Laudon, 1999). Enid Mumford and Frank Land were among the most influential researchers who initiated sociotechnical research in the IS field (Davenport, 2008; Land, 2000). Mumford applied the sociotechnical perspective to the design of computer systems in order to emphasise the important relationship between technical and social systems and the need to work with both in IS development (Mumford, 1974). PD methods (e.g. ETHICS), explained in Chapter 2, emerged from this perspective during the 1980s (Mumford, 1981). Mumford's work placed the social context and human needs at the centre of IS design, emphasising a humanistic approach to systems design and noticeably improved the quality of working life in terms of fit between personal and organisational goals.

\subsubsection{Relationships between ERSs and IS as sociotechnical systems}

Sociotechnical systems analysis has also been the focus of studies in the field of emergency management, e.g. in command and control systems (Walker et al., 2008). In the thesis, an ERS is defined as a system because it involves a collection of different actors and subsystems, and their interactions, methods, etc. Further, ERSs are viewed as sociotechnical systems because they are composed of social subsystems and components alongside technical ones. Actors, routines, policies, different responses to emergencies (e.g., responses to incidents involving chemical substances versus responses to traffic accidents) are examples of the social components of an ERS. There are certain social factors associated with these social components (or subsystems), such as actors' characteristics, nature of the incident, and law conflicts. The technical components of ERSs may include equipment and IT tools that are used either to perform response operations (such as fire extinguishers) or as support for actors for decisionmaking and communication (such as radios, telephones, and decision support systems). Since they are intertwined, it is important to include both social and technical aspects in the study of ERSs. Changes in ERSs, i.e. creating new forms of collaboration, involve more actors in 
response operations. One result of this is that interactions become more complex, with the introduction of various non-technical factors such as different working environments, tasks and responsibilities; size and type of incidents; actors' training and education; and last but not least, legal issues (Pilemalm et al., 2013). The sociotechnical systems view of an ERS may thus be helpful in analysis of new forms of collaboration in ERSs.

Similarly, IS, as defined in Chapter 2, are seen as sociotechnical systems in the thesis since IS also include both technical and social components. End users, stakeholders, and organisational context are some examples of the latter. Technical components may include IT artefacts such as databases, mobile apps, etc. To design IS in line with the sociotechnical systems view, both technical and social factors should be incorporated in the development process. While both IS and ERSs are viewed as sociotechnical systems in the thesis, certain distinctions are drawn between them. Both kinds of system may share certain social components, for example, actors in an ERS may also be end users of its related IS. However, certain social components of IS can be affected by ERSs, for example, the type of incident requiring a response can affect IS user needs. The technical components of each kind of system are also inherently different. Technical components in IS can only be IT artefacts, which distinguishes IS from other systems; however, an ERS may not necessarily contain any IT artefacts and actors can, for example, respond to a fire emergency using only a fire extinguisher. Another difference relates to the aims of the two types of system. ERSs contribute explicitly to specific ultimate goals, i.e. saving human lives and minimising environmental damage. Conversely, IS contribute to contextspecific goals. Used in an ERS context, IS contribute to goals that have been set by ERS organisations. If they are for example used in education systems, the goals are different. Therefore, IS do not have any associated specific goal from the outset, and IS boundaries, including their social and technical components, are influenced by the context in which it is used. From this perspective, an ERS may be viewed as an independent sociotechnical system. However, it is difficult to imagine an independent IS without any context of use. To summarise, IS can be used in the context of ERS and as subsystems of it to support the goals of ERS organisations by facilitating, for example, decision-making, communication and data analysis.

\subsubsection{IS development for ERSs using sociotechnical systems theory}

Different scholars have attempted to apply sociotechnical systems theory to analyse systems. Examples can be found in sociotechnical system based models by Bostrom and Heinen (1977), Rasmussen and Svedung (2000), Laudon and Laudon (1999), Davis et al. (2014) and Baxter and Sommerville (2011). All these models are in agreement that a sociotechnical system comprises several levels or components, including technology, human factors, work processes, organisational and managerial aspects, economics, law and politics. However, efforts have not always been made to study these simultaneously and to connect and analyse the results collectively (Rasmussen \& Svedung, 2000).

Five general and common components or levels of sociotechnical systems have been selected from existing models and renamed for use in the development of the thesis framework. Organisational, managerial and economic aspects are grouped under the heading 
structure/organisation, since they are all somehow related to organisations and their structures. Human factors are called actors, and this refers to all characteristics related to actors in response operations. Tasks and work processes are referred to as task/response operations to keep the focus on jobs related to response operations at an operative level. Since technological components exist in all models, these remain unchanged and are referred to as technology within the framework. Finally, environment/context refers to the legal, political and environmental aspects of response operations.

Bostrom and Heinen (1977) suggest a joint focus on the different aspects of a sociotechnical system. In this view, a sociotechnical system is composed of the interactions between its different components, which are called task, structure, technology and people. In their model, shown in Figure 3.1(A), Task and Technology are distinguished as technical subsystems and Structure and People as social systems. All these components are related to and can affect each other. Regarding IS development for ERSs and in order to show clearly the relationship between the different components of sociotechnical systems mentioned above, Bostrom and Heinen's model was selected for its simplicity and relevance to the IS field. However, it has been adapted to the context of the thesis. For instance, the Structure component is somewhat vague in the original model, and it is not clear whether the term refers to environmental aspects such as work conditions or to organisational aspects such as leadership. Therefore, Structure is divided into two separate components: structure/organisation and environment/context. The People component is renamed as actors and placed in the centre, to reflect the fact that the people who are part of a sociotechnical system interact with all other components and that (new) actors are strongly in focus in the framework and in new forms of collaboration. The original model separates technical systems from social systems, for example, Task belongs to the technical system. Such separation is not deemed important in the adapted model, since it complicates understanding of it. Rather than the distinction between social and technical systems within sociotechnical systems, the adapted model focuses on the importance of the relationships between different components. Task may be connected to both technical and social systems, as it includes both humans performing a task and the techniques to support that task; thus, separation of the two is unnecessary. The modified model is shown in Figure 3.1(B).

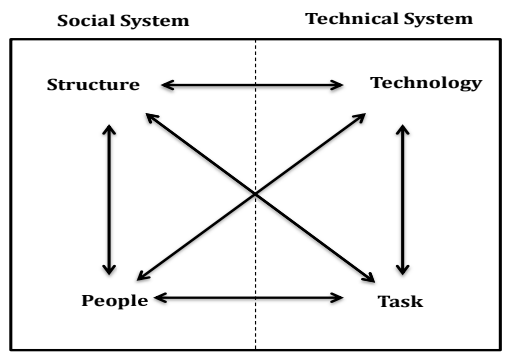

(A)

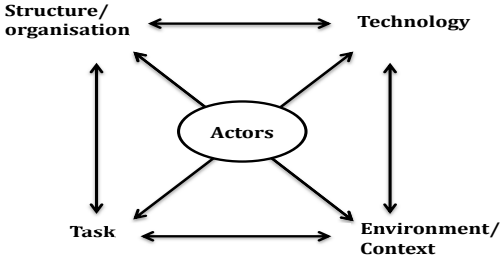

(B)

Figure 3.1: A) The sociotechnical perspective to IS by Bostrom and Heinen (1977). B) The adapted model used in the thesis framework for use of PD in ERSs. 
Sociotechnical systems theory is perceived to help saturate the analysis of new forms of collaboration by considering a wider set of factors in the process, to place the results in the IS field, and to broaden the application of the gained results. The adapted model is used as a point of departure for development of the thesis framework and restructuring of its dimensions in line with sociotechnical systems and for making the framework suitable for use in analysing such systems (here ERSs).

\subsubsection{Network governance theory}

In network governance, organisations are flexible social systems with high degrees of informal interaction (Jones et al., 1997). Organisations have a horizontal pattern of decision-making, knowledge exchange, and interdependent flow of resources (Powell, 1990; Snow et al., 1992). This is in contrast to conventional and traditional government models (hierarchical structures), which are based on hierarchical decision-making and have a vertical pattern of exchange in which the top levels of an organisation control the lower levels. Typical examples of government models are command and control, for example, in military or crisis response in which there are pre-defined hierarchies, including chain-of-command and responsibilities for every role (Walker et al., 2008).

In network governance, independent actors interact to achieve a public goal. It has been claimed that decentralised problem-solving and distributed information acquisition increases efficiency. Effectiveness of operations is also influenced by the emergence of collective problem solving by actors within the network (Dedeurwaerdere, 2007). However, there are problems associated with network governance, such as problems of politics and control, where it is not clear who has control over whom. There are also concerns about the ambiguity of actors' responsibilities in this setting, and problems with performance measurement make it difficult to evaluate each actor's performance (Christensen et al., 2007).

Network governance is not the main theme of the thesis; however, co-location of actors at the Safety House is viewed as a form of network governance, and thus network governance theory is used as a lens through which to study co-location of actors, to analyse interactions between actors, and to understand the associated challenges. The theory tends to help identify challenges and opportunities in co-location of actors, since the literature provides examples of known problems and benefits associated with the network governance model. Without network governance, it may be difficult to understand, explain, and discuss clearly the phenomenon of co-location and to relate it to other similar situations in the literature. Other new forms of collaboration, such as collaboration with volunteers and civilians, may also be interpreted as forms of network governance, since independent actors (e.g. volunteers) make decisions and interact with other actors, sometimes independently. Therefore, network governance may serve to discuss and complement the study of new forms of collaboration. 


\section{RESEARCH APPROACH AND METHODS}

This chapter briefly explains the three studies performed as part of the research process. The research design and research process are described, followed by an outline of the applied methods for data collection and data analysis.

The thesis is a paper collection thesis comprised of three papers. The thesis itself is an attempt to present and discuss the articles together and in more detail. It provides an opportunity to expand upon the research background, to clarify assumptions, to connect studies to the overall objectives, to answer objectives in more detail, and to discuss the results collectively. For instance, the second thesis objective is only partly explained in the articles, but is elaborated upon in the result section of the thesis.

Three studies were performed in sequence and three papers were produced. Study 1 was an exploratory case study in which data were gathered at the strategic level from the Swedish ERS. The main aim was to gain an initial understanding of different kinds of new collaboration in ERSs in general and specifically in the Swedish ERS. This initial study helped to recognise different new forms of collaboration in ERSs and to develop a tentative framework for performing descriptive research in the subsequent phases. In Study 2, co-location of actors at the Safety House as a form of new collaboration in the Swedish ERS was studied in depth with the help of the framework. The aims at this stage were to understand the phenomenon of colocation and related patterns, characteristics, challenges and opportunities and to use the initial framework to perform a PD needs analysis. In Study 3, theoretical groundings were added to the framework in order to improve it and to extend its application to the IS field. Further, the framework was developed according to feedback from its application in PD organisational and needs analyses from Study 2.

\subsection{Research process and research design}

A research process includes various activities that represent the different steps taken to achieve the objectives of a research project. A framework by Myers (2009) presents philosophical assumptions, research methods, data collection techniques, data analysis approach and written record as different steps or tasks in the research process. These steps are useful because they show how research is conducted from a practical point of view. However, Myers' framework only demonstrates these steps in sequence, and therefore may not be relevant to research carried out in iterative phases. The role of theory is not included in the framework. Furthermore, it does not include explicitly the step of quality assessment, as insisted on by others (e.g. Creswell, 2013). The framework was modified for the purposes of the thesis. Firstly, the research process was made iterative, implying that the results were successively assessed and evaluated in order to adjust the study, i.e. the framework in different iterations. Secondly, to clarify the role of 
theory in the research process, the application of theories was added as input and theoretical contributions as output to the framework. Thirdly, quality assessment was incorporated. Fourthly, instead of 'research method', the phrase 'research methodology' was used because in the thesis, case studies are referred to as a research methodology containing philosophical views and assumptions, rather than as a research method including solely techniques. Fifthly, all tasks were placed in logical order to reflect the whole research process. The adapted framework is shown in Figure 4.1.

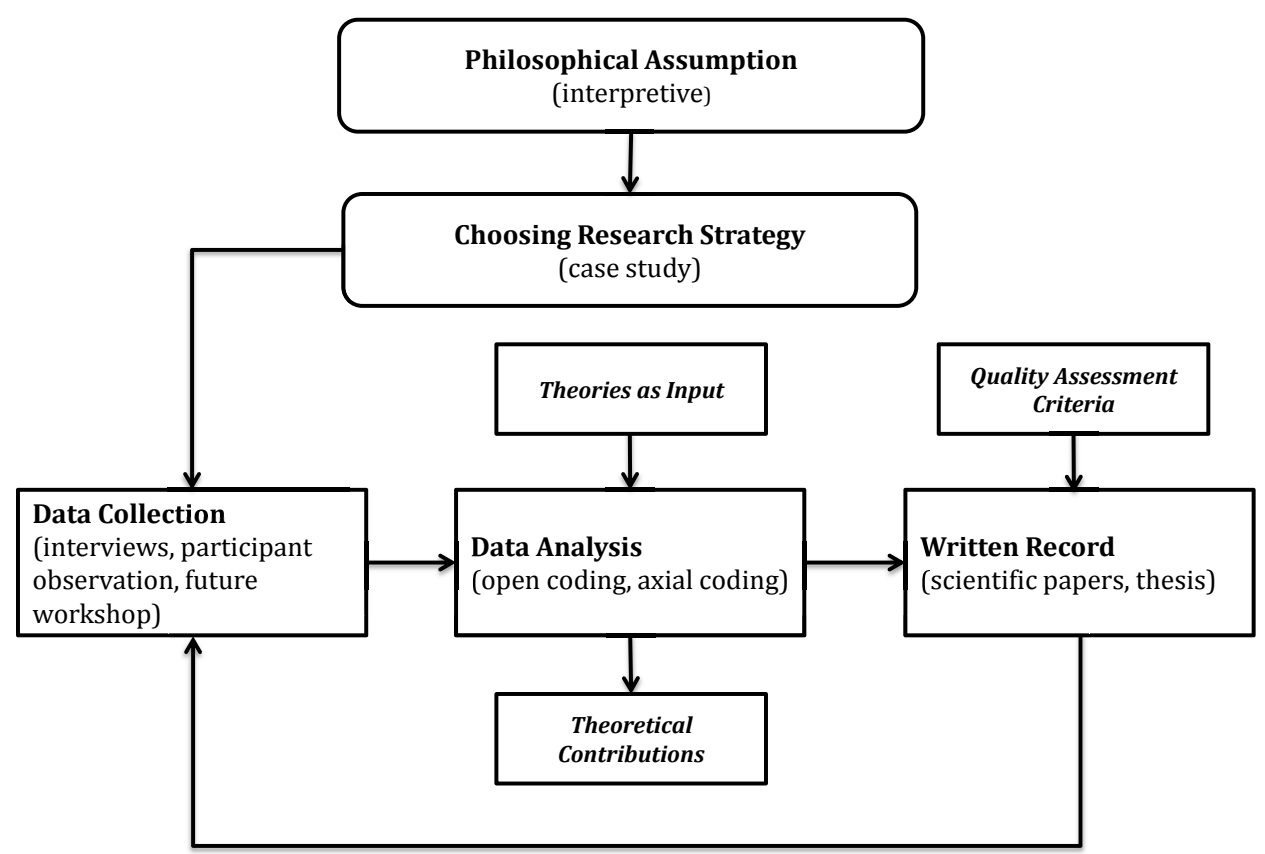

Figure 4.1: The research process, showing different tasks carried out in the thesis work.

In order to gain an understanding of the overall research process, and on written articles and their connections to the thesis objectives, Figure 4.1 is expanded upon and shown in a stepwise format in Table 4.1.

Table 4.1: Different phases/tasks performed as part of the research process.

\section{Study 1: To study new actors in the Swedish ERS \\ Type: Case Study (exploratory) \\ Contribution: To primary objective of the thesis}

$1 \quad$ Literature Review 1

To gain an understanding of involving new actors in ERSs and to identify similar experiences in ERSs worldwide 
2 Interviews 1, 2 and 3

3 Interview 4
To understand and explore the meaning of involving new actors in the Swedish ERS and related challenges

To study and understand the specific case of collaboration between security guards and fire and rescue services and related challenges and possibilities

Title: A framework for 'new actors' in Emergency Response Systems

Study 2: To study the co-location of actors at the Safety House as a new form of collaboration Type: Case Study (exploratory/descriptive)

Contribution: To secondary objective of the thesis

5 Interviews 5, 6, 7 and 8 To understand and explore the meaning of co-location of the Swedish ERS and related challenges; to apply the framework in PD organisational and needs analysis

6 Participant observation Same purpose as above

\section{Future workshop}

To reflect upon co-location of actors at the Safety House, problems/challenges related to the collaboration, possible IS needs and solutions to identified problems/ challenges

$8 \quad$ Article II

Title: Emerging communities of collaboration: co-location in emergency response systems at the Safety House in Sweden

Study 3: To add theoretical groundings to the resulted framework, develop it and place it in IS development

Type: Case Study (exploratory/descriptive)

Contribution: To primary and secondary objectives of the thesis

9 Empirical analysis

New analysis of empirical data from Study 2 to develop the framework, e.g. to rename, remove and add dimensions

10 Literature Review 2

To identify challenges in IS development for new forms of collaboration; to develop the framework and place it in the field of IS by applying sociotechnical systems theory and PD approaches

11 Article III

Title: Actor-centred Emergency Response System

Thesis work

Contribution: To primary and secondary objectives of the thesis, in more detail

12 Thesis

Title: New Forms of Collaboration in Emergency Response Systems: A framework for participatory design of information systems 


\subsection{Theoretical and philosophical assumptions}

The thesis research approach is qualitative in character. Denzin and Lincoln (2011) define qualitative research as an interpretative and naturalistic approach to the world. It is used to understand and interpret the study objects in terms of the meanings people bring to them (Boland, 1991; Orlikowski \& Baroudi, 1991), resulting in multiple interpretations. In the thesis, interaction between different actors in the Swedish ERS in the case of new collaborations, the challenges in general, and the difficulties related to IS development in particular are viewed as social phenomena reflecting the qualitative aspects of ERSs.

The corresponding philosophical view of the world is based on interpretivism, by which researchers assume that access to reality is achieved only through social construction and its instruments, such as shared meaning, language, and consciousness (Myers, 2009). It is perhaps the most common paradigm in qualitative research, and some use interpretivism as a preassumption in qualitative research approaches. However, one of the main critiques of this approach is the influence of researchers on the interpretation of data, which may lead to problems of bias or subjectivity in results (Myers, 2009). To mitigate this problem, Myers (2009) argues that that the interpretation of data requires prior knowledge of the related vocabulary, context and social conventions. Thus, gaining the proper prior knowledge is a prerequisite. In the thesis, new forms of collaboration in ERSs are studied and understood by using an interpretive perspective and social engagement methods including interviews, participant observation and future workshop. The positivist approach, i.e. to assume that reality is objective, stable and can be quantified and described by measurable indicators, is not suitable in this context, since the main goal of the thesis is not theory verification or measurement and quantification (Myers, 2009), but rather to help generate knowledge and to understand social constructions. To reduce the problem of bias in the research process, the researcher has attempted to gain an initial understanding of the ERS context, the related organisations and actors, and different kinds of collaboration by performing an initial literature review at the beginning of the research process.

Independent of the philosophical view of the research, the logical paths to knowledge or analytical reasoning may be categorised as inductive, deductive and abductive approaches. In inductive approaches, the results of research are derived purely from the data without preconditions. Deductive approaches are concerned with the confirmation of the current theories in the empirical data by developing propositions and testing them. Abductive approaches attempt to capture the benefits of both inductive and deductive approaches for theory development (Dubois \& Gadde, 2002). The thesis is based mainly on an inductive approach in the early phases, in that the initial framework was developed purely from the empirical data (even though the first literature review was used to gained initial understanding of the ERS domain, data from review was not used in the construction of the framework). This approach was selected to begin the study due to the lack of sufficiently formulated knowledge of new forms of collaboration in ERSs at this stage. In its subsequent phases, the research process also includes deductive elements, as the researcher sought appropriate theories to 
describe, improve and justify the results/framework and place it in the field of IS development. This phase of the research process thus involved adding theoretical grounds to the results and placing them in line with sociotechnical systems theory and PD approaches. In conclusion, the overall research approach may be seen as abductive in that the main aim is to assist knowledge development in emergency management as a basis for future research and potential theory generation.

\subsection{Case study research}

Case study research is used to investigate a contemporary phenomenon in its real-world context (e.g., an organisation, a change or an individual) where researchers have little or no control over behavioural events (Stake, 2000; Yin, 2013). Case study research often focuses on a single case, but it may explore multiple cases (Yin, 2012). There are three main types of case studies. Exploratory research investigates and characterises new phenomena about which detailed research and knowledge do not yet exist. It is a means to define questions and to construct hypotheses for developing descriptive and explanatory studies in relatively new scientific fields (Yin, 2012, 2013). Descriptive research seeks to reveal patterns and characteristics of a phenomenon in relation to theoretical constructions in order to develop theories (Tobin, 2010). Explanatory research explores and describes a phenomenon through detailed analysis explaining causal relationships (Harder, 2010; Yin, 2013).

Flyvbjerg (2006) performed a review of different works on case study research to identify related misunderstandings, critiques and challenges. He summarises the most common critique as follows: the results of an individual case are not generalisable, not suitable for theory building, and are biased by the pre-assumptions and aims of researchers. However, Flyvbjerg argues that these are misunderstandings stemming from generally accepted beliefs about case study research in the positivist approach, which are not valid for case study research in social sciences. Similarly, Ragin and Becker (1992) discuss that the main goal of case studies is not ultimately to prove something, but rather to explore a social phenomenon and learn from it in order to accumulate knowledge about a subject. Yin (2013) also claims that case study research is indeed generalisable, not to a statistical population but to propositions. The potential to generalise the results of the thesis for future propositions and theory development is briefly discussed in Chapter 6.

The case investigated in the thesis is new forms of collaboration in the Swedish ERS. Therefore, the case is not in the form of an organisation or system but a social phenomenon related to a growing trend in ERSs. Co-operative use of resources, involvement of volunteers and colocation of actors are the specific examples of new forms of collaboration. The thesis thereby belongs chiefly to exploratory studies, as the studied phenomenon is quite recent and there is little existing research available. However, a descriptive approach has also been used to structure, describe and categorise the results and to present them as a framework. It is not claimed that the thesis results will be applicable in all other cases, but they can at least be applied 
to similar situations or can help to gain a more profound understanding of similar situations where new forms of collaboration are emerging in ERSs and in the public sector worldwide. Access to the data in the three examples was not the same for each example (Figure 4.2). The size of the examples in Figure 4.2 demonstrates the amount of data and depth of the exploration to capture the complexity of respective new forms of collaboration in the Swedish ERS.

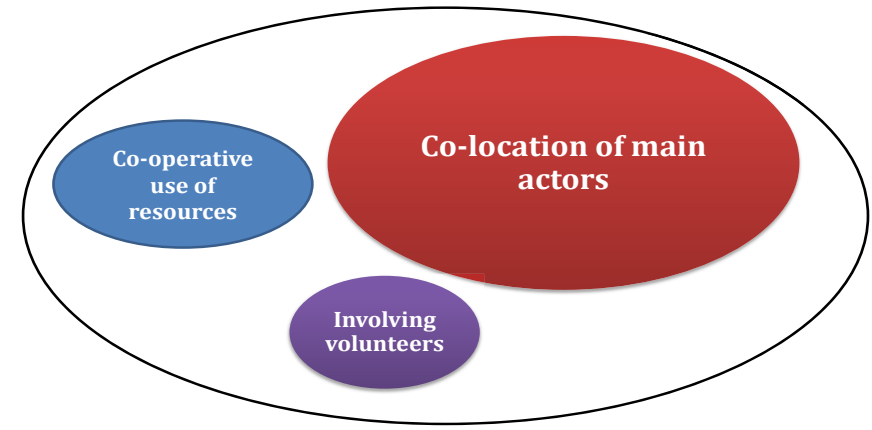

Figure 4.2: Three examples of new forms of collaboration in the Swedish ERS.

\subsubsection{Influences from action research and participatory action research}

Action research may be defined as a cyclic process of diagnosing (identifying the problem), action planning, action taking, evaluating and specifying learning by which the researcher(s) not only studies the setting, but also introduces changes into the setting for further improvements (e.g. Myers, 2009; Susman, 1983). For action research to be successful, first, a setting where there is a problem (such as an organisation) should provide the possibility, the support and the wish to solve the problem, and it should be a problem that is of interest for scientific communities (Baskerville \& Myers, 2004). Action without research is consulting (Baskerville \& Myers, 2004). Another similar approach is participatory action research, by which a research process is conducted together with the people connected to the subject under study (Reason \& Bradbury, 2013). The key difference as compared to action research might be the importance of active and direct participant involvement in the research and the acquisition of local or domain knowledge (Cornwall \& Jewkes, 1995).

In the past, case studies have been successfully combined with action research to allow for both interpretation/understanding of a setting and performing intervention/change within it (Stenmark, 2000; Vidgen \& Braa, 1997). The thesis work can also be viewed as action research, since the aim of the studies is not only to understand new forms of collaboration in the Swedish ERS but also to intervene in and change them. The thesis work is connected to the national mission by the Swedish government (i.e. the MSB) to create, improve and enhance new forms of collaboration in the Swedish ERS. In the mission statement, the MSB have emphasised that the research process should begin at a strategic level. Therefore, the researcher initiated the process by performing data collection at the MSB. The next stages involved other actors from the Safety House. The thesis work also has a character of participatory research, in the sense 
that PD and enabling actors to interact with researchers and systems developers and participate in design groups is central. Specifically, later generations of PD, which insist on involving a broader set of stakeholders than merely end users, have been applied. The future workshop was conducted to gather participants' different perspectives and to involve them in the design process with a view to actively improving their own setting, i.e. new forms of collaboration in which they are involved. In the thesis, the researcher also considered himself as a system developer during the study period. What differ is that the researcher is not responsible for implementing the suggested changes and solutions to identified problems and IS needs even though the research results in many cases have been provided to the involved response organisations. For this reason, the phrasing "inspiration from action research and participatory action research" is used.

\subsection{Data collection}

The methods used to collect the data include literature review, interview, participant observation and future workshop.

\subsubsection{Literature and documents reviews}

A literature review is defined by Robinson and Reed (Robinson \& Reed, 1998) as "a systematic search of published work to find out what is already known about the intended research topic". It is widely used in case study research to identify sources for data collection (Travers, 2001; Yin, 2013). A literature review helps to reveal any gaps in the chosen topic and to understand the impact of research methods in previous studies (Bless et al., 2006). Different texts have been written for different purposes. Researchers should aware of this and the literature review should include critical and analytical judgement and interpretation by the researcher (Myers, 2009).

In the thesis, the initial literature review was carried out in parallel with the first round of interviews in order to grasp the emerging picture of new forms of collaboration in ERSs. It was intended to enable the researcher to perform the other stages of data collection (i.e. interviews, participant observation, and future workshop), and to gain sufficient knowledge of the research topic to be able to hold discussions with interviewees. Moreover, the results of the literature review provided confirmation that the dimensions of the framework are generally in alignment with previous studies. The second literature review covered IS development generally and its related challenges in ERSs and the public sector in terms of cross-sector collaboration, involving volunteers, and dealing with heterogeneous actors. Specifically, the aim was to gain an understanding of the application of sociotechnical systems theory and PD approaches in IS development for new forms of collaboration, place the thesis results in the field of IS, and demonstrate the international relevance.

The literature review includes both academic papers and public project reports. Around 50 papers and reports in the ERS context (Literature Review 1) and around 50 papers in the IS 
field (Literature Review 2) were studied. In Literature Review 1, search terms such as 'new actors + emergency management', 'first response actors + emergency management', 'effective use of resources + emergency management', 'cross-sector collaboration', and 'involving volunteers in public sector + challenges' were used to gain an understanding of the research subject. The results were categorised as a) different new forms of collaboration in ERSs and b) associated challenges. In Literature Review 2, the IS field was in focus and examples of search terms were: 'IS development + emergency management + challenges', 'IS development + sociotechnical systems', 'IS-development + cross-sector collaboration', and 'participatory design + heterogeneous stakeholders + challenges'. The results thereof were categorised as a) general IS development and related challenges in emergency management, b) participatory design of systems development and related challenges, and c) IS development for new forms of collaboration in the public sector and related challenges.

\subsubsection{Interviews}

Interviewing is one of the most important and commonly used techniques for data collection in qualitative methods and specifically in case study research (Myers, 2009). Researchers use interviews to focus on a subject and gain a rich understanding of subjects' experiences and various perspectives on a topic (Seidman, 1998). However, the quality of data gained from interviews depends on how well questions are articulated and on interviewees' level of knowledge on the subject (Yin, 2013). Interviews may be of several different types. Structured interviews are composed of strict pre-formulated questions and require detailed planning beforehand. Structured interviews are useful for creating consistency across multiple interviews on the same subject by adhering to exactly the same questions each time. However, this method runs the risk of missing new insights since strictly formulated questions may delimit the answers. Conversely, unstructured interviews may include only a few general questions and interviewees may speak more freely. The aim here is to stimulate creativity in order to gather new and possibly unknown ideas. One disadvantage of unstructured interviews is the difficulty of managing interview sessions and keeping the focus on the subject at hand. Semi-structured interviews offer the advantages of both structured and semi-structured interviews, and were therefore selected as the interview method for the thesis. A set of pre-formulated questions or interview templates about new forms of collaboration was constructed. The questions asked were from the template, but interviewees were also free to narrate beyond the questions and provide additional information about new forms of collaboration which they considered important. In addition, unplanned questions about interviewees' unique experiences and observations were asked to encourage new insights.

In total, eight interviews were conducted with 10 respondents who were knowledgeable about new forms of collaboration and were officially located at different organisational levels, including strategic, operative and administrative. Respondents were asked about their experiences of cross-sector collaboration involving volunteers and other actors, regarding perceived strengths, problems and their needs. Three of the interviewees were the MSB employees with several years' experience in current ERS changes, e.g. in evaluation of response operations and strategies for strengthening response resources. They had also held other 
positions in the Swedish ERS in the past, such as fire engineer, researcher, and project manager. The subjects of the fourth interview were one security guard and the safety coordinator for the municipality of Södertälje. Guards may perform certain response tasks, such as containing small fires or supporting the fire and rescue services by providing maps and keys for buildings and information about incidents. Interviews 5 to 8 concerned co-location of actors and were with the project manager, a representative from the police, a representative from the fire and rescue services, and a representative from the Swedish Defence at the Safety House in Jämtland, respectively. Interviews 1 to 4 were performed by two researchers, including the author of the thesis. Interviews 5 to 8 were performed by the author of the thesis alone.

All interviews were conducted by presenting the research subject to interviewees. All interviews followed the same procedure. However, questions were adjusted for each interviewee by removing unsuitable questions and inserting appropriate replacements. Interviews were recorded in the form of notes taken during the interview and audiotaped for further transcription. Each interview lasted between 50-75 minutes. A summary of conducted interviews is provided in Table 4.2.

Table 4.2: Eight interviews were conducted to gather data about new forms of collaboration in the Swedish ERS.

\begin{tabular}{|c|c|c|c|}
\hline & Source & Organisational Level & Interviewees \\
\hline Interview 1 & MSB & Strategic & $\begin{array}{l}\text { expert working on strengthening the } \\
\text { response capacity of the Swedish ERS }\end{array}$ \\
\hline Interview 2 & MSB & Strategic & $\begin{array}{l}\text { expert working on strengthening the } \\
\text { response capacity of the Swedish ERS, } \\
\text { specifically by involving volunteers }\end{array}$ \\
\hline Interview 3 & MSB & Strategic & $\begin{array}{l}\text { expert working on strengthening the } \\
\text { response capacity of the Swedish ERS, } \\
\text { specifically by co-operative use of } \\
\text { resources (Sambruk) }\end{array}$ \\
\hline Interview 4 & $\begin{array}{l}\text { Södertälje } \\
\text { Municipality }\end{array}$ & $\begin{array}{l}\text { Operative/ } \\
\text { Administrative }\end{array}$ & $\begin{array}{l}\text { a representative from security guards } \\
\text { and the safety coordinator for the } \\
\text { municipality }\end{array}$ \\
\hline Interview 5 & Safety House & Administrative & the project manager \\
\hline Interview 6 & Safety House & Operative & a representative from the police \\
\hline Interview 7 & Safety House & Operative & $\begin{array}{l}\text { a representative from the fire and rescue } \\
\text { services }\end{array}$ \\
\hline Interview 8 & Safety House & Operative & a representative from Swedish Defence \\
\hline
\end{tabular}




\subsubsection{Participant observation}

Participant observation involves observing a phenomenon in its real-world setting and recording it for scientific purposes (Angrosino, 2007). A phenomenon can be of different types, for example, activities, interactions, actors, a particular setting, or conversations during the observation period (Creswell, 2013). DeWalt and DeWalt (2002) claim that participant observation improves the quality of data, facilitates the interpretation of situations, and simplifies the development of research questions and hypotheses. However, participant observation has also been criticised for the fact that it is only appropriate if researchers already possess adequate information about the context and the people involved. Otherwise, researchers may be misled as they attempt to formulate their findings, and may in turn mislead others with incorrect conclusions (Munck \& Sobo, 1998). One way to avoid this potential bias problem is to select informants who are competent in the study topic.

In the thesis, participant observation was employed along with interviewing to explore the phenomena of co-location in the case of Safety House. This involved observing the new settings and the actors performing their tasks in it. The researcher's role was chiefly that of participant observer (Creswell, 2013), which involved observing the actors, their physical setting and the collaboration without intervening in their daily routines. The researcher spent half a day visiting actors at the Safety House, including the police, the fire and rescue services, and the alarm centre. The researcher was given the chance to ask questions to the police director and the fire and rescue director during the observation. The same was not possible in the case of the alarm centre due to risk of interfering with actors' ability to answer emergency calls. The participant observation data were documented through memory and personal field notes. The researcher was aware that the observation period was not substantial, and may not necessarily qualify as observation from a social sciences perspective. However, the observation represents only one of several complementary data sources. The observation was also part of the PD process where a needs specification was to be delivered to Safety House; thereby using a pragmatic approach was required.

\subsubsection{Future workshop}

Future workshop as a technique was originally developed by Jungk and Müllert (1987) to allow participants to develop innovative ideas to enhance their situation in real life, for example, in public planning. This technique was later used in PD. Future workshop is now a common technique in PD (Kensing \& Munk-Madsen, 1995) and are usually divided into four phases: the preparation phase, the critique phase, the fantasy phase and the implementation phase. The first phase is the introduction to the methods, rules and subjects under study. The second phase aims at reflecting on the individuals' own work situation and areas for improvement. In the third phase, participants attempt to imagine future possibilities and focus on solutions for improvements to the current situation. Suggested solutions in this phase are not restricted by technical or organisational constraints. In the fourth phase, the solutions identified in the previous phases are evaluated regarding their practicality and their transformation into realistic, organisationally and technically feasible implementations (Kensing \& Madsen, 1992). 
In the thesis, a future workshop, including all four phases, sought to involve stakeholders who were knowledgeable about their work context and environment in order to find relevant and innovative solutions to problems. The focus was on challenges and potential improvements regarding collaboration at the Safety House. Specifically, the aim was to find solutions for current problems and obstacles and to identify user needs for developing new forms of collaboration and IS support. It was also intended that the results from the future workshop could be used to complement the data gathered from other sources by means of data triangulation. A half-day future workshop was arranged at the Safety House, in which eight actors from the police, the municipalities in Jämtland, the fire and rescue services and the representative from the Swedish Defence participated. The workshop participants were chosen from among actors at the Safety House, based on their accessibility and their role. Four of the Safety House interviewees were also among the participants. The future workshop was documented in post-it notes and discussions were audio taped and then transcribed.

\subsection{Data analysis: multi-grounded theory}

Grounded theory (GT) refers to the development of theories purely from analysis of empirical data, without any interference of other theory interests and/or existing literature (Strauss, 1987). Thereby, GT may be seen as an inductive approach where the main purpose is theory building and development. It does not only consist of describing data but focuses in performing analysis and formulation of the emergent results. Secondly, according to GT, researchers should avoid allowing prior knowledge and existing literature to produce pre-formulated results that do not originate from data in the first instance. Thirdly, GT is based on a systematic process for data analysis which consists of constant comparisons (Urquhart et al., 2010). Initial results or categories arising from the first set of data are successively and cautiously enriched and constructed through comparison with other sets of gathered data in order to complete, verify and saturate them. Many researchers have asserted the merits of GT due to its strength in generating new theories in fields where there is scarce pre-existing knowledge. On the other hand, it has also been criticised for its assumption that researchers are 'blank slates' who launch into data collection and analysis with a naive articulation and without any pre-study in the area, which may lead to incorrect conclusions and increases the risk of 're-inventing a wheel'(Urquhart \& Fernández, 2013). It has been argued that the above criticisms are misconceptions originating in misinterpretation of the GT approach (e.g. Urquhart \& Fernández, 2013). Goldkuhl and Cronholm (2010) performed a literature review of the strengths and weaknesses of GT and suggest a multi-grounded theory (MGT) approach, which attempts to combine certain aspects of inductivism and deductivism. The MGT approach includes not only empirical grounding but also theoretical and internal grounding in order to compare and saturate the emergent theory with existing knowledge (Goldkuhl \& Cronholm, 2010). This avoids weaknesses such as 'delayed literature review' and 'researcher as blank slate' associated with the original GT approach. Open coding and axial coding are two data analysis methods used in MGT. Open coding is the initial coding of data which attempts to assign labels and 
identify dimensions and categories in data (Corbin \& Strauss, 2007). Axial coding is a phase that is generally performed following or in parallel with open coding. Analysts, who perform axial coding, need first to gain an understanding of data and its different categories in order to make connections between categories (Corbin \& Strauss, 2007).

Data analysis in the thesis is inspired by MGT. The motivation behind this choice is the emergence of new forms of collaboration in ERSs as a relatively recent phenomenon on which there has been no explicit theorising to date. While some research exists on the subject (see Chapter 2), its focus differs slightly from that of the thesis. The phenomenon is also new for the author of the thesis as a researcher, meaning that the author entered the research process without any knowledge or pre-formulated results on the subject. More precisely, the framework in the thesis is developed in several steps. The initial emerging framework was based on analyses of the empirical studies from an inductive approach by performing open coding on the interview data from the MSB. The main question guiding the data analysis was: 'What are the important factors affecting new collaborations between actors?'. 'Line by line' analysis of transcribed interviews was deemed suitable in this case, since it generated more detailed results about new forms of collaboration and to some extent the related challenges, weaknesses and strengths. The analysis was performed by identifying different concepts/themes, labelling them, and generating categories. For example, transcribed interviews that concerned actors' tasks and related challenges were labelled as 'Task' and categorised with the same name. Categorised texts were then compiled to give a clear definition of the category 'Task', including exemplifications.

To avoid the problem of 'blank slate' and to gain an initial understanding of new forms of collaboration in ERSs, an initial literature review was performed prior to data collection to enable the researcher to design data collection methods. In the initial data analysis described above, the data collection process, including inquiries and consequently the data itself, was somewhat affected by the researcher's knowledge gained from the literature review. Therefore, this phase of empirical grounding may not be seen as a purely inductive approach, which is difficult to achieve completely where there is a need to acquire an initial understanding of the context and the subject under study. However, attempts were made to minimise the influence of related extant theories and the researcher's theoretical interests in this phase of empirical grounding. It is also generally acceptable in MGT to be open-minded and to allow theoretical insights and empirical observations to influence the research interests during the research process. To avoid the problem of 're-inventing the wheel' and knowledge isolation, the results from the literature review were compared to the emerging dimensions of the framework in order to identify similarities and differences with the existing body of knowledge.

In the next step, axial coding was performed on another set of data from the Safety House including the data from the new interviews, post-it notes from the future workshop, transcribed discussions of the future workshop and memory notes of the participant observation. The initial framework was then modified slightly, developed and matured. This involved clarifying each dimension by providing more examples, combining interdependent dimensions, and adding new dimensions. Similar to open coding, it is difficult to view this phase of empirical grounding 
as purely inductive. The results of this step were compared with the results of the literature review to show that the dimensions of the framework are in alignment with other studies.

Theoretical insights in terms of sociotechnical systems theory and PD were then applied in order to relate the results to the field of IS and broaden the application of the results. This phase followed deductive approaches, and was achieved by applying the adapted sociotechnical model explained in Chapter 3 to the framework in order to categorise its dimensions and formulate suggestions for its use in systems development processes. Internal grounding is the investigation of the consistency and coherency of a theory to ensure a good illustration of it. This was performed by presenting the framework in graphical format in order to show and categorise its dimensions clearly. This process of empirical grounding, internal grounding and subsequent theoretical grounding in the thesis is shown in Figure 4.3. Although the ultimate goal of MGT is to generate new theories (theoretical contributions), the framework is not to be considered as a theory in itself, but as an initial effort towards the formulation of new theories in future work. The role of theory in the thesis (theories as input) and the potential theoretical contributions are discussed in Chapter 6 and as future works. Assessment of the performed research as to credibility, transferability, dependability and conformability is also discussed in Chapter 6.

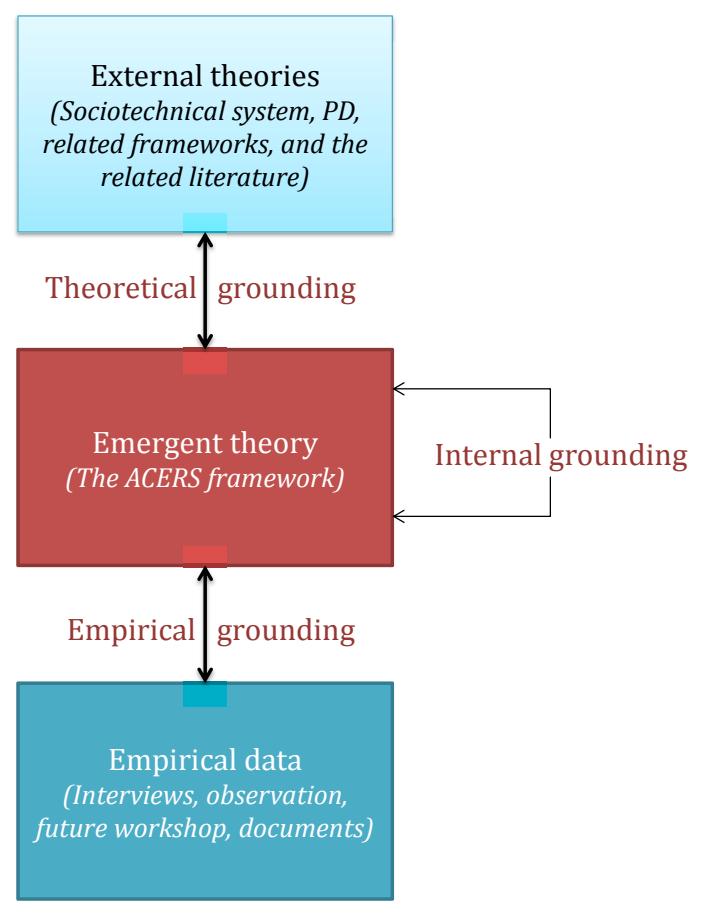

Figure 4.3: The process of framework generation inspired by MGT (Goldkuhl \& Cronholm, 2010). 


\subsection{Summary of research methods}

Table 4.3 shows a summary of the research methods and study design used in the thesis.

Table 4.3: Summary of research methods in the thesis.

\section{Research methods}

\begin{tabular}{|c|c|}
\hline $\begin{array}{l}\text { Research approach and type } \\
\text { of data inquiry }\end{array}$ & Qualitative research \\
\hline Research strategies & $\begin{array}{l}\text { Case study (exploratory and descriptive), new forms of } \\
\text { collaboration in ERSs }\end{array}$ \\
\hline $\begin{array}{l}\text { Theoretical paradigms and } \\
\text { perspectives }\end{array}$ & Multi-grounded theory, action research \\
\hline Method of data collection & $\begin{array}{l}\text { Interviews, literature reviews, participant observation, } \\
\text { future workshop }\end{array}$ \\
\hline Data analysis & Open coding, axial coding \\
\hline $\begin{array}{l}\text { Evaluation method } \\
\text { (discussed in Chapter 6) }\end{array}$ & Credibility, Transferability, Dependability, Conformability \\
\hline
\end{tabular}




\section{RESULTS}

This chapter presents a summary of the three papers included in the thesis. Following this, the results are described in more depth and are related to the thesis objectives.

\subsection{Summary of included papers}

The three papers are: 1) A Framework for 'New Actors' in Emergency Response Systems, 2) Emerging communities of collaboration: co-location in emergency response systems at the Safety House in Sweden, 3) Actor-Centred Emergency Response Systems: a framework for needs analysis and information systems development

\subsubsection{Paper 1}

Yousefi Mojir, K. \& Pilemalm, S. (2013) A Framework for 'New Actors' in Emergency Response Systems, Proceedings of the 2013 Information Systems for Crisis Response and Management (ISCRAM) conference, Baden Baden, Germany, pp. 741-745.

The first study was motivated by the need for a systematic way to perform rigorous analysis and to gain a profound understanding of new actors in emergency management and the related collaboration mechanisms, in order to identify the needs of new actors in this context and develop corresponding IS solutions. The main objective was to propose a tentative framework that would include the key aspects to be considered in the analysis of new forms of collaboration.

The framework presented is based on empirical data gained from interviews with experts active in involving new actors in emergency management and working at the Swedish Civil Contingencies Agency (MSB). Three interviewees were working on strengthening the response capacity in the Swedish ERS by involving volunteers and by co-operative use of resources (Sambruk) at the strategic level. The main aim of the literature review was to explore the role/s and the concept of new actors in the ERS context and to investigate the potential for international generalisation, but not to build the framework from it.

The major result of the paper is an initial framework consisting of 14 key dimensions that should be investigated before involving new actors in response operations. These are: 1) the actors' type and identity; 2) their roles in emergency management; 3) the type of incident in which they intervene; 4) the type of training they receive or should receive; 5) the problems they encounter in response operations; 6) their accessibility; 7) their structure and organisational form; 8) raised legal issues about involving them in emergency management; 9) the related costs and benefits of their involvement; 10) their responsibilities; 11) the type of equipment they use; 12) their competence in emergency management; 13) the kind of IT support they already receive or require; and 14) their communication methods with the other actors. 
The results from the literature review show many similarities in roles, tasks, resources and routines in ERSs worldwide. It may therefore be possible to adapt and apply the framework to ERSs outside Sweden. It was concluded that by covering different aspects of involving new actors in ERSs, the framework could provide a good starting point to perform adequate and rigorous analysis of their collaboration with main actors. It was also argued that these kinds of analyses may be useful in IS development for these actors.

\subsubsection{Paper 2}

Yousefi Mojir, K._\& Pilemalm, S. (2014) Emerging communities of collaboration: co-location in emergency response systems in the 'Safety House' in Sweden, Proceedings of the 2014 Information Systems for Crisis Response and Management (ISCRAM) conference, Pennsylvania State University, USA, pp. 548-555.

Temporary co-location at emergency sites facilitates effective communication and may increase efficiency due to better interpretation of information, co-ordination and task allocation. However, there is a lack of research on the permanent co-location of main actors and supportive actors in order to investigate the benefits, emergent problems, and actors' needs in the new setting. For this purpose, a case study was carried out at the permanent co-location of response organisations and supportive actors at the 'Trygghetens Hus' (Safety House) in Jämtland, Sweden.

The main objectives of the paper were twofold: 1) to investigate strengths and weaknesses of the co-location of actors, and to identify actors' needs for development of collaborative procedures and appropriate IS support; and 2) to test the initial framework and to highlight its benefits, challenges, and weaknesses.

The methods applied in the study included four interviews at the Safety House with the project manager, a representative from the police, a representative from the fire and rescue services, and a representative from the Swedish Defence. Participant observation was performed to observe the actors in their normal physical setting. A future workshop was also conducted to gain a richer, future-oriented set of data about actors' needs. Network governance theory was used as a lens to understand the co-location of actors, to analyse the interactions between actors, and to describe the existing related challenges.

The results showed that the actors at the Safety House were positive about the recent changes. Actors felt that the permanent co-location had increased efficiency of use of professional response resources and shortened response time. This had been achieved by close collaboration between independent actors, collective problem solving, and establishing a common understanding of the situation. Respondents reported that informal meetings and feedback had also had a strong influence on the improvement of this network structure. However, the new form of collaboration also presented some problems. It seems difficult to satisfy emerging needs and to implement changes in this new setting, since it is not always clear who should make certain decisions and whose tasks and assignments have priority over others. Evaluation of the 
current performance of the new structure in comparison with the previous one is even more problematic, as it is difficult to foresee the practical impact of improved social relations and interactions. A number of primary and general needs were also identified by the respondents. Firstly, actors' responsibilities should be documented, formalised, and circulated to make them clear and transparent to all actors. Secondly, the need for a steering group to implement the changes in the setting and handle feedback about the new setting was mentioned several times. Finally, any legal issues should be identified from the beginning when establishing co-location in order to be able to challenge them effectively. In terms of IS, the needs mentioned were for a shared IT communication system for actors, a documentation system and portable and sophisticated tools with which to view incident information.

In relation to the second objective, the framework was found to be useful in performing analysis and covering relevant themes and questions in the data collection. It was also deemed helpful to consider the new form of collaboration from different views/dimensions. Having selected the relevant framework dimensions for the co-location study, it was relatively simple to formulate the questions and to perform the analysis effectively and comprehensively.

It is argued that without using a framework, there is a clear risk of overlooking important aspects, e.g., legal issues. However, the use of the framework also revealed some challenges. Above all, strict adherence to the framework dimensions became problematic since it was not possible to follow the structure of the framework for all categories and there were deviations. It became clear that the framework needed to be further developed and complemented in order to achieve greater flexibility.

\subsubsection{Paper 3}

Yousefi Mojir, K. \& Pilemalm, S. (2016) Actor-Centred Emergency Response Systems: A framework for needs analysis and information systems development, International Journal of Emergency Management, in press.

The use of IS can support more effective and efficient response operations and facilitate collaboration between actors. Various factors such as actors' different roles, tasks and responsibilities in operations and the legal frameworks they work within in this new setting can influence actors' needs for IT solutions. However, these points have not yet received sufficient attention in research. Therefore, IS development processes should be adjusted to the ERS context to incorporate the specific characteristics of new forms of collaboration (e.g., crosssector collaboration or involving volunteers).

The main objective of the third paper was to complete the framework, to ground it theoretically in sociotechnical systems theory, and to describe its different dimensions and how it can be used in IS development. A further point of discussion was its potential role in formalising PD and improving the identification and involvement of stakeholders in its early phases, i.e., organisational analysis and needs analysis. 
The initial framework from Paper 1 was developed in several steps. First, the dimensions were reorganised, combined, renamed and elaborated upon with the help of feedback from the testing of the framework in Paper 2. Then, it was placed in the IS field by applying sociotechnical systems theory and by inspiration from the PD approach. The dimensions in the framework were re-categorised as five main dimensions: People, Task, Technology, Structure and Environment. The term Task was then replaced by 'Task/Response Operation' and People was replaced by 'Actors' to reflect the ERS context. Taking inspiration from PD, the Actors dimension was placed at the centre of the framework to emphasise the importance of actors' (users') role in the analysis and IS development processes. The centrality of Actors means that all other dimensions in the framework should be analysed in association with actors' identities, roles, background, education, and qualifications. The literature review from Paper 1 was complemented by reviewing the IS development related literature for example in the context of complex environments such as cross-sector collaboration. The aim was to identify IS aspects in analysing new forms of collaboration in ERSs and in the public sector generally, and to show the potential international relevance of such collaborations.

The new framework included 15 sub-dimensions in total, under the parent dimensions. These are: Type/Role, Attitude, Training, Background, Task and Responsibility, Availability/Accessibility, Incident Type, Communication Method, Information Technology, Emergency Supplies, Organisational Structure, Leadership, Costs/Benefits, Environment, and Regulations and Legal Issues. The literature review confirmed that the framework is in line and overlaps with other ERSs and public sector efforts globally aimed at new forms of collaboration. Therefore, it was argued that the framework may have the potential to be adapted to an international context and similarly to the public sector.

Regarding IS development processes, an initial suggestion was presented about how to use the framework for organisational analysis and needs analysis in the early phases of PD. To perform organisational analysis, it was suggested that the first step should be to gain a brief initial understanding of the current project, key organisations, involved actors and required IS without using the framework. In the next step, the dimensions relevant to the project should be selected from the framework in order to study them further. Then, relevant users and stakeholders who have adequate information about the preselected dimensions should be identified and involved in the project to explore each dimension in depth. By focusing on particular key dimensions, it becomes easier to form data collection, since the point of departure is explicitly provided by the framework and does not need to be investigated from scratch. To perform needs analysis, primary users can be identified by analysing the results of organisational analysis, including stakeholder analysis; however, most of the users will likely be clear from the beginning of a particular project. The framework again helps to formulate e.g. interviews, observations, and future workshops in order to cover the relevant dimensions by focusing on understanding and extracting user needs. For each relevant dimension, it should be determined how needs can be satisfied and what challenges may inhibit them. Similarly, the framework may also be used in the later phases of systems development to evaluate and investigate how final systems solutions satisfy user needs and to handle the potential challenges identified. 
It was argued that the initial testing of the framework at the Safety House offered some benefits in performing organisational analysis and initial needs analysis and it saved time and resources in this case. Therefore, use of the framework might offer similar benefits in similar cases. Without the framework, analysis may remain more rudimentary and lead to projects which are less grounded in user needs and organisational and societal prerequisites. The framework also presented some challenges, such as difficulty in selecting relevant dimensions due to insufficient knowledge about the project, multiple and subjective interpretation of dimensions, and neglecting emergent and new dimensions in the collected data. It was argued that these challenges can be addressed if those who are using the framework are fully aware of them and are prepared to manage them in the appropriate ways suggested. In conclusion, a possible future work may be to develop and standardise the ACERS framework or develop similar frameworks which are fundamentally targeted or adapted to specific contexts. These kinds of frameworks may have the potential to address general challenges in PD, including the lack of formalisation in sub-processes, difficulties in the identification of important stakeholders, and difficulties to involve an appropriate set of stakeholders.

\subsection{Results in relation to thesis objectives}

Table 5.1 recalls the thesis objectives. Subsequently, the results of the thesis as related to them respectively are presented in detail.

Table 5.1. Thesis objectives.

\section{Objectives}

To identify, categorise and highlight the key factors that may influence new Primary Objective: forms of collaboration between different actors in the ERSs; to present them in a framework; and to describe and exemplify them. The method for developing the framework will also be described.

To provide an initial suggestion for how the framework may be used to Secondary Objective: perform organisational analysis and needs analysis in the early phases of PD for new forms of collaborations in ERSs.

\subsubsection{To identify, categorise and highlight key aspects in new forms of collaboration in ERSs}

To satisfy the primary objective, 15 aspects relating to the establishment of new forms of collaboration in ERSs were identified, categorised, listed and described in a framework. The list was altered several times during the research process. The final list includes: 
1. Actors' identity - type and role. Types of actors, and particularly potential new actors, in ERSs are defined as semi-professionals, volunteers and bystanders (laymen). Their roles are categorised as first responders, assistants and supportive actors.

2. Actors' attitudes in new forms of collaboration. Actors' feelings and attitudes to and within new forms of collaboration are considered an important factor. Perceived fear of acting in an emergency, trust or mistrust between actors, and ambiguities in goals and visions in response operations are some examples.

3. Training. The extent and type of training (e.g., in firefighting, first aid, or cardiopulmonary resuscitation) that new actors receive have a great impact on their ability to participate in response operations.

4. Actors' background. Qualifications, experiences, age, and physical and cognitive capabilities are examples of factors that have a decisive role in what actors can do and what types of tasks they can be given.

5. Actors' tasks and responsibilities. Actors in response operations may perform many different actions, such as basic life support, putting out fires, logistic help, etc. However, the clarity of their responsibilities and tasks in response operations of different types should be identified, defined, explained and discussed.

6. Actors' availability and accessibility. The ways in which actors are available and can be accessed are important factors. Ways to involve and organisationally integrate actors in new forms of collaboration, including involvement procedures, agreements, contracts and financing should be identified, studied, discussed and implemented.

7. Incident type. In some incidents (e.g., fires, health issues and traffic accidents), new actors may act as first responders to provide first aid. Volunteers also may help, e.g., to search for missing persons and provide transportation services, vehicles and/or appropriate tools. Therefore, incident type along with actor type has an important impact on actors' tasks, roles and responsibilities.

8. Communication method. Effective communication is the base for effective collaboration and can support coordination between actors. The RAKEL system, SMS services, and mobile phones are current examples of common methods of communication between actors in the contemporary Swedish ERS.

9. Information Technology (IT). IT from the actors' perspective is a set of tools that can facilitate information exchange between actors in response operations, either to acquire information about incidents or to provide information to others. A shared platform for information exchange and portable devices for viewing information are examples of IT that can facilitate communication and collaboration. 
10. Emergency supplies. Inappropriate equipment causes problems in response operations. For example, using non-portable radio systems at an accident scene can hinder communication between actors. High-quality equipment that is designed according to actors' tasks and needs can have a significant positive impact on establishing new forms of collaboration.

11. Organisational structure. Actors are categorised under organised structures of varying sizes (e.g., Red Cross volunteers and local sport clubs) or unorganised structures (e.g., civil volunteers) and accordingly may have different tasks and needs in response operations.

12. Leadership. Decision-making and leadership has an important role in emergency response and in controlling the response operation. In some cases, e.g., in a network governance structure, the leadership role may not be clear as compared to hierarchical models and thus should be studied and considered carefully.

13. Costs/benefits. Associated benefits and costs such as resources, IS, and equipment should be analysed and calculated, especially at a strategic and political level, to be able to motivate, discuss, decide upon and implement new forms of collaboration.

14. Work environment. Actors may have different work environments, work in new organisational contexts, or may not even reside in an organisational work environment (e.g., civil volunteers). This can cause problems because regulations, information confidentiality, and job contracts may not be clear for actors in the new work environment. These problems may be especially great in cross-sector collaboration due to multiple organisational belonging, conflicts between rules, loyalties, and prioritisation of tasks.

15. Regulations and legal issues. Since the collaborations under study are relatively new, a number of problems may appear because it is not yet clear what Swedish law states about responsibilities, limitations, job contracts, financing, job safety and tasks of new actors in response operations. What new actors are legally and ethically allowed and not allowed to do must therefore be investigated.

More detailed definitions, examples and explanations of these factors can be found in Paper 3 .

\subsubsection{The ACERS framework}

The framework was built and presented in three steps.

Step 1. A tentative framework was built from the initial categorisation of the data collected from interviews with the MSB at the strategic level and the data from the interview with security guards at the operative level. The different categories that resulted from open coding (Chapter 4) were placed around the concept of 'new actors' to emphasise the importance of involving new actors in development processes. The initial illustration (below) of the categorisations provided a first version of the framework that could be developed in the later steps. There is no priority in selecting dimensions when studying them, but some dimensions may overlap (such 
as Training and Competence) or may seem difficult to study (e.g., Costs/Benefits). The initial framework is shown in Figure 5.1.

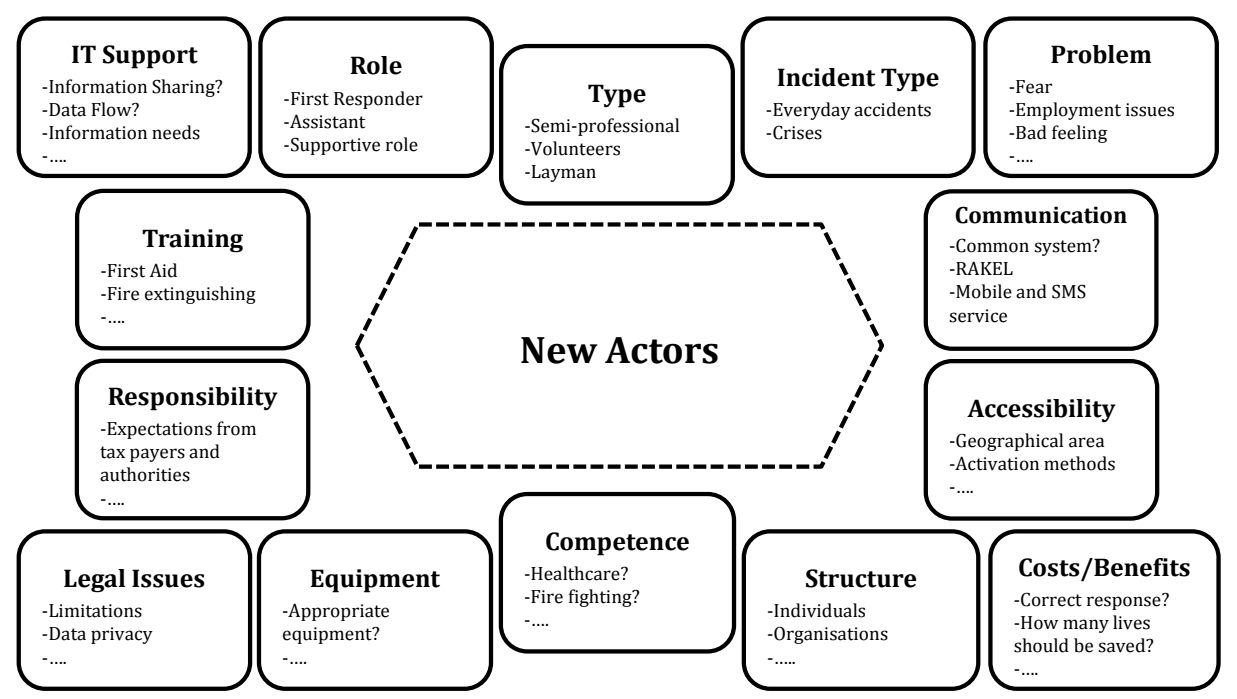

Figure 5.1: The initial framework shows the different dimensions to consider when involving new actors in the Swedish ERS.

Step 2. Subsequently, it was decided that to focus solely on 'new actors' gave a somewhat restricted view of current changes in ERSs. To focus instead on 'new forms of collaboration' seems more appropriate and more general, since there are some collaborations between existing main actors which can be still categorised as 'new'. One example of this is co-location of main actors at the Safety House. Furthermore, to focus on new forms of collaboration does not conflict with the initial framework and most of the original dimensions remain valid. Certain dimensions, such as actors' background and role, may not need to be explored when analysing collaboration between existing main actors, since these are probably clear from the beginning. Therefore, 'new forms of collaboration' covers both collaborations between new actors and main actors and new collaborations between main actors. Consequently, the framework was used to analyse co-location of actors at the Safety House. The framework was altered slightly before being used at the Safety House based on the feedback from internal seminars and own reviews of the initial framework by the researcher. First, the Problem dimension was removed from the initial framework, as it was perceived as ambiguous and difficult to define. However, the framework still intends to facilitate understanding of the problems involved in new collaborations by covering different aspects. In the next step, two new dimensions were added. The addition of the Background dimension reflects the high importance of gaining information about actors' background, such as their previous experiences, qualifications, etc. 'User's Task' was also presented as an independent dimension because of its centrality in collaborations. In the initial framework, tasks had been included as part of the Role dimension; however, it was a 
perceived risk to overlook it. The Competence and Training dimensions were combined under 'Training', as they were deemed inherently interdependent. Finally, all dimensions were categorised into three groups: Context Analysis, Task Analysis and User Analysis. This overall categorisation did not seem important in the practical use of the framework, but was performed to facilitate its understanding when discussing the framework, for example, with a project manager. The framework shown in Figure 5.2 is the version used at the Safety House.

\section{A framework for analysis of actors in ERS}
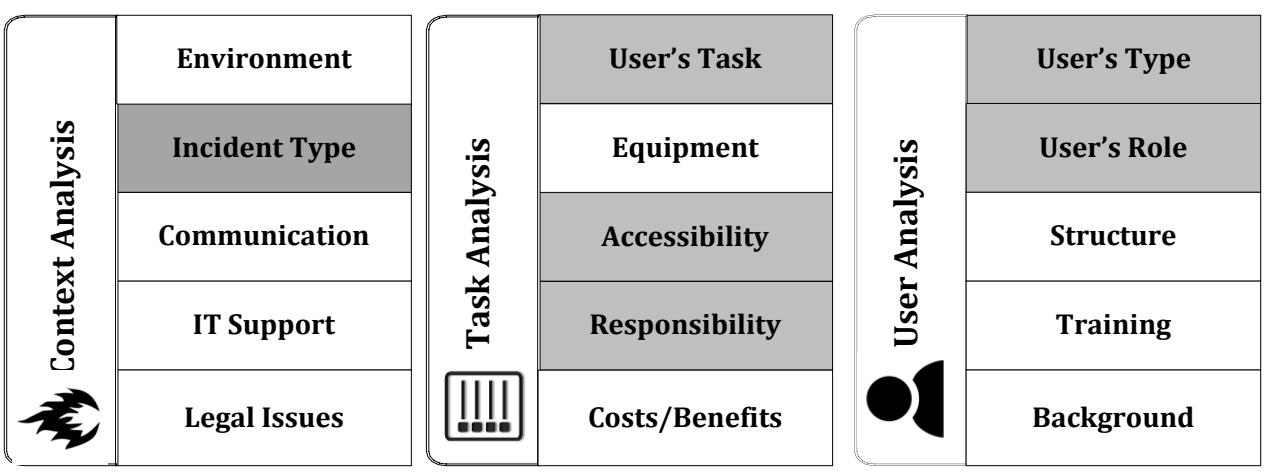

Figure 5.2: The altered framework prior to use at the Safety House.

Step 3. In this step, the framework was altered again following analysis of data sets and feedback from the Safety House study. First, two new dimensions - Attitude and Leadership were added. These were decided to be important when the actors located at the Safety House reflected on their positive and negative attitudes towards collaboration with others and the problem of ambiguity of leadership in response operations. The Type and Role dimensions were combined, since they were interpreted as having more or less the same meaning and the information acquired on each could not be separated into two different dimensions. Task and Responsibility were also combined for similar reasons. To distinguish between IT tools used in response operations and specific emergency equipment supply such as fire extinguishers, Equipment dimension was changed to 'Emergency Supplies'. Subsequently, the IT Support was renamed 'Information Technology' to denote only tools that include IT artefacts, such as map systems. Finally, to make the model more understandable, the Structure dimension was changed to 'Organisational Structure', Legal Issues to 'Regulations and Legal Issues' and Communication to 'Communication Method'.

By applying the theoretical framework based on sociotechnical systems theory and PD (Chapter 3, Figure 3.1), all dimensions were grouped into five parent dimensions: Actors, Task/Response operation, Technology, Structure/Organisation, and Environment/Context, with Actors placed 
at the centre to show that all other dimensions should be discussed in relation to the Actors parent dimension.

The name ACERS (Actor-Centred Emergency Response Systems) was chosen to reflect the centrality of actors (users/stakeholders) in the analysis of ERSs. The final version of the framework is shown in Figure 5.3.

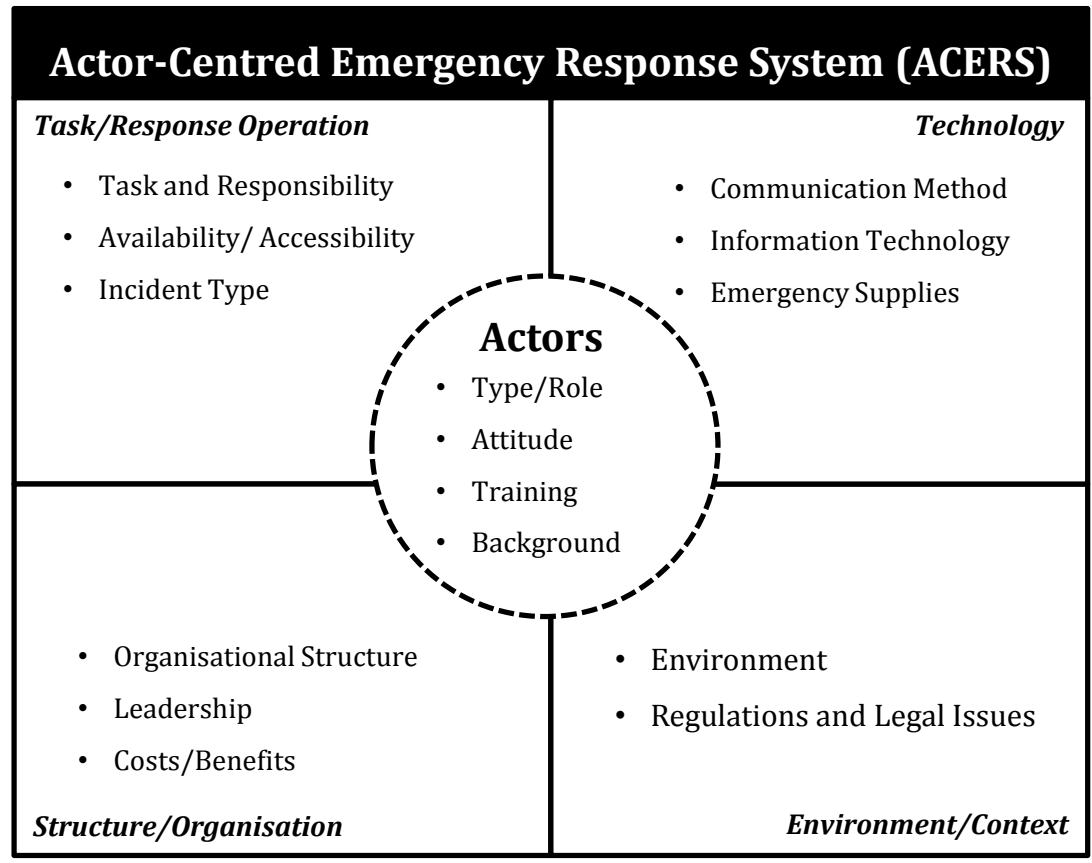

Figure 5.3: The final framework with added theoretical grounding.

\subsection{Initial suggestion for using the framework in IS development for ERSs}

Regarding the secondary objective of the thesis, the general principles for using the framework are first described and an initial suggestion for using the framework in the early phases of PD in ERSs is then presented. This suggestion is based partly on the experience of using the framework by the researcher as a system developer at the Safety House, as well as on PD principles. The usefulness of the framework and its potential benefit and contributions to PD are not evaluated within the scope of the thesis, but are discussed as part of possible future work in Chapter 6. 


\subsubsection{General principles for using the ACERS framework}

Generally, the ACERS framework is intended to be used for analysis of new forms of collaboration in ERSs and the related emerging challenges and possibilities. It facilitates this by describing the important aspects that need to be studied (e.g., responsibilities, legal issues, training, leadership). There is no fixed relationship between dimensions, though the Actor parent dimension is always the point of departure where the framework is used for analysis in order to avoid overlooking the importance of actors and their correlation with other dimensions. For example, actors' tasks, the types of incidents in which they participate, and legal issues should all be analysed by taking actors' characteristics such as their type, role, background and competencies into account. Some dimensions can be excluded if they are not deemed relevant to the current project. For example, the Leadership dimension may not be useful when the data under study concerns collaboration at the operative level.

\subsubsection{Application of the framework in PD in the ERS context}

IS development processes, in a very general sense, consist of analysis (i.e. organisational analysis, needs analysis, and requirement analysis), design, implementation, test/validation, and maintenance phases (Avison \& Fitzgerald, 2006a; Sommerville, 2004) as were described in Chapter 2. PD generally focuses on the early phases of development processes, and explicitly relies on the direct involvement of users and stakeholders in the development of technology to achieve a final product based on actual user needs (Ehn \& Kyng, 1987; Greenbaum \& Kyng, 1991). The ACERS framework can be applied in PD in ERSs for performing organisational/context analysis, needs analysis and requirement analysis.

\subsubsection{Organisational/context analysis}

The purpose of organisational or context analysis is usually to understand a process, a work environment, a change, or similar phenomena (here the analysis of new forms of collaboration). In order to perform organisational/context analysis and apply the framework in line with PD, a five-step process is suggested. An organisational analysis can be carried out in more detail and involve more steps; however, use of the framework may become complicated if it is extended much further beyond five steps.

To perform organisational analysis, the first step is to gain a brief overview of the involved actors, key organisations, types of collaboration, and required IS without the involvement of the framework. At the Safety House, an initial meeting between the systems developer and the project manager helped to gain an overview of the project, the relevant organisations and the current mechanism of collaboration. The project manager also described the history, aims and future plans of the Safety House project.

In the second step, all framework dimensions should be overviewed and the relevant dimensions for the project selected according to the information gathered in step 1. At the Safety House, this was performed at the initial meeting with project manager. The dimensions found relevant for analysing the co-location of actors were Background, Training, Organisational Structure, Emergency Supplies, Costs/Benefits, Environment, Communication Method, IT and 
Regulations and Legal Issues. Other dimensions were not taken as departure points for data collection, since they were more or less clear from the beginning. For example, actors' availability, role and incident type were clear at the Safety House because actors were professional actors in emergency management and were well-known.

In the third step, all stakeholder groups able to provide information about the selected dimensions should be identified and qualified as appropriate stakeholders. In ERSs, this may include main response actors (e.g., fire and rescue services, the police, ambulance services, alarm centres) as primary end users, and e.g., managers, administrators, economists and jurists as stakeholders. Stakeholders may also act as external experts if other stakeholder groups cannot provide sufficient information to cover the selected dimensions. For example, the framework demands involvement of persons with knowledge about laws or leadership if these are counted as relevant dimensions in a project. At the Safety House, the primary groups of stakeholders had been already selected and invited by the project manager and included the fire and rescue services, the police and the Swedish Defence. However, following interviews with representatives from these stakeholder groups, it transpired that some dimensions, such as Leadership and Organisational Structure, could not be explored. Attempts were made to involve more stakeholders. Some stakeholders, such as the police management and representatives from municipalities, could be invited and involved in the later phase of development, i.e. the future workshop, while others were added to the list of important stakeholders to be incorporated in the next phases.

The fourth step involves the planning of data collection methods by designing templates, questions, interviews, scenarios, surveys, participant observations, etc., taking the previously selected dimensions as points of departure. Identified qualified stakeholder groups are actively involved in the data collection process with the purpose of gathering detailed data. At the Safety House, interviews, the participant observation and the future workshop were conducted to collect data from involved actors. The interview questions were bound to the selected dimensions and intended to cover them sufficiently. The participant observation was performed by asking questions of actors to fill those gaps in understanding the dimensions that could not be covered in interviews. The future workshop was also designed in such a way that participants could discuss the relevant dimensions of the framework in order to identify opportunities and challenges in the new setting of the Safety House.

Finally, the fifth step is to identify and analyse the existing principles, rules, policies, work activities, tasks, etc. in the gathered data in order to understand the context. This should be done by placing actors at the centre of analysis to try to identify the possibilities and challenges they may encounter. At the Safety House, the gathered data on each dimension were analysed in connection to other dimensions and by placing Actors at the centre. For example, Communication Method dimension was analysed to understand how other dimensions such as Training, IT and Regulations and Legal Issues may impede or facilitate communication between actors. The process was repeated for all dimensions. 
Figure 5.4 shows the different steps for performing organisational analysis using the framework.

\section{A brief overview of the involved actors and key organisations is gained without the framework}

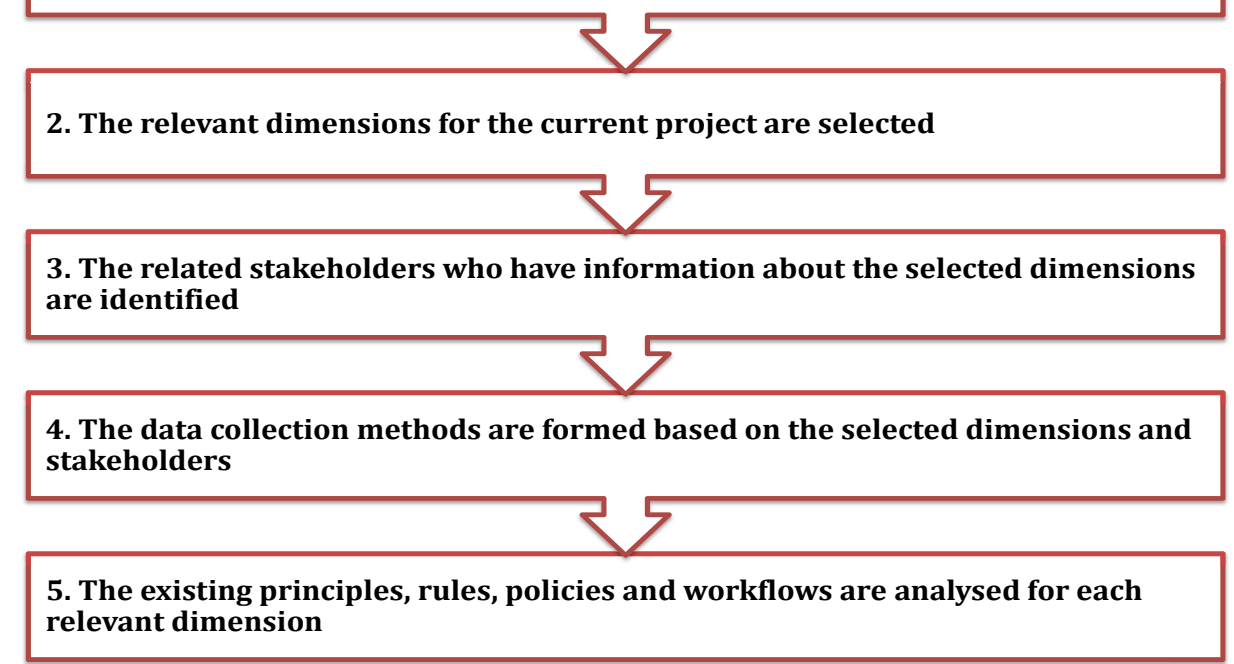

Figure 5.4: Five steps are suggested to perform an organisational/context analysis with the help of the ACERS framework.

\subsubsection{Needs analysis}

User needs are defined in relation to various factors such as equipment, work environment and technology. According to recent versions of $\mathrm{PD}$, all potential users of the required IS and even stakeholders should be actively involved in needs analysis, whether they are volunteer groups, citizens, semi-professionals or professional response organisations (e.g. Iivari et al., 2010; Pilemalm et al., 2015). When performing needs analysis, it is generally assumed that an organisational analysis has already been completed, relevant stakeholders have been identified, and the relevant dimensions have been explored in order to understand the context and identify problems, possibilities and mechanisms. However, at the Safety House, the main purpose was not to perform a complete needs analysis as a separate process; rather, needs analysis was combined with organisational analysis and performed at the same time. Various initial needs were mentioned by actors in interviews and could be used for an initial needs analysis. Moreover, the later phase of data collection (the future workshop) also focused on actors' needs for IS. Therefore, the following suggestion for needs analysis is based partly on experiences at the Safety House.

To perform the needs analysis, the first step is to select the relevant primary end users. Most often, these are reasonably clear from the beginning and/or from the results of the organisational analysis. Some other primary groups may not yet have been identified due to the complexity of 
the emerging context. For instance, users may be heterogeneous and from different societal sectors or may not belong to any organisation (e.g., civilians). To identify and define end user groups, the stakeholders (from the organisational analysis phase) are overviewed and those who are considered as end users are selected for more active involvement in the next steps. At the Safety House, the fire and rescue services, the police, the alarm centre and supportive actors are clearly recognised as end users and should be involved (however in the needs analysis at Safety House they were not, which should be seen as a limitation). Furthermore, following the interview with the representative from the police, it became clear that there is co-operation between the police and volunteers, for example, those who are sufficiently familiar with the region and landscape to search for missing persons. Therefore, volunteers can also be counted as potential users in this context.

In the second step, stakeholders are identified. These stakeholders are not direct users of IS but are somehow affected by the IS under development. System owners, sponsors, and actors at managerial level are examples of such stakeholders. These types of users can also be identified by referring to the results from the organisational/stakeholder analysis. At the Safety House, the municipality, the project manager and also the police management are examples of stakeholders that may not be direct users of the processes and IS under development, but were nonetheless involved in the future workshop as part of the needs analysis.

In the third step, a design group should be formed by involving important primary users and stakeholders from steps 1 and 2. The group should work actively with the purpose of identifying user needs and recognise how challenges and possibilities identified in the organisational analysis may affect them. For example, the Task dimension may be discussed with the input of users to identify how IS may help to accomplish a certain task. The same is true for Incident Type, to see how user needs vary between different incidents and how IS can provide support accordingly. The Regulation and Legal Issues dimension can be studied and analysed to understand how laws and policies may affect or inhibit user needs, e.g., in relation to information exchange. At the Safety House, it was attempted to form a group of available important primary users and stakeholders including representatives from the police and the police management, the fire and rescue services, the Swedish Defence, the municipality of Östersund, and the project manager. The group was activated in the form of a future workshop to complete the organisational analysis and to focus on actors' needs for IS in the co-location form of collaboration. The output of this phase is a structured list of user needs that contains the identified needs, their detail and their relation to the dimensions in the framework.

\subsubsection{Requirement analysis}

Requirement analysis focuses on the functions, features and elements IS should include in order to satisfy identified user needs (Sommerville, 2004). As an example, actors in ERSs, including new actors, may need to share information with one another. To meet this need, IS may provide functionalities such as information sharing by email, SMS or other specific platforms which are categorised as IS requirements. At the Safety House, requirement analysis was not performed, and the following suggestion is based solely on the theoretical perspective and the systems 
developer's general experiences of requirement analysis. One way to perform requirement analysis using the framework is to link the needs specification to the results of the organisational analysis for each relevant dimension. According to PD, this may be achieved by involvement of systems developers, the same group as used in the previous phase, and other experts if needed in order to discuss how needs are connected to organisational goals, actors' tasks and identified challenges. The results are subsequently used to prioritise and formulate needs in terms of IS requirements. The framework can be used to identify the problem in satisfying different requirements. For instance, to satisfy one requirement may not be feasible because of existing laws, and this can be identified quickly by looking at the analysis results for the Regulations and Legal Issues dimension in the framework. Such kinds of requirements can either be omitted or revised in order to comply with all relevant dimensions in the framework. The output of this phase is a structured requirement specification that contains the list of IS requirements and their relation to the dimensions in the framework. Figure 5.5 shows the different steps suggested for performing needs and requirement analysis by using the framework.

1. The relevant primary end users are identified from the stakeholders who are already known from the organisational analysis.

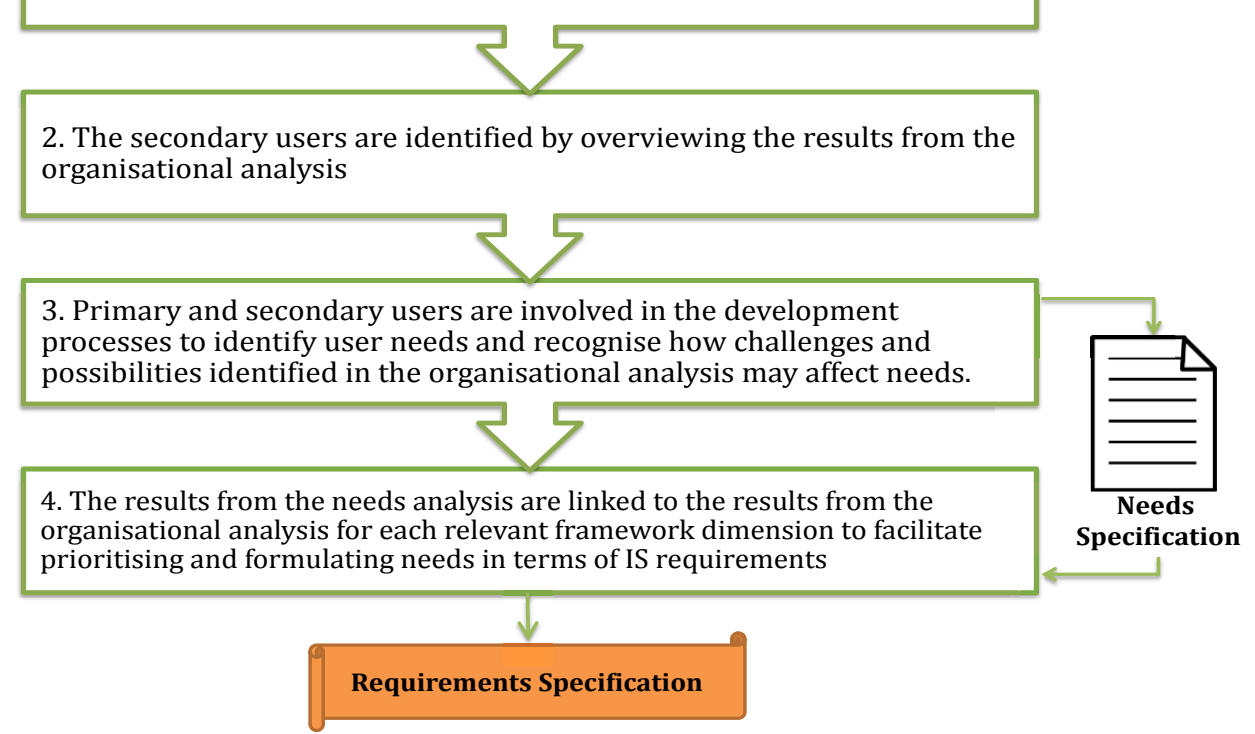

Figure 5.5: There are four suggested steps for performing a user needs and requirements analysis with the help of the ACERS framework.

\subsubsection{Application of the framework in the later phases of IS development}

The framework may also be helpful in the later phases of IS development processes, including design, implementation and validation phases. The framework was not tested at the Safety 
House in these phases. Therefore, a suggestion is presented in the following for how the framework may be used for this purpose.

It is suggested that, in the design phase, the selected stakeholder groups including users which were active in the needs and requirement analysis phases can have a central role to give feedback on the one or more suggested solutions. Solutions can be, for example, in the form of prototypes or commercial off-the-shelf (COTS) systems. The suggested solutions are investigated to determine whether they are in alignment with the needs analysis and the organisational analysis. Here, the same relevant framework dimensions as in the organisational and needs analysis should be studied either by analysing the existing data from these phases or by a new investigation of the suggested solutions to ensure that the relevant dimensions have been incorporated appropriately. This may reveal problems in design in good time before they can affect the final product in the implementation phase.

It is unlikely that the framework will explicitly contribute to the implementation phase in terms of architecture and programming. However, it may have an implicit impact on this phase since the implementation of a system aims at satisfying its users' needs, which have been identified with the help of the framework. In the evaluation phase, primary end users and even stakeholders can be involved in testing the final product. The same approach as in the design phase can be taken in relation to the final product. The aim is to test whether the system truly satisfies the identified needs. Identified challenges related to each dimension are reviewed to ensure that they are addressed by the final system. In addition, users require training and joint exercises to be able to use the new system. Some parts of the organisational analysis may have the potential to be used or complemented with further data collection for this purpose. The results from organisational and needs analysis may potentially be used, for example, for designing training programmes, courses and guidelines as they yield sufficient information about users' educational level, their background, their tasks, training needs, etc.

In the maintenance phase, users may need new functions. The framework may be applied similarly to previous phases to justify the appropriateness of newly added functions. Even problems arising once the system is in use can be investigated in light of the organisational and needs analysis to identify their roots and how they are related to the framework dimensions. This may help to solve problems more easily and quickly and thus save time and resources. 


\section{DISCUSSION}

This chapter discusses the thesis results in the context of current societal problems and trends affecting the ERS in Sweden and globally. The specific contributions of the thesis and its potential implications for ERSs, the public sector, and PD are then discussed. Finally, theoretical considerations and research validity are addressed.

\subsection{ERSs as increasingly complex systems and the ACERS framework}

Budget cuts and limited resources stemming from an ongoing global financial crisis, along with social unrest resulting from urbanisation, migration, extremist groups and the threat of terrorism, have meant that ERSs globally must search for alternative ways to organise themselves and create new forms of collaboration (e.g. Barsky et al., 2007; Venema et al., 2010; Waugh \& Streib, 2006). In Sweden, the long distance between residents and response organisations in sparsely populated areas and the centralisation of response organisations have also motivated the Swedish ERS to search for alternative solutions, for example, bringing in complementary societal resources at the incident scene (e.g., Weinholt \& Andersson Granberg, 2015; Pilemalm et al., 2013; Stenberg et al., 2010; Sund, 2006). Despite the potential and expected benefits of these new forms of collaboration, it also means that ERSs are becoming increasingly complex systems by involving heterogeneous actors with diverse backgrounds and needs from different organisations and sectors, or even civil volunteers who may not formally belong to any organisation. A wide range of aspects and challenges, such as roles and responsibilities of actors in response operations, their needs for training and supplies, legal issues, and many more have been reported as necessary aspects need to be understood and resolved in the emerging contexts (e.g. Christensen et al., 2013; Fischer et al., 2011; Jungert et al., 2006; Palm \& Törnqvist, 2008; Pelinka et al., 2004; Pilemalm et al., 2013).

The results of the thesis in many respects confirm the above picture of emerging complexities and challenges. For example, actors at the Safety House and security guards in Södertälje reported a lack of proper training and equipment, and difficulty adapting to a new environment because they did not have a clear and correct idea of how to deal with information confidentiality in relation to other actors with whom they collaborate very closely. Almost all actors who participated in data collection at the Safety House cited conflicts between ordinary and new tasks. In addition, the interviews with the MSB revealed ambiguities in Swedish law with respect to responsibility, insurance, financing, job contracts, restriction and job safety when involving semi-professionals and civilians in the Swedish ERS. Furthermore, cross-sector collaboration at the Safety House may be interpreted as a shift from bureaucratic structures to network governance-oriented forms of collaboration. Problems concerning priority for decision-making and policy-making, and ambiguity of actors' responsibilities have already been associated with this kind of collaboration (Christensen et al., 2007). Actors at the Safety House 
also reported ambiguities in goals and visions of the co-location and in rules, e.g., related to actors' responsibilities, data confidentiality and control of response operations.

The main goal of the new collaborations is to reduce costs and compensate for limited resources. However, to ignore the challenges mentioned above, i.e. to fail to identify and address them in the development of new forms of collaboration, can cause failure in collaborative processes and increase the associated costs and workload of involved actors. Paradoxically, the costs may end up exceeding the benefits and the main goal may not be satisfied. Therefore, it is important to perform systematic and rigorous analyses of new collaborations in ERSs before proceeding to real-world implementations.

The early results from the literature review implied that the research literature had not sufficiently highlighted the important factors to be considered when establishing new forms of collaboration. Furthermore, systematic methods for identifying such factors were not available. Rather, information on these factors was fragmented and spread throughout the related research literature. Equally importantly, a structured framework can be very helpful when developing IS in a new domain in order to structure that domain and facilitate understating of the context and the related actors and stakeholders. However, for new forms of collaboration, such frameworks either do not exist or are at an abstract level and not constructed specifically for this purpose. Unstructured IS development may result in rudimentary systems analysis, failed IS projects and IS which are ineffective for emergency organisations. The thesis contributes to the ERS field by providing the ACERS framework, which suggests 15 key factors for the analysis of new forms of collaboration in ERSs and for use in the development of associated IS.

\subsubsection{Applicability of the ACERS framework to ERSs}

The ACERS framework is based on a limited set of data from the Swedish ERS. The data at the strategic level from the MSB, the co-operative use of security guards and the co-location at the Safety House provide the grounds for the framework. However, the framework is also likely to be useful for analysing other forms of collaboration related to co-operative use of resources, involving semi-professionals and citizens in response operations and co-location of actors since all of them share similar characteristics such as involving heterogeneous actors, assigning them new tasks, and sharing information and equipment.

In many respects, ERSs in different countries share roles, training, resources, equipment, and ultimately the same basic goals: to save lives and to mitigate damage to the environment. Therefore, the ACERS framework may be relevant in other countries and may have the potential to be applied in ERSs internationally. When making an international comparison, several existing studies discuss similar dimensions across ERSs. For example, the roles of new actors have been highlighted and categorised as volunteers, bystanders and semi-professionals (Venema et al., 2010; Waugh \& Streib, 2006). Type of training for bystanders as new actors has been analysed and shown as a key factor in the success of response operations when trauma care is performed (Pelinka et al., 2004). These findings correspond to the Actors dimension in the framework. There are also studies that describe and highlight the tasks of first responders 
in response operations and categorise them as first aid, supplying food and equipment, providing emotional assistance and providing transport (Barsky et al., 2007; Tierney et al., 2001; Quarantelli, 1994; Valenzuela et al., 2000; Weinholt \& Andersson Granberg, 2013). Other studies have discussed the role of new actors for a specific incident type (e.g., cardiac arrest vs. drowning) (Valenzuela et al., 2000; Venema et al., 2010), which demonstrates that incident type is also considered an important factor in the success of response operations. These examples are represented under the Task/Response Operation dimension in the framework. In relation to the Technology dimension, there are studies which draw attention to the importance of designing and providing appropriate equipment for first responders to use at the incident scene (Jack, 2005; Schraagen \& Ven, 2011). Other studies discuss differences in policies when heterogeneous actors collaborate and legitimacy and trust issues arise (Christensen \& Lægreid, 2010; Palm \& Törnqvist, 2008). In the framework, these are categorised under the Structure/Organisation dimension. Conflicts regarding policies and legal issues, and problems in the categorisation of tasks and responsibilities have also been cited as challenges in crosssector collaboration (Burt \& Taylor, 2004; Christensen \& Lægreid, 2010; Ödlund, 2010; Pilemalm et al., 2013). These are represented in the framework by the Environment/Context dimension. All the above examples show that numerous studies overlap with the dimensions in the ACERS framework, and suggest that it therefore may be adapted to ERSs in other countries or used as a departure point from which to develop more standardised frameworks in the future.

\subsubsection{Everyday emergencies versus large-scale disasters}

Quarantelli (2000) argues that, despite both quantitative and qualitative differences between everyday emergencies and large-scale disasters, research and development work in different types of emergencies can learn from each other. Large-scale incidents are more demanding in terms of resources and unpredictable compared to everyday incidents. The infrastructure and services in a society may become unavailable for a time, and response operations generally involve a huge number of actors from different sectors, regions and even countries, for example, in the form of 'mega communities' (Kleiner \& Delurey, 2007). Although the ACERS framework is based on data that mainly concerns frequent, smaller-scale incidents, the framework may be applicable, with alterations, to the development of new forms of collaboration in large-scale disasters due to similarities in resources, roles, and IT support. For example, the communications system RAKEL is used by Swedish professional response organisations in both small- and large-scale emergencies. The same organisations/actors are responsible for managing both types, and much of the equipment, basic training and procedures are the same. IS that are used in everyday emergencies may be used more effectively in largescale incidents than IS that are designed only for the latter, as actors do not need extra training for them when the crisis occurs. To apply the framework to large-scale emergencies in the future, it will likely require changing and complementing by other data collections in order to cover actors' needs in related circumstances such as collaboration between actors from different countries and lack of infrastructure (e.g., communication, electricity and transport) at the incident scene. One solution would be to involve actors and researchers from ERSs in different countries to complete the framework and test it in developing collaborations for international, large-scale disaster contexts. 


\subsubsection{ACERS framework applications beyond ERSs}

From a wider public sector perspective, there are currently many concrete examples of crosssector collaboration from around the world and they are expanding all the time. For instance, Grudinschi et al.(2013) have discussed the cross-sector collaboration occurring between the public and private sectors in eldercare in Finland. In a remote area of New South Wales in Australia, a cross-sector collaboration was established between different authorities and organisations to compensate for gaps in education and health services for children (Jones et al., 2015). In Southwest Virginia in the USA, innovative community response has been studied as a solution to insufficient health organisational resources (Merwin et al., 2006). Not limited to ERSs, new forms of collaboration can thus be seen as a fast emerging trend in the public sector, discussed under various different terms such as network governance, new public management, e-government and e-health (i.e. using IT to enhance healthcare services).

It is possible that the ACERS framework may be relevant to the public sector in a more general sense, for analysing new forms of collaboration (e.g., cross-sector collaboration, e-government, and involving volunteers) and/or for developing corresponding IS. However, for such purposes the framework must be adapted, standardised, or else used only as inspiration in its current form for developing similar frameworks. Certain dimensions in the framework are clearly contextspecific and bound to ERSs, such as Incident Type and Emergency Supplies. When applying the framework in other public sector contexts, irrelevant dimensions should be omitted or renamed and other context-specific dimensions added. Nevertheless, most dimensions in the framework are general (e.g., Regulations and Legal Issues, Task) and do not need to be reviewed. In any case, a brief initial organisational analysis should be performed in order to review the definition of each dimension and align it with the current project. Systems developers, project managers and experienced actors are examples of stakeholders who may help in this work.

\subsubsection{Limitations of the framework}

Having made these claims for the potential generalisation of the ACERS framework for different forms of new collaboration in the Swedish ERS and in different countries, the use of framework should not be seen as a complete and perfect way for analysing such collaborations. The framework is still at an early stage and needs to be tested in different cases, improved and evaluated. For example, the framework has not yet been used for analysing collaboration with volunteers and the framework data does not include this group any more than existing response organisations having suggested what is needed when involving volunteers. Rather, the framework should serve as a starting point and as a structured support to perform analysis, and might need to be developed or adapted prior to real-world use in different cases.

To use the framework for performing organisational analysis and needs analysis may cause bias in the analysis if the analysts/developers are too bound to the framework and ignore data that are not explicitly connected to any dimension. It is important to maintain a balance when using the framework. Stakeholder ideas, answers and observations that do not fit with any particular 
dimension should also be assessed (if relevant) to avoid missing emergent and new possible dimensions. It may also be difficult in the beginning to choose the relevant dimensions for a project due to insufficient knowledge about the project and its objectives. This may be solved by gaining initial knowledge about the context before using the framework. There are also certain redundancies between dimensions that are inevitable. For example, the Task and Type/Role dimensions may overlap and become confusing for systems developers. To address this, it is important to follow the definition of each dimension closely and attempt to cover them with relevant information. New improvements, such as adding new dimensions, should be considered if this makes the framework more complete. In conclusion, these limitations need not be major obstacles for researchers and practitioners to use the framework, if they are aware of such limitations and endeavour to manage them properly. It is believed that the suggested benefits exceed the drawbacks in most cases, which should motivate future research to explore the use and development of similar frameworks.

\subsection{Using frameworks in line with emerging generations of PD}

PD has been applied for decades as a way to involve users directly in development processes and to design and build successful technological solutions for them (Ehn, 1993; Mumford, 1981). From the beginning, PD had a clear and plain ideology of involving civil citizens in urban planning and shop-floor workers in designing technological solutions (Ehn, 1993). However, early PD applications were generally limited to designing technology for contexts involving homogenous end users, resulting in small, stand-alone applications. This might be referred to as the first generation of PD (Pilemalm \& Timpka, 2008). Its application was extended in the second generation to focus on designing technology for collaborative working environments, usually inside organisations. The third generation of PD focused on interorganisational collaboration, with heterogeneous end users and in increasingly complex work environments and large-scale systems reflecting societal and technological development (Pilemalm \& Timpka, 2008).

Societal development and increasing organisational and technological complexity appear to be the main forces influencing the different generations of PD. In modern society, there are a large number of stakeholder groups that need to be identified and involved in IS development processes in order to grasp real user needs and perform a comprehensive analysis. It has been suggested that PD is important in increasingly complex contexts such as cross-sector collaboration, for example, to involve civilians in the design of e-services in e-government (e.g. Karlsson et al., 2012). At the same time, difficulties in identifying and involving stakeholders and a lack of formalisation in processes have been frequently cited as challenges involved in the use of PD approaches (Besselaar, 1998; Cavaye, 1995; Karlsson et al., 2012; Oostveen \& van den Besselaar, 2004). The need to modify PD approaches has also been stressed repeatedly, in general (Balka, 2006; Besselaar, 1998; Kyng, 2010) and specifically in emerging cross-sector collaboration and e-government contexts (Pilemalm et al., 2015). The existence of a broad set of heterogeneous actors with different needs, attitudes and characteristics creates certain 
requirements for the correct, efficient and effective implementation of PD. Pilemalm et al. (2015) suggest that emerging generations of user participation must adapt to contemporary trends of cross-sector collaboration and the involvement of heterogeneous stakeholders/users such as volunteers, non-profit organisations and citizens. Furthermore, the participation processes should be supported with suitable design tools and techniques. There seems to be a growing need to return to PD fundaments but at the same time to attempt to shift them from an abstract, visionary level to practical applications in real-world complex contexts by incorporating methods, tools, and clear processes. In summary, it seems necessary to add formalisations to PD in order to make it more effective, particularly in large-scale cross-sector collaboration related-projects reflecting emerging trends in the public sector. The ACERS framework may serve as a starting point to achieve this in the future and address the challenges mentioned above.

\subsubsection{Potential of the ACERS framework for adding formalisation to PD sub- processes}

PD has often been criticised as an ineffective approach in which the aim to satisfy democratic promises is time-consuming and resource-intensive (e.g. Pilemalm, 2002; Trigg, 2000). One reported reason for this is the perceived lack of formalisation in PD sub-processes. Despite the existence of different tools and methods for PD (e.g., future workshop, prototyping), there is often a lack of corresponding rigid methodologies and structured sub-processes for identifying stakeholders and involving them using the existing tools (Besselaar, 1998; Tollmar, 2001). Furthermore, PD does not focus on the later phases of development processes. It has been claimed that lack of clear and coherent methods in PD may lead to products that are incomplete or of limited use (e.g. Gallivan \& Keil, 2003; Wilson et al., 1997). The initial application of the ACERS framework at the Safety House was perceived to add formalisation to the PD-related elements of the analysis process. For example, the preselected dimensions were used as the starting point to design the data collection processes for involving users and capturing users' needs (questions, templates, interviews, future workshop) and helped to formulate inquiries. Without the framework, it would have been difficult to categorise inquiries and to design coherent data collection methods. It may also have been time-consuming to identify appropriate inquiries if they had needed to be investigated from scratch. The categorisation and accessing of data became straightforward and uncomplicated because they could be easily related to each dimension and reused in the analysis. Overall, it was felt that the application of the framework at the Safety House saved time and resources in the analysis process. Therefore, more developed and standardised versions of the ACERS framework may have the potential to act as a support to PD sub- processes, especially in the early design phases, and to provide a more structured method of analysing new forms of collaboration in the organisational and needs analysis phases. This may also answer the suggestion for emerging PD generations to include new supports and techniques for complex contexts such as cross-sector collaboration and e-government.

\section{Structured and transparent stakeholder analysis}

While the need to involve stakeholders from different levels, e.g. the operative and the managerial levels, is emphasised in the later generations of PD, it is often difficult, time- 
consuming, uncertain and confusing to choose among many stakeholder groups, since not all can be represented in development processes. It has also been claimed that none or very few of the benefits of PD can actually be seen because involvement may not really be implemented (Damodaran, 1996), be implemented partially or wrongly (Heeks, 1999), or include only a limited set of users at the operational level (Markus \& Mao, 2004). Moreover, it has been argued that shop-floor users rarely have sufficient time or the required attitude and/or knowledge about the higher levels in an organisation (Gulliksen \& Eriksson, 2006) to allow effective participation. The need to identify users and other stakeholder groups in complex environments has therefore gained increased attention from scholars in the past decade (e.g., Følstad et al., 2004; Pilemalm et al., 2015). It seems that PD should clearly employ stakeholder analysis methods in the early phases of development, for example, before organisational analysis. However, it is often unclear who the stakeholders are and how they can be identified. Efforts have thus been made to present methods and frameworks for this purpose (e.g., Lindgren, 2013).

At the Safety House project, the ACERS framework was used as a tool to identify stakeholders by connecting them to the relevant dimensions, and to select stakeholders who had sufficient and valuable knowledge about these dimensions. One example of this was the application of the framework to form inquiries and participation sessions, e.g., scenarios, interviews, and the future workshop. With the help of the framework, the systems developer was made aware of how stakeholder analysis should be performed overall and who the appropriate stakeholder groups were. It was also revealed that the representatives invited by the project manager could not cover all the relevant dimensions, and other stakeholders would therefore need to be involved in the development processes. For example, to study dimensions such as Leadership and Organisational Structure, managerial stakeholders should be involved. The Regulations and Legal Issues dimension requires persons who are knowledgeable about current laws and rules, e.g., jurists. The Costs/Benefits dimension can be covered by persons who are economists or who have sufficient domain knowledge. Without the framework, important stakeholders may be overlooked or ignored, especially those at the higher organisational levels, which could negatively affect the subsequent IS development processes and possibly lead to the creation of systems that are not organisationally implementable. Using the framework for involving relevant stakeholders in development processes might result in IS that are a better fit for actors, and help to identify systems functionality problems and the ways in which IS might be developed and improved. It is crucial to structure future generations of PD, because, as it was already mentioned in the thesis, contexts such as cross-sector collaboration and e-government which are based on heterogeneous actors face different or intensified challenges. Examples are conflicts in ordinary tasks and new tasks, different needs among users, difficulties to prioritise user needs, legal issues, and diversity in background and education. It is thus suggested that an improved and standardised version of ACERS framework may have the potential to help perform structured stakeholder analysis as a distinct part of PD processes. 


\subsubsection{Potential and challenges of using the framework in PD}

In summary, a more standardised, developed and sufficiently tested version of the ACERS framework may have the potential to address difficulties in using PD in complex environments and contribute to the enhancement of PD in such cases. Such a framework helps to involve influential stakeholders who may be absent in the beginning of a project; to involve a more appropriate set of stakeholders to cover different aspects of a project; and to support formalisation of PD processes. However, in order to be usable in this respect, such a framework should be a clear and distinct part of PD processes, e.g., to ensure that stakeholder analysis and stakeholder participation are not overlooked.

Figure 6.1 shows the potential contributions of frameworks to PD.

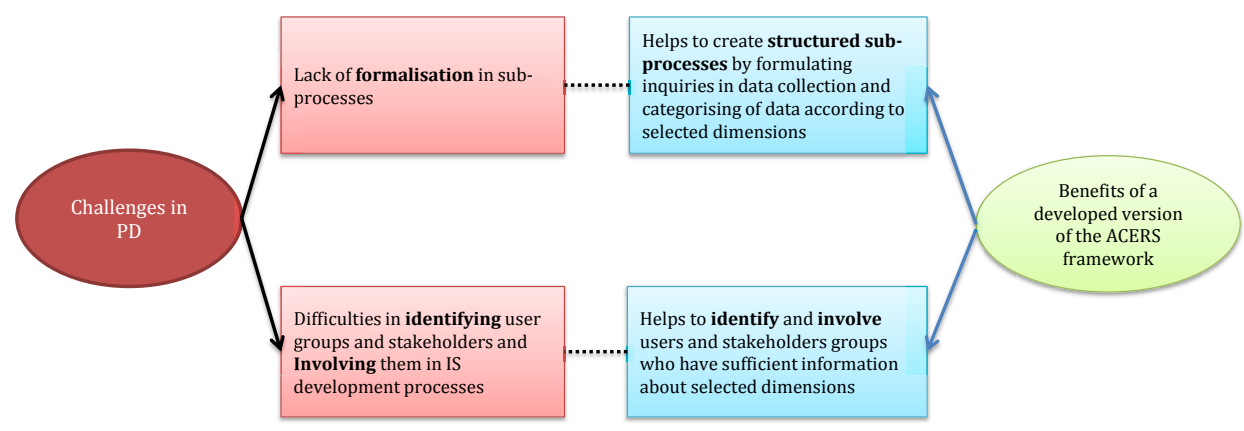

Figure 6.1: The potential to address challenges associated with PD approaches.

At the same time, the thesis is based on small and limited studies as regards the PD aspects. The involvement of all stakeholders at the Safety House project could not be completed in the scope of the thesis. In the next step and as future work, the framework should be tested in more cases and used to analyse different new forms of collaboration as well as different stakeholders. The results from different cases should be analysed, compared and the potential benefits and usefulness of the framework should, if possible, be evaluated in comparison to not using the framework in PD processes. The framework dimensions should be improved and new dimensions should be added if it is considered that any have been missed. If, for example, system developers rely solely on the framework they may miss emerging and new possible dimensions. Also other stakeholder ideas, answers and observations that cannot be related to any specific dimension in the framework should also be considered important if they are relevant, and be incorporated in the analyses. Also, in the initial suggestion explained above, several steps are presented in order to performs the analyses. Adding many steps includes the risk of the framework rather becoming an obstacle in the PD processes, since each step takes time. The balance of the framework becoming a support tool rather than a hindrance is crucial here. Therefore, the framework must be tested and evaluated as to how it and its steps affect the development processes, before it is possible to make more specific claims for that using the framework adds to formalization and effectiveness of PD. Amendments may also be needed. 
The PD processes should thus be systematised and clarified in all phases, e.g. in design and evaluation by showing clear examples and demonstrations of the framework application in different cases/projects. It should be used by other systems developers on different projects and the results should be evaluated and discussed. These are presented as potential future works in the next chapter.

\subsection{Theoretical considerations}

In this section, the implications of applying sociotechnical systems theory and network governance theory in the thesis are discussed. E-government and new public management (NPM) are discussed as alternative future perspectives.

\subsubsection{Applying sociotechnical systems theory}

In the thesis, ERSs are defined as systems comprised of a set of interdependent components such as actors, organisations and other subsystems which aim to satisfy defined objectives. The systems view of ERSs helped to define ERSs also as sociotechnical systems, i.e. systems having both social and technical aspects/components. To define ERSs in this way simplified the study of new forms of collaboration in ERSs since it was assumed from the beginning that both technical and non-technical aspects should be studied. It is also possible to assume that ERSs are purely social contexts or purely technological contexts; however, this would not satisfy the objectives of the thesis.

Specifically, sociotechnical systems theory was used to create the ACERS framework. Sociotechnical systems theory is connected to improving people's working environments by matching technical and social subsystems in organisations (Mumford, 2000). To grasp real user needs and perform a comprehensive analysis, the interactions between humans, machines and the environment should be taken into account (Reddy et al., 2003; Ropohl, 1999; Walker et al., 2008). In the thesis, sociotechnical systems theory helped to categorise the important aspects of ERSs into Actors, Task, Context, Organisation and Technology. The researcher considered these labels useful to categorise the results from the data analysis and present them in an understandable way. Moreover, sociotechnical systems theory served to relate the framework to IS development since many IS development approaches originate from sociotechnical systems perspectives, e.g., participatory design (PD). Further, the theory served to support the argument that failures in understanding of the interactions between actors, tasks, context, organisation and technology would lead to failure in resulting IS as it is also stressed in previous studies (e.g. Bostrom \& Heinen, 1977; Laudon \& Laudon, 1999). It was claimed that a framework based on sociotechnical systems theory could help to highlight these key aspects and facilitate understanding of them in a formal way in the ERS context and in related PD processes. Sociotechnical systems theory did not necessarily help to understand the mechanism of the collaboration; however, this was not the objective of the thesis. There are several other theoretical perspectives in which technological and social entities are considered together, 
rather than as separate entities, or are seen as extremely interconnected. Actor network theory (ANT) and socio-materiality are two examples of such perspectives. They may be helpful in understanding the nature and the mechanism of collaboration (Kaghan \& Bowker, 2001). However, they have not been applied in the thesis since their focus is on the internal mechanism of systems and not directly on the relation between technical and non-technical aspects of systems. Therefore, they might be helpful to understand the internal nature of collaborations themselves, but may be challenging to be used directly in the IS development for new forms of collaboration.

\subsubsection{Applying network governance theory}

Organisations with a network governance structure are characterised by a horizontal pattern of decision-making. Independent resource flows and higher degrees of information interaction are other common traits (Jones et al., 1997; Powell, 1990; Snow et al., 1992). In contrast to the hierarchical model, some scholars discuss the benefits of network governance in increasing effectiveness and efficiency in organisations by decentralised, collective problem solving and enabling more effective information exchange. However, ambiguity of responsibilities and the problem of control are two examples of reported problems with this model (e.g. Christensen et al., 2007). The co-location of actors at the Safety House in Sweden showed some similarities with network governance and confirmed many of the identified characteristics; for example, high degrees of informal interaction were observed, since actors share the same physical place and often meet at lunchtime. Collective problem solving by different actors in a shared decision room is another example. The problem of 'decision right' in response operations also arose, i.e. a lack of clarity about who is responsible for controlling the operation when all actors collaborate closely. Actors also frequently mentioned ambiguities in tasks and visions.

In the thesis, network governance theory has been applied only to co-location. However, other new forms of collaboration, such as co-operative use of resources and involving volunteers, display many of the same characteristics observed in the co-location study. For example, in Nyköping, the fire and rescue services and the social care services collaborate closely and make co-operative use of buildings and cars. However, ambiguity in the visions and goals of new settings have caused conflicts over certain responsibilities relating to control of the work environment and sharing expenses, for example, for procurement of equipment. Actors may also be unclear on how to manage confidentiality of information during informal interactions (Pilemalm et al., 2015). Projects in Medelpad and other counties in sparsely populated areas in the north of Sweden involving civil volunteers may be interpreted similarly. Here, volunteers have a degree of responsibility and can act autonomously in response operations while waiting for the professional organisations to arrive. Some associated problems include ambiguity in the responsibilities of actors at the incident scene and in insurances and laws concerning the lifethreatening risks for actors and victims, and the confidentiality of alarm information (Pilemalm et al., 2015). Therefore, using the network governance perspective may provide insights into new forms of collaboration and complete previous analyses performed from, for example, a sociotechnical systems perspective. In this way, it may be possible to develop the framework in future works by grounding it also in network governance theoretical perspectives. 


\subsubsection{E-government as an enabler of cross-sector collaboration}

The late 1950s and early 1960s saw the first generation of e-government, with government organisations moving from paper-based systems to digital ones. In the 2000s, this trend gained increased attention through the availability and popularity of the Internet. Certain tasks were digitalised, launched online and handed over to citizens to be performed themselves instead of by the authorities (e-services) (Lenk, 2002). The aim of e-services was to create better communication between authorities and civilians, increase effectiveness in the public sector, save money and provide a better service overall to the public (Yildiz, 2007). The second generation of e-government has been characterised by the pervasiveness of social media in people's daily lives, which increases democracy in e-government by providing more opportunities for citizens to collaborate with governments (Bonsón et al., 2012). Citizens now have the possibility to express their opinions on local policies, regulations and government services in online communities so that policymakers can be more informed, responsive and citizen-centric (e-participation). Increased e-participation can imply more extensive use of IS, making it possible to claim that development of related IS should be effective, efficient, and based on user needs. Although the end users in e-government are mainly civil citizens, relatively little attention has been paid to ways of involving them in the design of e-services (Holgersson \& Karlsson, 2014). The complexity of identifying and involving stakeholders in e-service design has been researched (e.g. Lindgren, 2013). PD has been suggested as an appropriate approach to give citizens a central role in the design of e-services (Holgersson \& Karlsson, 2014).

E-government can be seen as an enabler of cross-sector collaboration between authorities and the public (Lu et al., 2010). For example, the involvement of volunteers in response operations, as in Medelpad, can be interpreted as a form of e-government because volunteers use specific IT solutions provided by the response organizations to receive alarms and partake in response operations. To develop such IT and e-services in the ERS context, a developed and tested version of the ACERS framework may have the potential to be used as a starting point and a tool in PD processes for stakeholder analysis and needs analysis. This approach has not been explored in the thesis; however, it could form part of future research to adapt, develop and test the framework for designing e-services and IT support for volunteers and citizens in ERSs and possibly other parts of the public sector.

\subsubsection{New public management as a potential future perspective}

New public management (NPM) refers to attempts to increase cost efficiency and effectiveness in the public sector by measures such as involving private organisations in the delivery of services, better financial management, and decentralisation of services (Gruening, 2001; Hood, 1991). While NPM involves various measures, a key point is decentralisation of service delivery. This may require organisations with different structures, rules and needs to collaborate with others. Scholars have discussed at length the difficulties that arise in the implementation of NPM due to complexities such as the change in the structure of the public sector, combining different cultural norms, and ambiguity in the borders of organisations (Christensen \& Lægreid, 
2010; Koppell, 2010). Weber and Khademian (2008) also argue that without engaging a wide variety of stakeholders to solve the emerging challenges, we are unlikely to find solutions to the problems associated with NPM. Even though NPM is not applied in the thesis, recent changes in ERSs aimed at involving extra resources (e.g., semi-professionals, private sectors) in the public sector can be considered in line with NPM reforms. Indeed, NPM and ERS reforms share main goals, such as increasing cost efficiency and compensating for limited resources. Due to such similarities between NPM and recent changes in ERSs, to use NPM as another perspective from which to understand the challenges and important aspects to consider in the analysis and implementation of reforms may help complete understanding of new forms of collaboration in ERSs. New dimensions may be added to the ACERS framework. Some dimensions in the framework, such as actors' tasks or costs/benefits, can be analysed or redefined from an NPM perspective because they have probably been discussed in general NPM literature. In summary, NPM may help to develop the framework and enrich its theoretical grounds.

\subsection{Methodological reflections}

There are intense debates on standards and measures for assessing qualitative research (Corbin \& Strauss, 2007; Lincoln \& Guba, 1985). One issue concerns assessment criteria used in quantitative research and their unsuitability for qualitative research, since these involve different approaches, e.g., 'positivism' versus 'interpretivism'. There is no real agreement on how qualitative research should be assessed. Some of the criteria suggested by different scholars have been summarised by Creswell (Creswell, 2013, p. 243). Measures such as credibility (validity), transferability, dependability, and conformability are cited frequently in the literature by other researchers (e.g., Bryman, 2012; Lincoln \& Guba, 1985). The credibility of a study is concerned with whether the research process adheres to scientific methods and principles and whether the findings are reasonable and acceptable to others. Transferability refers to how generalisable a research result is. Dependability refers to making all phases of the research process (e.g. problem formulation, interview transcripts, selection of participants, data analysis) accessible to others as auditors. Conformability concerns the way in which results have been achieved from data and the impact of the personal values of researchers on the results.

In the thesis, the above four measures were found suitable and useful to assess the quality of case study research. To satisfy the credibility of the research, it was attempted to apply a clear research methodology by discussing and showing the different parts of the research process and the research design (explained in Chapter 4). In order to gain a clear and comprehensive view of new forms of collaboration in ERSs, three different instances of collaboration including volunteer involvement, co-operative use of resources and co-location of actors were used as the starting point for data collection. However, the quality and amount of data was different for each. In some cases, it was possible to gain a deep understanding of the study object and to capture its complexity (e.g., co-location at the Safety House), while the availability of data sources in other cases, such as direct interviews with volunteers, was limited. Data triangulation 
was used at the Safety House, where data was gathered from three different sources, i.e. interviews, the participant observation and the future workshop. For example, in all data sources, participants mentioned ambiguity in tasks and responsibilities in the context of colocation. When different sources point to the same finding, it can increase the credibility of the results. It was attempted to apply this approach to the entire thesis when developing the framework. However, the usefulness of the framework in IS development (i.e. organisational analysis and needs analysis) and the evaluation and testing of its benefits are not in the scope of the thesis, but form part of a possible next step or future work.

Regarding transferability, as has been discussed, the results of the thesis are not applicable to all instances of cross-sector collaboration. However, there is a fair chance that the results could be used as a point of departure to analyse such collaborations in the public sector and in ERSs worldwide. Since, the case study research with influences from participatory action research was used to understand the phenomenon of new forms of collaboration, new cases of using ACERS framework in similar contexts can improve the understanding of the phenomenon. Therefore, performing new case studies will increase the transferability of the thesis results. The framework should be tested by and with other researchers and/or systems developers and the results and feedback analysed in order to evaluate its benefits and comprehensiveness.

To satisfy dependability and confirmability, an 'auditing approach' was applied throughout the entire research process by which the research findings (i.e. the framework) were made accessible to peers and researchers for critical review. Peer review, seminars and workshops were the methods used for auditing. However, the use of the framework in IS development was limited to the case of the Safety House and performed solely by the researcher. This may be considered as bias in the research process. To minimise this problem, the research tried to gain an initial understanding of the ERS context and different kinds of new collaboration by performing an initial literature review. The further testing of the framework in different cases in the future can also help to cope with the bias problem. 
New Forms of Collaboration in Emergency Response Systems:

A framework for participatory design of information systems 


\section{CONCLUSION AND FUTURE WORKS}

This chapter outlines the key contributions of the thesis and connects them to the results and the discussion. The implications of the work for future research are subsequently discussed.

\subsection{Summary of key contributions}

The principal contribution of the thesis to the ERS field is a framework for analysing new forms of collaboration. First, the factors deemed important to be incorporated in the analysis process were highlighted. Accordingly, the need for an ERS-specific framework for performing a structured analysis was identified. The ACERS framework, encompassing 15 dimensions in total, was subsequently developed and presented. The framework was then modified for the specific purpose of IS development by applying sociotechnical systems theory and PD principles. The specific contributions of the thesis to the field of IS are thus a domain-specific framework and an initial suggestion for how it may be applied in the early phases of PD in ERSs.

In a more general sense, it was then argued that developed and sufficiently tested versions of the framework may have the potential to be adapted to and be useful in ERSs in different countries and in other parts of the public sector. Examples include e-government, NPM reforms and e-health initiatives. Moreover, it was argued that future, more standardised versions of ACERS framework may help to make PD processes more effective by addressing challenges such as lack of formalisation and identifying and involving stakeholder groups in complex environments with heterogeneous stakeholders. This may serve to shift PD from an academic to a more practical approach, eventually leading to more effective participatory IS development. The thesis contribution and potential assertions may thus be summarised as:

- Contribution 1: The thesis contributes to the ERS field by providing a conceptual framework for the analysis of new forms of collaboration in ERSs in order to understand the collaboration, actors' tasks within it, and the emergent related challenges.

- Contribution 2: The thesis contributes specifically to the IS field by presenting an initial domain-specific framework and by providing an initial suggestion for its use in PD in new forms of collaboration in ERSs.

- Assertion 1: The framework may initiate future works for the analysis of new forms of collaboration in the public sector.

- Assertion 2: The framework may initiate future works for adding formalisation to the use of PD in complex environments with heterogeneous stakeholders. 


\subsection{A changing world: the increasing need for analysis of new forms of collaboration in the public sector}

The research process for the thesis was initiated in 2012. Since then, large-scale disasters such as storms (e.g. Typhoon Haiyan in the Philippines in 2013, killing 6,300 people) and forest fires (e.g. the Västmanland wildfire in Sweden in 2014) have continued to occur globally, including in Sweden. Epidemics and pandemics are difficult to control due to increasing passenger flows between countries. Recent examples include the Ebola outbreak in Africa in 2014. Wars and terrorism in the Middle East leading to increased migration to the EU. Climate change, the ongoing financial crisis since 2008 and corresponding steady decrease in public sector resources, the emergence of extremist groups, and terrorism threats all increase societal challenges. Recent world events have thus put a huge strain on emergency response organisations in modern societies. At the same time, these organisations are the main actors responsible for delivering essential services in case of frequently occurring, smaller-scale emergencies such as traffic accidents and fires. Consequently, while emergency response actors are under extreme pressure, they need to be more effective than ever. These challenges are not limited to ERSs, but can be observed across the public sector. The responsible authorities and organisations experience substantial difficulty managing the situation alone, and are increasingly seeking help from other resources and sectors in society. As a result, new forms of collaboration are becoming more common. The phenomenon may also be discussed in different terms, such as cross-sector collaboration, e-health, e-government, network governance and NPM reforms.

In Sweden, budget cuts, lack of professional resources, and great physical distances between response actors are problems typically affecting society and rural areas in particular. These challenges are being addressed by reorganising the Swedish ERS, equipping professional response organisations with the right techniques and methods, and involving extra resources such as semi-professionals, citizens and volunteers. The co-location of actors in Jämtland, the co-operative use of resources in Nyköping, and the SMS life-saving project (http://www.smslivraddare.se/) in Stockholm are early examples mentioned in the thesis. A project involving volunteers as first responders in the county of Medelpad began in 2013. Cooperative use of resources has been implemented in other parts of Sweden, for example, in the Öckerö, Norrköping, and Varberg municipalities. Volunteer organisations and individual volunteers have also started their own initiatives. Landräddningen is a project that involves volunteers to help people in specific emergency situations (e.g. simple emergencies) where it may not be necessary to engage professional response organisations (http://www.landraddningen.se/). Recently, the organisation Missing People has been very active on social media for ad-hoc mobilisation of volunteers (http://missingpeople.se), and other such examples are fast emerging. There are also different forms of IS and mobile applications under development in the ad-hoc mobilisation projects (e.g., Tryvge, http://www.trygve.se/). In such cases, the authorities have little or no influence in terms of processes, challenges, and IS support. 
In light of the far-reaching and often very challenging societal changes discussed above, an increasingly broad set of heterogeneous stakeholders inevitably become involved in new forms of collaboration. This introduces a number of issues to be addressed, and analysis of these new collaborations becomes complex. Rudimentary analyses may result in failure of related projects. Therefore, to carry out research and development around new forms of collaboration and corresponding IS development seems increasingly crucial. The thesis intends to facilitate understanding of current and future processes of change in ERSs/the public sector in order to establish such changes successfully and support the involved actors with effective IS. However, this is only the beginning, and there are other new forms of collaboration (e.g. involving different groups of semi-professionals and volunteers in response operations) that need to be studied similarly. Standard frameworks, tested structured ways of performing related analysis, and guidelines and checklists for implementing suggested changes are still missing. Moreover, general challenges in IS development, such as identifying stakeholders in such complex environments and developing IS based on user needs, become more difficult to manage. Some examples of how the identified research needs might be fulfilled are presented in the future works section below.

\subsection{Future works}

The ACERS framework is based on a limited set of data. The framework also showed some limitations, such as overlap between dimensions and risk of bias in data analysis. More research and case studies are needed in order to compare the gained results from cases, evaluate and elaborate the benefits of ACERS framework and identify and address its limitations to be able to construct more standardised and developed frameworks. NPM and network governance can also be added to the theoretical grounds of the framework, as explained in the discussions, to improve and complete the framework dimensions. The ACERS framework can also serve as a starting point to develop similar frameworks to be applied to other contexts in which new forms of collaboration and network governance are in focus, e.g. in e-government and e-health.

Regarding IS development, an effort similar to the present work is the call by Pilemalm et al. (2015) for the fourth generation of user participatory IS development to allow for its use in complex environments such as cross-sector collaboration. Another example is Lindgren's (2013) framework for identifying and characterising stakeholders in public e-services which can be used in PD processes. In line with these two examples, a number of possibilities for future research aimed at supporting PD sub-processes in complex contexts are suggested in the discussions in section 6.2. The focus of the thesis is chiefly on the early phases of PD processes and related challenges. This may preclude using the framework in later phases, since it is not sufficiently discussed and explored how the framework and the results gained from its use may be connected to them. One way for future research could therefore be to focus on the challenges in other phases of PD and to integrate the framework in all phases. 
The theoretical grounds for the study relate chiefly to sociotechnical systems theory and the PD approach in general. Other theories and schools of thought such, socio-materiality and network governance may be applied to gain a deeper understanding of the internal mechanisms and social construction of collaboration where heterogeneous actors interact with each other.

In the context of this thesis work, the next step is to use the framework as a departure point for analysing the potential co-operative use of resources and cross-sector collaboration in the ESKORT project (Efficient communal use of municipal resources for increased safety and security) in the municipality of Norrköping. The aim of this project is to involve semiprofessional resources such as building technicians, eldercare personnel and security guards to assist in emergencies. These actors patrol within the municipality and may be more immediately available than professional response resources, if they receive an alarm at the same time. Since the collaboration does not yet exist, and the framework will be applied from scratch to analyse the possibilities and challenges in relation to different groups of actors, further research will be involved in order to test the use of framework and to evaluate its usefulness in PD processes. ESKORT will also aim to develop prototype IT tools such as mobile apps and decision support systems which will be also be evaluated in an exercise. By using the framework as support for this, it may be possible to achieve a clear example of testing and developing such tools in more phases of PD, and in turn provide further recommendations for use of PD in development of IS for ERSs.

Finally, from a long-term perspective, it may be possible to compare results from different analyses of different new forms of collaboration in which the departure point has been the ACERS framework. This could allow researchers to identify similarities and differences between news forms of collaboration in ERSs and, consequently, to build theories about them and their related challenges. This in turn could lead to increased standardisation and transparency in involving new actors such as volunteers, citizens and semi-professionals, as well as providing checklists in order to 'certify' different groups to partake in a response operation. In the long term, such work could contribute to the more effective establishment of new forms of collaboration in the Swedish ERS and ERSs internationally. 


\section{References}

Agarwal, R., \& Lucas, H. C. Jr. (2005). The Information Systems Identity Crisis: Focusing on HighVisibility and High-Impact Research. MIS Quarterly., 29(3), 381-398.

Agranoff, R. (2007). Managing Within Networks: Adding Value to Public Organizations. Washington, D.C: Georgetown University Press.

Agranoff, R., \& McGuire, M. (2003). Collaborative Public Management: New Strategies for Local Governments. Washington, DC: Georgetown University Press.

Alford, J., \& O'Flynn, J. (2012). Rethinking Public Service Delivery: Managing with External Providers. Houndmills, Basingstoke, Hampshire; New York: Palgrave Macmillan.

Ali, M., Miyoshi, C., \& Ushijima, H. (2006). Emergency medical services in Islamabad, Pakistan: A public-private partnership. Public Health, 120(1), 50-57.

Alter, C., \& Hage, J. (1993). Organizations working together. Newbury Park, CA: Sage Publications.

Andersson Granberg, T., \& Värbrand, P. (2007). Decision support tools for ambulance dispatch and relocation. Journal of the Operational Research Society, 58(2), 195-201.

Angrosino, M. (2007). Doing Ethnographic and Observational Research. Los Angeles, CA: SAGE Publications.

Avison, D., \& Fitzgerald, G. (2006a). Information Systems Development: Methodologies, Techniques and Tools ( $4^{\text {th }}$ edition.). London: McGraw-Hill Higher Education.

Avison, D., \& Fitzgerald, G. (2006b). Methodologies for Developing Information Systems: A Historical Perspective. In D. Avison, S. Elliot, J. Krogstie, \& J. Pries-Heje (Eds.), The Past and Future of Information Systems: 1976-2006 and Beyond (pp. 27-38). Springer US.

Babiak, K., \& Thibault, L. (2009). Challenges in Multiple Cross-Sector Partnerships. Nonprofit and Voluntary Sector Quarterly, 38(1), 117-143.

Balka, E. (2006). Inside the Belly of the Beast: The Challenges and Successes of a Reformist Participatory Agenda. In Proceedings of the Ninth Conference on Participatory Design: Expanding Boundaries in Design - Volume 1 (pp. 134-143). New York, NY, USA: ACM.

Barsky, L., Baumann, J., Torres, M., \& Aguirre, B. (2007). Managing volunteers: FEMA's Urban Search and Rescue programme and interactions with unaffiliated responders in disaster response. Disasters, 31(4), 495-507.

Baskerville, R., \& Myers, M. (2004). Special Issue on Action Research in Information Systems: Making IS Research relevant to practice foreword. MIS Quarterly, 28(3).

Baxter, G., \& Sommerville, I. (2011). Socio-technical systems: From design methods to systems engineering. Interacting with Computers, 23(1), 4-17.

Benbasat, I., \& Zmud, R. W. (2003). The Identity Crisis within the IS Discipline: Defining and Communicating the Discipline's Core Properties. MIS Quarterly., 27(2), 183-194.

Bentley, R., Hughes, J. A., Randall, D., Rodden, T., Sawyer, P., Shapiro, D., \& Sommerville, I. (1992). Ethnographically-informed Systems Design for Air Traffic Control. In Proceedings of the 
1992 ACM Conference on Computer-supported Cooperative Work (pp. 123-129). New York, NY, USA: ACM.

Bergmark, L., \& Tollander, J. (2008). Samverkan vid Kommunal I räddningstjänst. Department of fire safety engineering and system safety, Lund University Sweden, report 5286, 19-21.

Van den Besselaar, P. (1998). Democratizing Technological Change: Limits to Steering. In R. Henderson Chatfield, S. Kuhn, \& M. Muller (Eds.), Proceedings of the Participatory Design Conference 1998 (pp. 1-10). Palo Alto, CA: CPSR.

Bjorn-Andersen, N., \& Eason, K. (1980). Myths and realities of information systems contributions to organizational rationality. In A. Mowshowitz (Ed.) Human Choice and Computers. Amsterdam: North-Holland.

Bless, C., Higson-Smith, C., \& Kagee, A. (2006). Fundamentals of Social Research Methods: An African Perspective. Juta and Company Ltd.

Boehm, B. W., \& Papaccio, P. N. (1988). Understanding and Controlling Software Costs. IEEE Trans. Softw. Eng., 14(10), 1462-1477.

Boland, R. J. (1991). Information systems use as a hermeneutic process. In H-E. Nissen, H. Klein, \& R. Hirschheim (Eds.), Information Systems Research: Contemporary Approaches and Emergent Traditions (pp. 439-464)

Bonsón, E., Torres, L., Royo, S., \& Flores, F. (2012). Local e-government 2.0: Social media and corporate transparency in municipalities. Government Information Quarterly, 29(2), 123-132.

Bostrom, R. P., \& Heinen, J. S. (1977). MIS Problems and Failures: A Socio-Technical Perspective. Part I: The Causes. MIS Quarterly, 1(3), 17-32.

Brinkerhoff, J. M. (2002). Government-nonprofit partnership: a defining framework. Public Administration and Development, 22(1), 19-30.

Brodsky, H. (1984). The bystander in highway injury accidents. Social Science \& Medicine (1982), 19(11), 1213-1216.

Bryman, A. (2012). Social Research Methods, 4th Edition (4th edition.). Oxford; New York: Oxford University Press.

Bryson, J. (2004). What to do when stakeholders matter. Public Management Review, 6(1), 21-53.

Bryson, J., Crosby, B., \& Stone, M. (2006). The Design and Implementation of Cross-Sector Collaborations: Propositions from the Literature. Public Administration Review, 66, 44-55.

Bull-Kamanga, L., Diagne, K., Lavell, A., Leon, E., Lerise, F., MacGregor, H., Maskrey, A., Meshack, M., ... Yitambe, A. (2003). From everyday hazards to disasters: the accumulation of risk in urban areas. Environment and Urbanization, 15(1), 193-204.

Burt, E., \& Taylor, J. (2004). Drawing Voluntary Organisations into the Information Polity: Information Resources and Macro Politics. Public Policy and Administration, 19(1), 66-81.

Cavaye, A. L. M. (1995). User participation in system development revisited. Information \& Management, 28(5), 311-323.

Checkland, P., \& Holwell, S. (1997). Information, Systems and Information Systems: Making Sense of 
the Field ( $1^{\text {st }}$ edition.). Chichester; New York: Wiley.

Checkland, P., \& Scholes, J. (1990). Soft Systems Methodology in Action. Chichester: Wiley.

Chen, R., Sharman, R., Rao, H. R., \& Upadhyaya, S. (2007). Design principles for critical incident response systems. Information Systems and E-Business Management, 5(3), 201-227.

Christel, M., \& Kang, K. (1992). Issues in Requirements Elicitation (No. CMU/SEI-92-TR-012).

Pittsburgh, PA: Software Engineering Institute, Carnegie-Mellon University.

Christensen, T., \& Lægreid, P. (2010). Complexity and Hybrid Public Administration-Theoretical and Empirical Challenges. Public Organization Review, 11(4), 407-423.

Christensen, T., Lægreid, P., Roness, P. G., \& Røvik, K. A. (2007). Organization Theory and the Public Sector: Instrument, Culture and Myth. London: Routledge.

Christensen, T., Laegreid, P., \& Rykkja, L. (2013). Wicked Problems and the Challenge of Transboundary coordination: the case of emergency preparedness and crisis management in Norway. Presented at the COCOPS Working Paper No. 11.

Corbin, J., \& Strauss, A. (2007). Basics of Qualitative Research: Techniques and Procedures for Developing Grounded Theory ( $3^{\text {rd }}$ edition.). Los Angeles, Calif: SAGE Publications, Inc.

Cornwall, A., \& Jewkes, R. (1995). What is participatory research? Social Science \& Medicine, 41(12), 1667-1676.

Creswell, J. W. (2013). Qualitative inquiry and research design: choosing among five approaches. Los Angeles: SAGE Publications.

Damodaran, L. (1996). User Involvement in the Systems Design Process - A Practical Guide for Users. Behaviour \& Information Technology, 15(6), 363-377.

Danielsson, E., Johansson, R., \& Eliasson, L. (2010). Samverkan i praktiken. Myndigheten för samhällsskydd och beredskap. ISBN 978-91-7383-154-3.

Davenport, E. (2008). Social informatics and sociotechnical research - a view from the UK. Journal of Information Science, 34(4), 519-530.

Davis, M. C., Challenger, R., Jayewardene, D. N. W., \& Clegg, C. W. (2014). Advancing sociotechnical systems thinking: A call for bravery. Applied Ergonomics, 45(2, Part A), 171-180.

Dedeurwaerdere, T. (2007). The contribution of network governance to sustainability impact assessment. In S. Thoyer \& B. Martimort-Asso (Eds.), Participation for Sustainability in Trade (pp. 209-228). Surrey, UK: Ashgate.

Denzin, N. K., \& Lincoln, Y. S. (Eds.), (2011). The SAGE Handbook of Qualitative Research (4 ${ }^{\text {th }}$ edition.). Thousand Oaks: SAGE Publications, Inc.

DeWalt, K. M., \& DeWalt, B. R. (2002). Participant Observation: A Guide for Fieldworkers. Lanham, MD: Rowman Altamira.

DiMaggio, P. J. (1995). Comments on 'What Theory is Not'. Administrative Science Quarterly, 40(3), 391-397.

Dubois, A., \& Gadde, L-E. (2002). Systematic combining: an abductive approach to case research. 
Journal of Business Research, 55(7), 553-560.

Ehn, P. (1993). Scandinavian Design: on Participation and Skill. In D. Schuler \& A. Namioka (Eds.), Participatory Design: Principles and Practices (pp. 41-77). Hillsdale, NJ: Lawrence Earlbaum.

Ehn, P., \& Kyng, M. (1987). The Collective Resource Approach to Systems Design. In P. Ehn, M. Kyng, \& G. Bjerknes (Eds.), Computers and Democracy (pp. 19-57). Aldershot, UK: Avebury.

El Sawy, O. A. (2003). The IS Core - IX: The Three Faces of IS Identity: Connection, Immersion, and Fusion. Communications of the Association for Information Systems, 12(1), 588-598.

Emery, F. E., \& Trist, E. L. (1960). Socio-technical systems. In F.E. Emery (Ed.). (1969). Systems thinking (pp. 83-97). Harmondsworth: Penguin.

Fischer, P., Krueger, J. I., Greitemeyer, T., Vogrincic, C., Kastenmüller, A., Frey, D., Heene, M., Wicher, M., \& Kainbacher, M. (2011). The bystander-effect: A meta-analytic review on bystander intervention in dangerous and non-dangerous emergencies. Psychological Bulletin, 137(4), 517-537.

Fleishman, R. (2009). To Participate or Not to Participate? Incentives and Obstacles for Collaboration. In L. Bingham \& R. O'Leary (Eds.), The Collaborative Public Manager: New Ideas for the TwentyFirst Century. Washington, D.C.: Georgetown University Press.

Flyvbjerg, B. (2006). Five Misunderstandings About Case-Study Research. Qualitative Inquiry, 12(2), 219-245.

Følstad, A., Jørgensen, H. D., \& Krogstie, J. (2004). User Involvement in e-Government Development Projects. In Proceedings of the Third Nordic Conference on Human-computer Interaction (pp. 217224). New York, NY, USA: ACM.

Fredholm, L. (2006). Hantering av små till stora samhällspåfrestande olyckor. I L. Fredholm \& A-L. Göransson (Red.), Ledning av räddningsinsatser i det komplexa samhället (s. 13-30).

Räddningsverket.

Freeman, R. E., Harrison, J. S., Wicks, A. C., Parmar, B. L., \& de Colle, S. (2010). Stakeholder Theory: The State of the Art. Cambridge University Press.

Gajda, R. (2004). Utilizing Collaboration Theory to Evaluate Strategic Alliances. American Journal of Evaluation, 25(1), 65-77.

Gallivan, M. J., \& Keil, M. (2003). The user-developer communication process: a critical case study. Information Systems Journal, 13(1), 37-68.

Gazley, B. (2008). Inter-Sectoral Collaboration and the Motivation to Collaborate: Toward an Integrated Theory. In L.B. Bingham \& R. O'Leary (Eds.), Big Ideas in Collaborative Public Management (pp. 36-54). New York: M.E.Sharpe.

Gazley, B., \& Brudney, J. L. (2007). The Purpose (and Perils) of Government-Nonprofit Partnership. Nonprofit and Voluntary Sector Quarterly, 36(3), 389-415.

Goldkuhl, G., \& Cronholm, S. (2010). Adding Theoretical Grounding to Grounded Theory: Toward Multi-Grounded Theory. International Journal of Qualitative Methods, 9(2), 187-205.

Goldsmith, S., \& Eggers, W. D. (2004). Governing by Network: The New Shape of the Public Sector. Washington, D.C: Brookings Institution Press and the Innovations in American Government Program at the John F. Kennedy School of Government at Harvard University. 
Gould, J. D., \& Lewis, C. (1985). Designing for Usability: Key Principles and What Designers Think. Communications of the ACM, 28(3), 300-311.

Greenbaum, J., \& Kyng, M. (1991). Design at Work: Cooperative Design of Computer Systems. Hillsdale, NJ, USA: Lawrence Erlbaum Associates.

Greve, C., \& Hodge, G. (Eds.). (2005). The Challenge of Public-Private Partnerships: Learning from international experience. Cheltenham, UK; Northampton, MA: Edward Elgar Pub.

Grudinschi, D., Kaljunen, L., Hokkanen, T., Hallikas, J., Sintonen, S., \& Puustinen, A. (2013).

Management Challenges in Cross-Sector Collaboration: Elderly Care Case Study. The Innovation Journal, 18(2), article 7.

Gruening, G. (2001). Origin and theoretical basis of new public management. International Public Management Journal, 4(1), 1-25.

Gulliksen, J., \& Eriksson, E. (2006). Understanding and Developing User Involvement at a Public Authority. Presented at the fourth Nordic conference on Human-Computer Interaction, October 14-18, 2006. Oslo, Norway.

Gunnarsson, B., \& Svavarsdóttir, H. (2007). Ambulance Transport and Services in the Rural Areas of Iceland, Scotland and Sweden. Journal of Emergency Primary Health Care, 5, 1-12.

Haddow, G., Bullock, J., \& Coppola, D. P. (2013). Introduction to Emergency Management, Fifth Edition ( $5^{\text {th }}$ edition.). Waltham, MA: Butterworth-Heinemann.

Hallstrom, A., Ornato, J., Weisfeldt, M., Travers, A., Christenson, J., McBurnie, M., Zalenski, R., Becker, L., ... Proschan, M. (2004). Public-Access Defibrillation and Survival after Out-of-Hospital Cardiac Arrest. New England Journal of Medicine, 351(7), 637-646.

Harder, H. (2010). Explanatory Case Study. In A. Mills, G, Durepos, \& E. Weibe (Eds.), Encyclopedia of Case Study Research (pp.371-372). Thousand Oaks, CA: SAGE Publications, Inc.

Heeks, R. (1999). The tyranny of participation in information systems: learning from development projects. Institute for Development Policy and Management, University of Manchester.

Holgersson, J., \& Karlsson, F. (2014). Public e-service development: Understanding citizens' conditions for participation. Government Information Quarterly, 31(3), 396-410.

Holgersson, S. (2005). Yrke: POLIS : Yrkeskunskap, motivation, IT-system och andra förutsättningar för polisarbete (Doctoral thesis). Linköping University, Linköping.

Hollenberg, J., Riva, G., Bohm, K., Nordberg, P., Larsen, R., Herlitz, J., Pettersson, H., Rosenqvist, M., \& Svensson, L. (2009). Dual dispatch early defibrillation in out-of-hospital cardiac arrest: the SALSA-pilot. European Heart Journal, 30(14), 1781-1789.

Hood, C. (1991). A Public Management for All Seasons? Public Administration, 69(1), 3-19.

Huxham, C., \& Vangen, S. (2000). Ambiguity, Complexity and Dynamics in the Membership of Collaboration. Human Relations, 53(6), 771-806.

Iivari, J., Isomäki, H., \& Pekkola, S. (2010). The user - the great unknown of systems development: reasons, forms, challenges, experiences and intellectual contributions of user involvement. Information Systems Journal, 20(2), 109-117. 
Jack, G. (2005). Equipping First Responders. Compliance Magazine, 12(2), 20-21.

Jansen, A. (2006). Strategies for User Involvement in eGovernment Projects: What can be learned from the Scandinavian IS tradition? Presented at the NordiCHI'06 Workshop on User involvement and Representation in e-Government Projects, 11, Oslo.

Jones, C., Hesterly, W. S., \& Borgatti, S. P. (1997). A General Theory of Network Governance: Exchange Conditions and Social Mechanisms. The Academy of Management Review, 22(4), 911-945.

Jones, D. M., Lyle, D., Brunero, C., McAllister, L., Webb, T., \& Riley, S. (2015). Improving health and education outcomes for children in remote communities: A cross-sector and developmental evaluation approach. Gateways: International Journal of Community Research and Engagement, 8(1), 1.

Jungert, E., Hallberg, N., \& Hunstad, A. (2006). A service-based command and control systems architecture for crisis management. International Journal of Emergency Management, 3(2-3), 131148 .

Jungk, R., \& Müllert, N. R. (1987). Future Workshops: How to Create Desirable Futures. London, UK: Institute for Social Inventions.

Kaghan, W. N., \& Bowker, G. C. (2001). Out of machine age?: complexity, sociotechnical systems and actor network theory. Journal of Engineering and Technology Management, 18(3), 253-269.

Karlsson, F., Holgersson, J., Söderström, E., \& Hedström, K. (2012). Exploring user participation approaches in public e-service development. Government Information Quarterly, 29(2), 158-168.

Kensing, F., \& Blomberg, J. (1998). Participatory Design: Issues and Concerns. Computer Supported Cooperative Work (CSCW), 7(3-4), 167-185.

Kensing, F., \& Madsen, K. H. (1992). Generating Visions: Future Workshops and Metaphorical Design. Design at work, pp. 155 - 168, L. Erlbaum Associates Inc. Hillsdale, NJ, USA.

Kensing, F., \& Munk-Madsen, A. (1995). Participatory Design: Structure in the Toolbox. In Participatory Design conference, pp. 47-53

Kettl, D. F. (2005). The Global Public Management Revolution ( $2^{\text {nd }}$ edition.). Washington, D.C: Brookings Institution Press.

Ki Kim, J.K., \& Sharman, R. (2006). Framework for Analyzing Critical Incident Management Systems (CIMS). In System Sciences, 2006. HICSS'06, Proceedings of the $39^{\text {th }}$ Annual Hawaii International Conference (Vol. 4, pp. 79a-79a). IEEE.

Kleiner, A., \& Delurey, M. (Eds.). (2007). The Megacommunity Way: Mastering Dynamic Challenges with Cross-Boundary Leadership. Booz Allen Hamilton.

Koppell, J. G. (2010). Administration without Borders. Public Administration Review, 70, 46-55.

Kristensen, M., Kyng, M., \& Palen, L. (2006). Participatory Design in Emergency Medical Service: Designing for Future Practice. In Proceedings of the SIGCHI Conference on Human Factors in Computing Systems (pp. 161-170). New York, NY, USA: ACM.

Kuutti, K. (1996). Activity theory as a potential framework for human-computer interaction research. Context and consciousness: Activity theory and human-computer interaction, 17-44. Cambridge, MA: MIT press. 
Kyng, M. (2010). Bridging the Gap Between Politics and Techniques: On the next practices of participatory design. Scandinavian Journal of Information Systems, 22(1), 5.

Kyng, M., Nielsen, E. T., \& Kristensen, M. (2006). Challenges in Designing Interactive Systems for Emergency Response. In Proceedings of the 6th Conference on Designing Interactive Systems (pp. 301-310). New York, NY, USA: ACM.

Land, F. (2000). Evaluation in a Socio-technical Context. In Organizational and social perspectives on information technology (pp. 115-126). Springer US.

Larson, R. C., Metzger, M. D., \& Cahn, M. F. (2006). Responding to Emergencies: Lessons Learned and the Need for Analysis. Interfaces, 36(6), 486-501.

Laudon, K. C., \& Laudon, J. P. (1999). Management Information Systems: Organization and Technology in the Networked Enterprise ( $6^{\text {th }}$ Sub edition.). Upper Saddle River, NJ: Prentice Hall.

Lee, A. S. (2001). MIS Quarterly's Editorial Policies and Practices. MIS Quarterly, 25(1), iii-vii.

Lee, D. (1987). Computer Information System Development Methodologies: A Comparative Analysis. In AFIPS Conference Proceedings (Vol. 56, pp. 683-92). Reston, VA: AFIPS Press.

Lenk, K. (2002). Electronic Service Delivery - A driver of public sector modernisation. Information Polity, 7(2,3), 87-96.

Levine, S., \& White, P. E. (1961). Exchange as a Conceptual Framework for the Study of Interorganizational Relationships. Administrative Science Quarterly, 5(4), 583-601.

Lincoln, Y. S., \& Guba, E. G. (1985). Naturalistic Inquiry (1 ${ }^{\text {st }}$ edition.). Beverly Hills, CA: SAGE Publications.

Lindgren, I. (2013). Public e-Service Stakeholders : A study on who matters for public e-service development and implementation. Ph.D Thesis. Linköping Studies in Arts and Science, No. 580. Linköping: Linköpings universitet.

Lindgren, I., \& Jansson, G. (2013). Electronic services in the public sector: A conceptual framework. Government Information Quarterly, 30(2), 163-172.

Lindstrom, L., \& Jeffries, R. (2004). Extreme Programming and Agile Software Development Methodologies. Information Systems Management, 21(3), 41-52.

Lundman, M. (2006). Involving disabled users in the development of e-services. Presented at the Workshop on User involvement and representation in e-Government projects, 75, Oslo, Norway.

Lu, Z., Zhang, N., \& Meng, Q. (2010). Understanding Cross-Sector Collaboration in E-Government Development: Theoretical Consideration Based on Extended Bryson's Framework. PACIS 2010 Proceedings.

Maiden, N. A. M., \& Rugg, G. (1996). ACRE: selecting methods for requirements acquisition. Software Engineering Journal, 11(3), 183-192.

Markus, M. L. (1983). Power, Politics, and MIS Implementation. Communications of the ACM, 26(6), $430-444$.

Markus, M. L., \& Mao, J.-Y. (2004). Participation in Development and Implementation - Updating An Old, Tired Concept for Today's IS Contexts. Journal of the Association for Information Systems, 
$5(11), 14$.

Martin, J. (1991). Rapid Application Development. Indianapolis, IN, USA: Macmillan Publishing Co., Inc.

Mattsson, B., \& Juås, B. (1997). The importance of the time factor in fire and rescue service operations in Sweden. Accident Analysis and Prevention, 29(6), 849-857.

Merwin, E., Snyder, A., \& Katz, E. (2006). Differential access to quality rural healthcare: professional and policy challenges. Family \& Community Health, 29(3), 186-194.

Miles, M. B., \& Huberman, A. M. (1994). Qualitative Data Analysis. SAGE.

Mitchell, R. K., Agle, B. R., \& Wood, D. J. (1997). Toward a Theory of Stakeholder Identification and Salience: Defining the Principle of Who and What Really Counts. Academy of Management Review, 22(4), 853-886.

Mumford, E. (1974). Computer Systems and Work Design: Problems of Philosophy and Vision. Personnel Review, 3(2), 40 - 49.

Mumford, E. (1981). Participative System Design: Structure and Method. Systems, Objectives, Solutions, 1(1), 5-19.

Mumford, E. (1995). Effective Systems Design And Requirements Analysis: The Ethics Method (1 edition.). London: Palgrave Macmillan.

Mumford, E. (2000). Socio-Technical Design: An Unfulfilled Promise or a Future Opportunity? In R. Baskerville, J. Stage, \& J. I. DeGross (Eds.), Organizational and Social Perspectives on Information Technology (pp. 33-46). Springer US.

Mumford, E. (2006). The story of socio-technical design: reflections on its successes, failures and potential. Information Systems Journal, 16(4), 317-342.

De Munck, V. C., \& Sobo, E. J. (1998). Using Methods in the Field: A Practical Introduction and Casebook. Rowman Altamira.

Myers, M. D. (2009). Qualitative Research in Business \& Management. Los Angeles: SAGE Publications Ltd.

Nævestad, T.-O. (2009). Mapping Research on Culture and Safety in High-Risk Organizations: Arguments for a Sociotechnical Understanding of Safety Culture (SSRN Scholarly Paper,ID 1410333). Rochester, NY: Social Science Research Network.

Norman, D. A., \& Draper, S. W. (Eds.). (1986). User Centered System Design: New Perspectives on Human-Computer Interaction. Hillsdale, NJ, USA: Lawrence Erlbaum Associates, Inc.

Ödlund, A. (2010). Pulling the Same Way? A Multi-Perspectivist Study of Crisis Cooperation in Government. Journal of Contingencies and Crisis Management, 18(2), 96-107.

O’Leary, R., \& Bingham, L. B. (2009). The Collaborative Public Manager: New Ideas for the TwentyFirst Century. Washington, D.C: Georgetown University Press.

Oostveen, A.-M., \& van den Besselaar, P. (2004). From Small Scale to Large Scale User Participation: A Case Study of Participatory Design in e-Government Systems. In Proceedings of the Eighth Conference on Participatory Design: Artful Integration: Interweaving Media, Materials and Practices 
- (Vol. 1, pp. 173-182). New York, NY, USA: ACM.

Orlikowski, W. J., \& Baroudi, J. J. (1991). Studying Information Technology in Organizations: Research Approaches and Assumptions. Information Systems Research, 2(1), 1-28.

Orlikowski, W. J., \& Iacono, C. S. (2001). Research Commentary: Desperately Seeking the 'IT' in IT Research - A Call to Theorizing the IT Artifact. Info. Sys. Research, 12(2), 121-134.

Palm, J., \& Törnqvist, E. (2008). Governing the sea rescue service in Sweden: communicating in networks. Journal of Risk Research, 11(1), 269-280.

Pelinka, L. E., Thierbach, A. R., Reuter, S., \& Mauritz, W. (2004). Bystander trauma care - effect of the level of training. Resuscitation, 61(3), 289-296.

Pilemalm, S. (2002). Information Technology for Non-Profit Organisations: Extended Participatory Design of an Information System for Trade Union Shop Stewards. Doctoral thesis. Linköping University.

Pilemalm, S., Lindgren, I., \& Ramsell, E. (2015). Fourth Generation of User-Centered Design Developing for E-government and Cross-sector Collaborations. In Electronic Government and Electronic Participation (Vol. 22, pp. 178 - 192).

Pilemalm, S., Stenberg, R., \& Andersson Granberg, T. (2013). Emergency Response in Rural Areas. International Journal of Information Systems for Crisis Response and Management, 5(2), 19-31.

Pilemalm, S., \& Timpka, T. (2008). Third generation participatory design in health informatics Making user participation applicable to large-scale information system projects. Journal of Biomedical Informatics, 41(2), 327-339.

Powell, W. W. (1990). Neither market nor hierarchy: Network forms of organization. In B. M. Staw \& L. L. Cummings (Eds.), Research in Organizational Behavior (Vol. 12, pp. 295-336). Greenwich, CT: JAI Press.

Quarantelli, E. L. (1994). Emergent Behaviors and Groups in the Crisis Time Periods of Disaster. Disaster Research Center Preliminary Paper, 206.

Quarantelli, E. L. (2000). Emergencies, Disaster and Catastrophes Are Different Phenomena. Disaster Research Center Preliminary Paper, 304.

Räddningsverket. (2008). Räddningstjänst $i$ samverkan. Ansvar och uppgifter för räddningstjänstansvariga myndigheter och samverkande organisationer. Räddningsverket, Karlstad.

Ragin, C. C., \& Becker, H. S. (Eds.). (1992). What is a case?: Exploring the foundations of social inquiry. Cambridge, England: Cambridge University Press.

Rasmussen, J., \& Svedung, I. (2000). Proactive Risk Management in a Dynamic Society. Karlstad, Sweden: Swedish Rescue Services Agency.

Reason, P., \& Bradbury, H. (Eds.). (2013). The SAGE Handbook of Action Research: Participative Inquiry and Practice ( $2^{\text {nd }}$ Edition edition.). London: SAGE Publications Ltd.

Reddy, M., Pratt, W., Dourish, P., \& Shabot, M. M. (2003). Sociotechnical requirements analysis for clinical systems. Methods of Information in Medicine, 42(4), 437-444.

Ring, P. S., \& van de Ven, A. H. (1994). Developmental Processes of Cooperative Interorganizational 
Relationships. The Academy of Management Review, 19(1), 90-118.

Robinson, D., \& Reed, V. (Eds.). (1998). The A-Z of Social Research Jargon. Aldershot, Hants, England; Brookfield, Vt., USA: Ashgate Publishing Ltd.

Ropohl, G. (1999). Philosophy of Socio-Technical Systems: Techné: Research in Philosophy and Technology, 4(3), 186-194.

Salamon, L. M. (1995). Partners in Public Service: Government-Nonprofit Relations in the Modern Welfare State. Baltimore, MD: Johns Hopkins University Press.

Schraagen, J. M., \& van de Ven, J. (2011). Human factors aspects of ICT for crisis management. Cognition, Technology \& Work, 13(3), 175-187.

Schuler, D., \& Namioka, A. (Eds.). (1993). Participatory Design: Principles and Practices. Hillsdale, NJ, USA: Lawrence Erlbaum Associates Inc.

Seidman, I. (1998). Interviewing as Qualitative Research: A Guide for Researchers in Education and the Social Sciences. New York, NY: Teachers College Press.

Smith, K., Rich, D., Pinol, J. P., Hankin, J., \& McNeil, J. (2001). Acceptance of a medical firstresponder role by fire fighters. Resuscitation, 51(1), 33-38.

Snow, C. C., Miles, R. E., \& Coleman, H. J. J. (1992). Managing 21st Century Network

Organizations. Organizational Dynamics, 20(3), 5-20.

Sommerville, I. (2004). Software Engineering, 7th Edition (7 $7^{\text {th }}$ edition.). Boston: Addison Wesley.

Stake, R. E. (2000). Case studies. In N.K. Denzin \& Y.S. Lincoln (Eds.), The SAGE Handbook of Qualitative Research ( ${ }^{\text {nd }}$ Edition). Thousand Oaks: SAGE Publications, Inc.

Stenberg, R., Blondin, M., \& Andersson Granberg, T. (2010). Förstainsatsaktörer-Vad är det egentligen? Pilotprojekt för forskning om förstainsatsaktörer (FIA) - forskningsperspektiv och praktiker (CARER rapport, $n r$ 1). Linköping, Sweden: Linköping University Electronic Press.

Stenmark, D. (2000). Collaborative Aspects of Information Retrieval Tools: Summarising Three Action Case Studies.

Strauss, A., Fagerhaugh, S., Suczek, B., \& Wiener, C. (1985). Social Organization of Medical Work. Chicago: University of Chicago Press.

Strauss, A. L. (1987). Qualitative Analysis for Social Scientists. Cambridge University Press.

Sund, B. (2006). Sambruk av samhällets jour-och beredskapsresurser är lönsamt! [Is cooperative use of the on call and emergency standby resources profitable?]. Räddningsverket [Rescue Services Agency]: Karlstad.

Sund, B., Svensson, L., Rosenqvist, M., \& Hollenberg, J. (2012). Favourable cost-benefit in an early defibrillation programme using dual dispatch of ambulance and fire services in out-of-hospital cardiac arrest. The European Journal of Health Economics: HEPAC: Health Economics in Prevention and Care, 13(6), 811-818.

Sun, J. H., \& Wallis, L. A. (2012). The emergency first aid responder system model: using community members to assist life-threatening emergencies in violent, developing areas of need. Emergency Medicine Journal: EMJ, 29(8), 673-678. 
Susman, G. (1983). Action Research: A Sociotechnical systems perspective. In G. Morgan (Ed.), Beyond Method: Strategies for Social Science Research. London: Sage Publications.

Sutton, R. I., \& Staw, B. M. (1995). What Theory is Not. Administrative Science Quarterly, 40(3), 371-384.

Taber, N. (2008). Emergency response: E-learning for paramedics and firefighters. Simulation \& Gaming, 39(4), 515-527.

Thomson, A. M., \& Perry, J. L. (2006). Collaboration Processes: Inside the Black Box. Public Administration Review, 66, 20-32.

Tierney, K., Bevc, C., \& Kuligowski, E. (2006). Metaphors Matter: Disaster Myths, Media Frames, and Their Consequences in Hurricane Katrina. The ANNALS of the American Academy of Political and Social Science, 604(1), 57-81.

Tierney, K. J., Lindell, M. K., \& Perry, R. W. (2001). Facing the Unexpected: Disaster Preparedness and Response in the United States. Washington, D.C: Joseph Henry Press.

Tobin, R. (2010). Descriptive Case Study. In Encyclopedia of Case Study Research. Thousand Oaks, CA: SAGE Publications, Inc.

Tollmar, K. (2001). Towards CSCW Design in the Scandinavian Tradition. Ph.D. Dissertation, NADA - KTH / SU. Stockholm University.

Travers, M. (Ed.) (2001). Qualitative Research Through Case Studies. SAGE Publications.

Trigg, R. H. (2000). From Sandbox to 'Fundbox': Weaving participatory design into the fabric of a busy non-profit. Proceedings of PDC 2000, pp. 174-183.

Trnka, J., \& Woltjer, R. (2014). Characteristics of Command and Control in Response to Emergencies and Disasters. In P. Berggren, S. Nählinder, \& E. Svensson (Eds.), Assessing Command and Control Effectiveness - Dealing with a changing world (pp. 83-102). Farnham: Ashgate

Turoff, M. (2002). Past and Future Emergency Response Information Systems. Commun. ACM, 45(4), $29-32$.

Turoff, M., Chumer, M., van de Walle, B., \& Yao, X. (2004). The Design of a Dynamic Emergency Response Management Information System (DERMIS). Journal of Information Technology Theory and Application (JITTA), 5(4), Article 3.

Urquhart, C., \& Fernández, W. (2013). Using grounded theory method in information systems: the researcher as blank slate and other myths. Journal of Information Technology, 28(3), 224-236.

Urquhart, C., Lehmann, H., \& Myers, M. D. (2010). Putting the 'theory' back into grounded theory: guidelines for grounded theory studies in information systems. Information Systems Journal, 20(4), $357-381$.

Valenzuela, T. D., Roe, D. J., Nichol, G., Clark, L. L., Spaite, D. W., \& Hardman, R. G. (2000). Outcomes of Rapid Defibrillation by Security Officers after Cardiac Arrest in Casinos. New England Journal of Medicine, 343(17), 1206-1209.

Venema, A. M., Groothoff, J. W., \& Bierens, J. J. L. M. (2010). The role of bystanders during rescue and resuscitation of drowning victims. Resuscitation, 81(4), 434-439. 
Vidgen, R., \& Braa, K. (1997). Balancing Interpretation and Intervention in Information System Research: The Action Case Approach. In A. S. Lee, J. Liebenau, \& J. I. DeGross (Eds.), Information Systems and Qualitative Research (pp. 524-541). Springer US.

Vigoda-Gadot, E. (2003). Managing Collaboration in Public Administration: The Promise of Alliance among Governance, Citizens, and Businesses. Westport, Conn.: Praeger.

Von Hippel, E. (1986). Lead Users: A Source of Novel Product Concepts. Manage. Sci., 32(7), 791805 .

Walker, G. H., Stanton, N. A., Salmon, P. M., \& Jenkins, D. P. (2008). A review of sociotechnical systems theory: a classic concept for new command and control paradigms. Theoretical Issues in Ergonomics Science, 9(6), 479-499.

Walle, B., \& Turoff, M. (2006). ISCRAM: Growing a global R\&D community on information systems for crisis response and management. International Journal of Emergency Management, 3(4), 364.

Walle, B., \& Turoff, M. (2008). Decision support for emergency situations. Information Systems and E-Business Management, 6(3), 295-316.

Walters, S. A., Broady, J. E., \& Hartley, R. J. (1994). A Review of Information Systems Development Methodologies. Library Management, 15(6), 5-19.

Wankhade, P., \& Murphy, P. (2012). Bridging the theory and practice gap in emergency services research: a case for a new journal. International Journal of Emergency Services, 1(1), 4-9.

Waugh, W. L., \& Streib, G. (2006). Collaboration and Leadership for Effective Emergency Management. Public Administration Review, 66, 131-140.

Weber, E. P., \& Khademian, A. M. (2008). Wicked Problems, Knowledge Challenges, and Collaborative Capacity Builders in Network Settings. Public Administration Review, 68(2), 334-349.

Weick, K. E. (1995). What Theory is Not, Theorizing Is. Administrative Science Quarterly, 40(3), 385-390.

Weinholt, Å., \& Andersson Granberg, T. (2013). Evaluation of Enhanced Collaboration Between Fire and Rescue Services and Security Officers. Presented at the Proceedings of the 2013 Information Systems for Crisis Response and Management (ISCRAM) conference, Baden Baden, Germany, pp. $735-740$

Weinholt, A., \& Andersson Granberg, T. (2015). New collaborations in daily emergency response: Applying cost-benefit analysis to new first response initiatives in the Swedish fire and rescue service. International Journal of Emergency Services, 4(2), 177-193.

Weisfeldt, M. L., Sitlani, C. M., Ornato, J. P., Rea, T., Aufderheide, T. P., Davis, D., Dreyer, J., Hess, E. P., ... ROC Investigators. (2010). Survival after application of automatic external defibrillators before arrival of the emergency medical system: evaluation in the resuscitation outcomes consortium population of 21 million. Journal of the American College of Cardiology, 55(16), 1713-1720.

Wilson, S., Bekker, M., Johnson, P., \& Johnson, H. (1997). Helping and Hindering User Involvement \&Mdash; a Tale of Everyday Design. In Proceedings of the ACM SIGCHI Conference on Human Factors in Computing Systems (pp. 178-185). New York, NY, USA: ACM.

Wondolleck, J. M., \& Yaffee, S. L. (2000). Making Collaboration Work: Lessons From Innovation In Natural Resource Managment (New title edition.). Washington, D.C: Island Press. 
Yildiz, M. (2007). E-government research: Reviewing the literature, limitations, and ways forward. Government Information Quarterly, 24(3), 646-665.

Yin, R. K. (2012). Applications of Case Study Research. Thousand Oaks, CA: SAGE.

Yin, R. K. (2013). Case Study Research: Design and Methods. SAGE Publications.

Young, D. R. (2000). Alternative Models of Government-Nonprofit Sector Relations: Theoretical and International Perspectives. Nonprofit and Voluntary Sector Quarterly, 29(1), 149-172.

Young, R. R. (2002). Recommended Requirements Gathering Practices, in CrossTalk. The Journal of Defense Software Engineering, 15(4), 9-12. 



\section{Papers}

The articles associated with this thesis have been removed for copyright reasons. For more details about these see:

http://urn.kb.se/resolve?urn=urn:nbn:se:liu:diva-129233 